Operadores de interação multimídia para criação automática de documentos:

Interactors

Didier Augusto Vega Oliveros 


\section{Operadores de interação multimídia para criação automática de documentos: Interactors}

\section{Didier Augusto Vega Oliveros}

Orientadora: Profa. Dra. Maria da Graça Campos Pimentel

Dissertação apresentada ao Instituto de Ciências Matemáticas e de Computação - ICMC-USP, como parte dos requisitos para obtenção do título de Mestre em Ciências - Ciências de Computação e Matemática Computacional. VERSÃO REVISADA.

USP - São Carlos

Junho/2011 
Ficha catalográfica elaborada pela Biblioteca Prof. Achille Bassi e Seção Técnica de Informática, ICMC/USP, com os dados fornecidos pelo(a) autor(a)

Vega Oliveros, Didier Augusto

operadores de interação multimídia para criação

$\mathrm{V} 4220$ automática de documentos: Interactors / Didier Augusto Vega Oliveros; orientadora Maria da Graça Campos Pimentel -- São Carlos, 2011.

$151 \mathrm{p}$.

Dissertação (Mestrado - Programa de Pós-Graduação em Ciências de Computação e Matemática Computacional) -Instituto de Ciências Matemáticas e de Computação, Universidade de São Paulo, 2011.

1. Vídeo Interativo. 2. Engenharia de Documentos. 3. TV digital. 4. Aplicações Captura e Acesso. 5. Autoria documentos multimídia. I. Pimentel, Maria da Graça Campos, orient. II. Título. 


\section{Agradecimentos}

A Deus, porque sem Ti não somos nada e só por Tua misericórdia temos a oportunidade de ser melhores a cada dia.

A minha família, pelo apoio, pela compreensão e pela força em todos estes anos. "Ña Lulú ya comí".

A minha orientadora, Profa Dra. Maria da Graça Pimentel, pela paciência, pela oportunidade de poder vir ao Brasil e toda ajuda oferecida.

À querida Lilian Berton, pelo amor e carinho, pelo grande apoio, compreensão e ajuda em todos os momentos. Sem você teria sido muito difícil.

Aos professores Rudinei Goularte, Renata Fortes, Rodrigo Mello, Solange Rezende, e Rodrigo Guido, pela amizade e as muito valiosas contribuições feitas ao longo do tempo.

Aos colegas do Intermídia e amigos, especialmente ao Fernando Leite e o Bruno Tenório, que foram como uma família para mim.

A todas as pessoas do ICMC, à USP e ao Brasil, pelo apoio financeiro concedido mediante a CNPq. 


\section{Resumo}

$\mathrm{N}$

este trabalho foi investigado o problema de autoria automatizada de informação multimídia sob a perspectiva da computação ubíqua de modo geral, e da interação do usuário com aplicações de captura e accesso (C\&A) de modo particular. O objetivo do projeto foi a definição de operadores sobre interação do usuário em ambientes e em aplicações para permitir a geração automática de documentos multimídia interativos, um dos temas de pesquisa da área de engenharia de documentos. A abordagem da proposta foi a generalização dos operadores Inkteractors, definidos sobre a interação do usuário com aplicações baseadas em tinta eletrônica, considerando a interação do usuário na voz, mensagens de texto, vídeo e lousa. Como resultado foram definido os novos Interactors: operadores de interação sobre informação capturada em aplicações que envolvem interação do usuário com as mídias. Os Interactors foram validados no contexto de engenharia de documentos ao serem utilizados para a geração automática de documentos multimídia interativos, associados a aplicações de C\&A para oferecer novas possibilidades de indexar, visualizar e acessar os documentos multimídia. 


\title{
Abstract
}

\begin{abstract}
his study investigated the problem of automated authoring of multimedia information from the perspective of ubiquitous computing in general, and the user interaction with applications of capture and acess (C\&A) in particular. The project goal was to formalize operators on user interaction environments and applications to enable automatic generation of interactive multimedia documents, one of the themes of the research area of document engineering. The proposed approach is a generalization of the Inkteractors operators, defined on the user interaction with electronic ink-based applications on the user's interaction with digital voice, text messaging, video and whiteboard. As a result we defined the new Interactors: interaction operators of captured information in applications that involve user interaction with the media. TheInteractors were validated in the context of document engineering to be used for the automatic generation of interactive multimedia documents, and in C\&A aplications to offer new possibilities for indexing, viewing and accessing multimedia documents.
\end{abstract}




\section{Sumário}

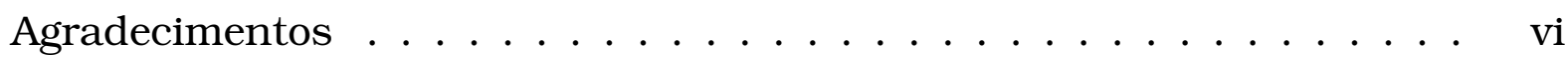

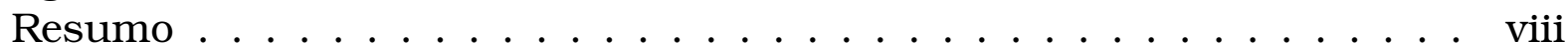

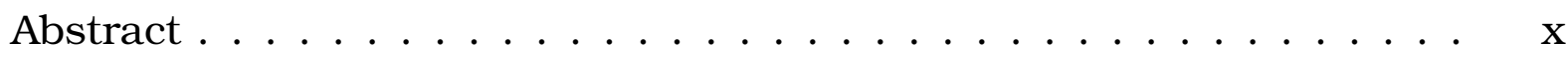

1 Introdução $\quad 1$

1.1 Contextualização . . . . . . . . . . . . . . . . . 1

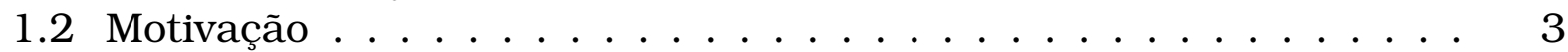

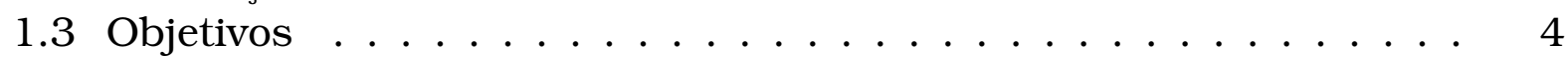

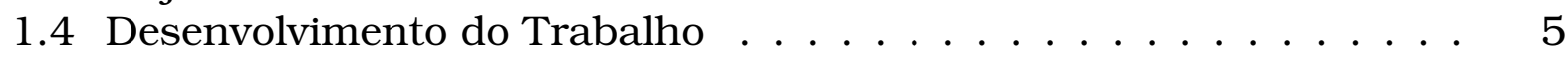

1.5 Resultados e limitações . . . . . . . . . . . . . . . . . . . 6

1.6 Estrutura do Documento . . . . . . . . . . . . . 7

2 Fundamentação Teórica $\quad 9$

2.1 Aplicações de Captura \& Acesso . . . . . . . . . . . . . . . . . . . 10

2.1.1 Fases do Problema de Captura \& Acesso . . . . . . . . . . . 12

2.1.2 Classificação da Captura de Eventos de Interação . . . . . . 13

2.1.3 Exemplo de Domínios de Captura \& Acesso . . . . . . . . . . 14

2.2 Engenharia de Documentos . . . . . . . . . . . 18

2.2.1 Documentos Hipertexto . . . . . . . . . . . . . . . 19

2.2.2 Documentos Multimídia ou Hipermídia . . . . . . . . . . . 20

2.3 Televisão Digital . . . . . . . . . . . . . . . . . . . . 22

2.3.1 Equipamento de Conversão de TV Digital . . . . . . . . . . . 24

2.3.2 Sistema Brasileiro de TV digital . . . . . . . . . . . . . . . 24

2.4 Operadores de Interação . . . . . . . . . . . . . . . . . 27

2.4.1 Classificação Por Operadores de Interação . . . . . . . . . . 27

2.4.2 Classificação Por Mecanismos de Visualização . . . . . . . . . 28

2.5 Considerações Finais . . . . . . . . . . . . . . . . 29

3 Interactors: Eventos de Interação

Baseados em Mídias $\quad 31$

3.1 Operadores de Interação: abordagem inicial . . . . . . . . . . . . . . 32

3.2 Generalização dos Operadores de Interação:

Interactors . . . . . . . . . . . . . . . 35

3.2.1 Redefinição dos Inkteractors . . . . . . . . . . . . . . . 36

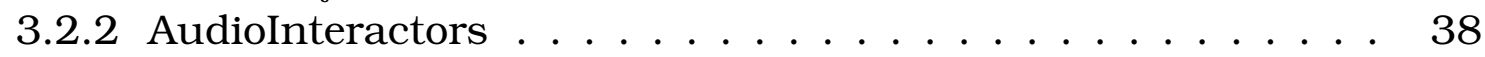

3.2 .3 TextInteractors .................. 39

3.2.4 BoardInteractors . . . . . . . . . . . . 40 
3.2 .5 VideoInteractors . . . . . . . . . . . . . . . 41

3.3 Ciclo de Vida dos Eventos de Interação . . . . . . . . . . . . . . . . 42

3.4 A Teoria de Conjuntos e os Eventos de Interação . . . . . . . . . . . 44

3.5 Considerações Finais . . . . . . . . . . . . . . . . . 47

4 Protótipos e Resultados $\quad 49$

4.1 Descrição do Ambiente de Captura . . . . . . . . . . . . . 50

4.2 Geração Automática de

Documentos Multimídia Interativos . . . . . . . . . . . 51

4.2.1 Documento de Intercâmbio de Informação . . . . . . . . . . . 52

4.2.2 Document Generation Component . . . . . . . . . . . 54

4.2.3 Estudo de Caso: Cenário de VideoConferência . . . . . . . . . 57

4.3 Navegação e Acesso sobre

Documentos Multimídia Gerados . . . . . . . . . . . . 58

4.3.1 Navegação via Menu de Operadores . . . . . . . . . . . . . 59

4.3.2 Casos de Estudo . . . . . . . . . . . . . . . . . . 60

4.3 .3 Avaliações . . . . . . . . . . . . . . . . . . . 64

4.4 Formalização do Documento

de Intercâmbio de Informação . . . . . . . . . . . . . . . . . 68

4.4.1 Registro de Eventos da Fase de Captura . . . . . . . . . . 70

4.4.2 Registro de Eventos da Fase de Autoria e Pós-Processamento 72

4.4.3 Registro de Eventos da Fase de Extensão . . . . . . . . . . . 75

4.5 Considerações Finais . . . . . . . . . . . . . . . . . 76

5 Conclusões $\quad 77$

5.1 Resultados e Contribuições . . . . . . . . . . . . . . . . 77

5.2 Limitações . . . . . . . . . . . . . . . . . . . . . . . 78

5.3 Trabalhos Futuros . . . . . . . . . . . . . . . . . 79

$\begin{array}{lc}\text { Referências } & 93\end{array}$

A Operadores de Interação nas Aplicações de Captura e Acesso 95

A. 1 Eventos de Interação: Uma Revisão Sistemática . . . . . . . . . . 95

A.1.1 Planejamento . . . . . . . . . . . . . . . 9 96

A. 1.2 Condução . . . . . . . . . . . . . . . . . . . . . 99

A. 1.3 Resultados . . . . . . . . . . . . . . . . . . 100

B Classificação dos Estudos Primarios $\quad 105$

B.1 Classificação dos estudos por

Domínio de Aplicação . . . . . . . . . . . . . . . . . . . . . . 105

B.1.1 Domínio Educacional . . . . . . . . . . . . . . . 105

B.1.2 Domínios de Reuniões e Trabalho de Escritório . . . . . . . . 113

B.1.3 Outros Domínios . . . . . . . . . . . . . . . . . . . 115

B.2 Classificação dos estudos baseados em

operadores de interação . . . . . . . . . . . . . . . . . . 118

B.3 Classificação dos estudos segundo a forma

de visualização . . . . . . . . . . . . . . . . . . . . 126 


\section{Lista de Figuras}

2.1 Ciclo de vida de geração de multimídia. Extraído de Vega-Oliveros et al. (2010a) . . . . . . . . . . . . . . . . . . . 12

2.2 Captura \& Acesso do sistema eClass . . . . . . . . . . . . . . 14

2.3 Captura \& Acesso do sistema SmartClassroom . . . . . . . . . . . . 15

2.4 Distribuição dos operadores de interação usados nos estudos primários segundo o tipo de mídia . . . . . . . . . . . . 28

3.1 Resultado da aplicação do operador IdleTime $0 \ldots \ldots$. . . . . . . . . 34

3.2 Resultado da aplicação do operador ChangeOnAuthor0 . . . . . . . . . 34

3.3 Processo proposto de ciclo de vida de eventos para a geração de documentos multimídia via operadores de interação baseados em mídias. . . . . . . . . . . . . . . . . .

3.4 Imagem ilustrando dois conjuntos de Interactors mapeados na linha de tempo (Vega-Oliveros et al., 2011a) . . . . . . . . . . . .

4.1 Diagrama inicial dos interactors para geração automática de documentos multimídia interativos . . . . . . . . . . . . .

4.2 Extração ilustrando a estrutura global do documento de intercâmbio de informação . . . . . . . . . . . . . . . .

4.3 Estrutura global do iMMD. Linhas contínuas são notificações intradocumento e linhas tracejadas são eventos iniciados pelo usuário . . . . . . . .

4.4 Extração do documento declarativo automaticamente gerado com foco nas âncoras . . . . . . . . . . . . . . . . . . . . . . .

4.5 Extração do documento procedural automaticamente gerado que representa o modelo da aplicação (timeline model) . . . . . . . . . .

4.6 Imagem da interface do documento multimídia gerado . . . . . . . .

4.7 Screenshot ilustrando a abordagem do menu de Interactors para visualização e acesso de eventos . . . . . . . . . . . . . . . .

4.8 Estrutura do documento multimídia interativo final do cenário da webconferência ilustrando a linha de tempo decorada com o Interactor baseado em texto. . . . . . . . . . . . . . . . . . .

4.9 Screenshot ilustrando o menu de operadores aberto do documento multimídia interativo final gerado da vídeo palestra. . . . . . . . . .

4.10Screenshot ilustrando a interface proposta após os resultados da avaliação heurística . . . . . . . . . . . . . . . 
4.11 Principais elementos da estrutura do novo documento de intercâmbio de informação . . . . . . . . . . . . . . . . .

4.12 Exemplo de um documento de intercâmbio com os eventos de interação gerados na fase de captura. . . . . . . . . . . . . . . .

4.13 Exemplo de ferramenta de autoria com as possiveis opções para o usuário: (i) editar layout, (ii) enriquecer o documento, (iii) editar o documento e (iv) gerar o documento multimídia . . . . . . . . . . . .

4.14 Exemplo de um documento de intercâmbio com os eventos de interação gerados após a fase de autoria. . . . . . . . . . . . . . 74

4.15Exemplo de um documento de intercâmbio com os eventos de interação gerados após a fase de extensão. . . . . . . . . . . . . . 75

A.1 Distribuição de estudos primários em relação ao tipo de fonte . . . 100

A.2 Distribuição dos estudos primários por ano . . . . . . . . . . 101

A.3 Distribuição dos estudos primários em relação às fontes por ano. Em sua ordem ACM, IEEE, Springer, Elsevier, Outros e a curva das

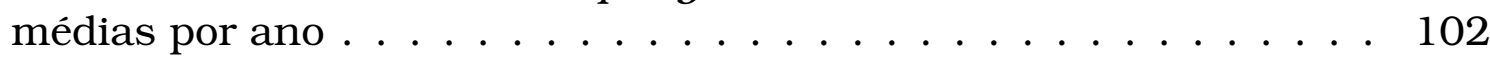

A.4 Distribuição dos estudos primários por países . . . . . . . . . . . 102

A.5 Distribuição dos critérios de inclusão sobre os estudos primários 103 


\section{Lista de Tabelas}

4.1 Interactors usados nos protótipos . . . . . . . . . . . . 63

A.1 Seleção preliminar dos trabalhos . . . . . . . . . . . . . . 99

A.2 Seleção final dos trabalhos . . . . . . . . . . . . . . . . 100

B.1 Classificação dos estudos primários baseados nos operadores de interação . . . . . . . . . . . . . . . . 118

B.2 Classificação dos estudos primários baseados nos mecanismo de visualização . . . . . . . . . . . . . . . . . . . . . . 126 


\section{Lista de Acrônimos}

API Interface de programação, do inglês Application Programming Interface.

ASF Advanced Streaming Format.

C\&A Aplicações de Captura e Acesso.

CSS Cascading Style Sheets.

DiGaE Distributhed Gathering Environment.

ECMAScript Linguagem de programação baseada em scripts, padronizada pela ECMA International.

ED Engenharia de Documentos.

Ginga-CC Núcleo comum do Ginga, do inglês Ginga Common Core.

Ginga-J Ambiente do Ginga de execução de aplicações imperativas escritas em Java.

Ginga-NCL Ambiente do Ginga de apresentação de aplicações declarativas escritas em NCL.

GPL GNU General Public License.

HDTV TV de alta definição, do inglês High-Definition Television.

HTML5 Hypertext Markup Language versão 5.

iMMD Documento multimídia interativo, do inglês Interactive Multimidia Document.

MIT Massachusetts Institute of Technology.

MVC Padrão de desenho Modelo-Visualizador-Controlador, do inglês Model-ViewController.

NCL Nested Context Language. 
PDA Assistente pessoal digital, do inglês Personal Digital Assistant.

PUC-Rio Pontifícia Universidade Católica de Rio de Janeiro.

SBTVD Sistema Brasileiro de TV Digital.

SDTV Definição padrão de TV, do inglês Standard Definition Television.

SMIL Synchronized Multimedia Integration Language.

STB Set-Top Box.

TVD Televisão Digital.

TVDI Televisão Digital Interativa.

UFPB Universidade Federal da Paraíba.

UHF Freqüência ultra alta, do inglês Ultra-High-Frequency.

UIT-T União Internacional de Telecomunicações - serviços Telemáticos.

VHF Freqüência muito alta, do inglês Very-High-Frequency.

w3C World Wide Web Consortium.

XHTML Extensible Hypertext Markup Language.

XML Extensible Markup Language. 


\section{Trabalhos Publicados}

\section{Trabalhos completos publicados em anais de congressos}

Vega-Oliveros, D. A.; Martins, D. S.; Pimentel, M. G. C. Interactors: operators to automatically generate interactive multimedia documents from captured media. Em: Webmedia '10: Proceedings of Brazilian Symposium on Multimedia and the Web, Belo Horizonte, MG, Brasil: ACM, 2010a, páginas 163-170.

Vega-Oliveros, D. A.; Martins, D. S.; Pimentel, M. G. C. Media-oriented operators for authoring interactive multimedia documents generated from capture sessions. Em: SAC '11: Proceedings of Symposium on Applied computing, New York, NY, USA: ACM, 2011a, páginas 1267-1272..

Vega-Oliveros, D. A.; Martins, D. S.; Pimentel, M. G. C. Viewing by interactions: Media-oriented operators for reviewing recorded sessions on tv. Em: EUROITV'11: Proceedings of the 11th European conference on Changing Television Environments (To appear), New York, NY, USA: ACM, $2011 \mathrm{~b}$.

Vega-Oliveros, D. A.; Pedrosa, D. D. C.; Pimentel, M. G. C.; Mattos Fortes, R. An approach based on multiple text input modes for interactive digital tv applications. Em: SIGDOC '10: Proceedings of the 28th ACM International Conference on Design of Communication, New York, NY, USA: ACM, 2010c, páginas 191-198.

\section{Resumos expandidos publicados em anais de congressos}

Pedrosa, D. C.; Vega-Oliveros, D. A.; Pimentel, M. G. C.; Fortes, R. P. M. Text Input in Digital Television: a Component Prototype. Em: Adjunct Proc. of EuroITV '10: Proc. 8th Int. Interactive Conf. Interactive TV and Video, 2010a, páginas 75-78.

Pedrosa, D. C.; Vega-Oliveros, D. A.; Pimentel, M. G. C.; Fortes, R. P. M. What do you want to watch (again)? Video Navigation Using Recency Frames. Em: Adjunct Proc. of EuroITV '10: Proc. 8th Int. Interactive Conf. Interactive TV and Video, 2010b, páginas 115-118.

Vega-Oliveros, D. A.; Martins, D. S.; Pimentel, M. G. C. "This conversation will be recorded": automatically generating interactive multimedia documents from captured media. Em: DocEng '10: Proceedings of the Symposium on Document Engineering, ACM, 2010b páginas 37-40.

Vega-Oliveros, D. A.; Pedrosa, D. C.; Pimentel, M. G. C.; Goularte, R. Video navigation based on recent frames. Em: Webmedia '09: Proc. Brazilian Symposium on Multimedia and the Web, Fortaleza, CE, Brasil:.ACM, 2009, páginas 15-19. 


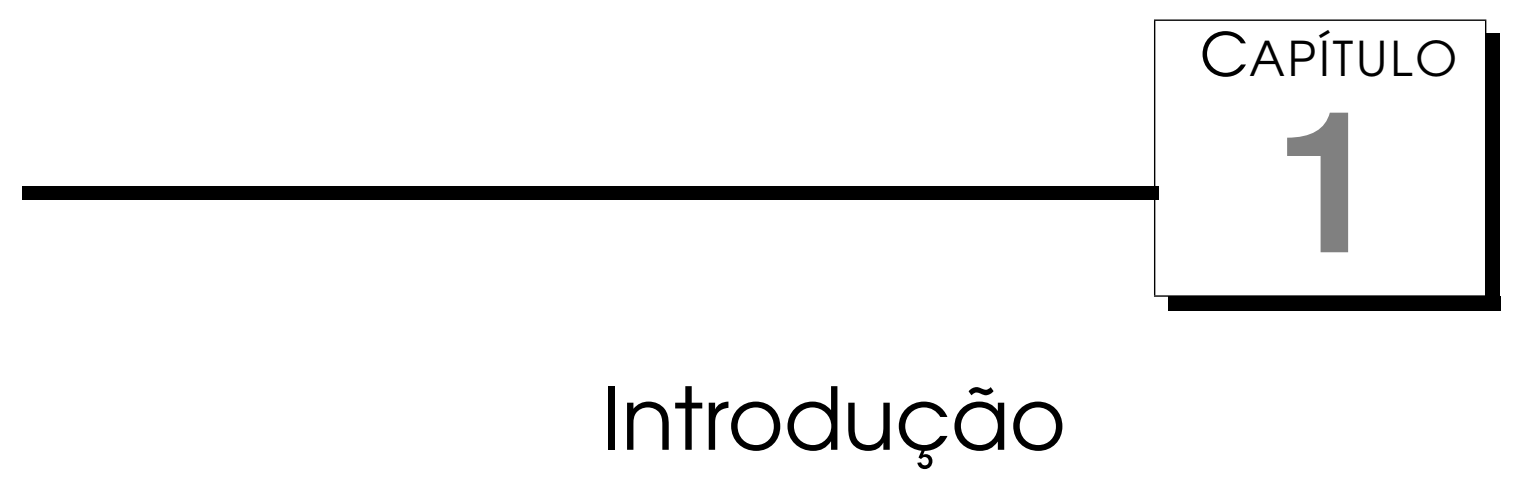

\subsection{Contextualização}

plicações de captura \& acesso construidas para apoiar "a tarefa de pre-
servar um registro de alguma vivência que será revista em algum ponto
no futuro" (Abowd et al., 2002). Essas aplicações automatizam o processo de captura de atividades cotidianas, permitindo a geração automática de documentos passiveis de armazenamento, recuperação, visualização e extensão ao longo do tempo. Aplicações de captura e acesso podem processar informações capturadas da interação natural do usuário com o ambiente (via tinta eletrônica, voz e vídeo, por exemplo) e fazer uso de informações de contexto adquiridas, por exemplo, via sistemas de identificação que utilizam interfaces multimodais.

Em sessões de trabalho remotas, como videconferências ou educação a distância, ferramentas síncronas de comunicação permitem de forma colaborativa intercambiar dados como textos, imagens, documentos, áudios ou vídeos. Nesses cenários, faz-se importante armazenar os dados capturados para serem revistos. Algumas das razões importantes para rever sessões capturadas incluem: manter registros precisos da sessão para revisitá-los quando alguma parte da sessão não ficou muito clara; obter pontos chaves; e referenciar algumas idéias. Particularmente, no caso das ferramentas de webconferência, a abordagem normalmente adotada para a gravação de uma sessão é gerar um vídeo linear com o conteúdo das mídias trocadas. Tal abordagem faz com que o processo de revisão da sessão seja também linear consumindo tempo do usuário, especialmente se 
apenas conta com as operações tradicionais de vídeo (por exemplo, reproduzir, parar, avançar, retroceder) disponíveis no player (Cattelan et al., 2008b).

$\mathrm{O}$ acesso não-linear às mídias capturadas é usualmente realizado por ferramentas especializadas chamadas de navegadores. As abordagens atuais para o desenvolvimento de navegadores apresentam algumas desvantagens: estas ferramentas geralmente estão focadas em um ou dois tipos de índices (por exemplo, apenas de áudio, vídeo, artefatos ou fala) (Whittaker et al., 2007), oferecendo experiências de navegação pobres em dispositivos com restrições de hardware (tais como dispositivos móveis ou Set-Top Box (STB)) e falhando no suporte à filtragem e visualização dos dados da sessão(navegação através de versões resumidas das mídias capturadas, por exemplo) (Tucker e Whittaker, 2004). Além disso, o desenvolvimento de frameworks ad-hoc é uma prática comum que faz com que aumente o nível de acoplamento entre o ambiente de captura específico e a ferramenta de navegação.

Pesquisas relacionadas a sistemas de Captura \& Acesso (Truong e Hayes, 2009; Yu e Nakamura, 2010) têm se preocupado com os métodos para rever sessões capturadas, geralmente abordando a questão do desenvolvimento de índices de modo que os usuários possam atingir pontos específicos da sessão de modo não linear. Minneman et al. (1995) and Geyer et al. (2005) categorizam esses índices em quatro grandes classes: intencionais, ao serem realizados de modo explícito pelo participante no momento da captura; colaterais, produzidos pela captura da interação do participante com os equipamentos ou as mídias; derivados, obtidos automaticamente fazendo análises do conteúdo; e os índices post-hoc, que consistem em interações usuário-mídia no momento da revisão do conteúdo.

Abowd et al. (1998) e Pimentel et al. (2001) propõem o modelo de cinco fases do ciclo de vida da criação de conteúdo multimídia nos sistemas de C\&A: cada fase do ciclo de vida apresenta oportunidade para construir índices baseados nos diferentes tipos de interações. Na primeira fase, a de pré-produção, pode ser gerado índices relacionados com segmentação e recomendação de conteúdo (Macedo et al., 2010). Durante a segunda fase, a de gravação ao vivo, anotações online são normalmente capturados (Branham et al., 2010). A geração de índices derivados (Behera et al., 2007) podem acontecer na terceira fase, a de pósprodução. No momento da revisão, os índices de interação usuário-mídia são especificamente obtidos durante a quarta fase, a de acesso, na qual as revisões do usuário podem gerar novos elementos de mídia. As interações usuário-mídia podem ser usadas para enriquecer e gerar novas versões de elementos de mídia originais (Cattelan et al., 2008b; Teixeira et al., 2010a), usadas na quinta fase, a de extensão. 
A partir dessa categorização, observou-se que a principal dimensão está nos índices de interação de usuário (usuário-mídia, usuário-dispositivo ou usuáriousuário) e as fases do ciclo de vida das mídias em que essas interações aconteceram. Também foi observada a necessidade de oferecer mecanismos que facilitem a revisão não linear de sessões síncronas que capturam diferentes tipos de mídia e que esses índices sirvam como mecanismos para visualizar e acessar os dados da sessão. Além disso, poderiam ser construídas de forma automática aplicações de sessões capturadas baseadas nesses índices, de modo que possam ser generalizadas e estendidas a diferentes infraestruturas e cenários.

\subsection{Motivação}

A interação natural do usuário - baseada em caneta eletrônica, áudio, vídeo ou qualquer outro tipo de dado digital sobre o ambiente - pode ser capturada de maneira a produzir transparentemente documentos multimídia associados, que possam ser posteriormente revistos com integração e sincronização das mídias correspondentes. A forma tradicional de visualização consome tempo ao ser apresentada e exige que o usuário fique assistindo o documento até chegar ao ponto que lhe interessa. Se múltiplos pontos de interesse são desejados, tal operação precisa ser repetida várias vezes. É possível considerar um cenário em que um aluno deseja assistir os pontos, nos quais, o professor falou sobre algum tema específico, de tal forma que consiga rever as observações do professor sem ter que assistir todo o conteúdo. Analogamente, o professor pode querer identificar os temas da aula em que a maioria dos estudantes teve problemas, devido à frequência de buscas feitas pelos alunos nos temas da aula. Outra situação poderia ser querer versões resumidas dos dados capturados. Por exemplo, quando o usuário deseja encontrar as palavras-chave relacionadas com uma palestra para saber se vale a pena assistir o material; ou, em uma aula remota, fazer anotações de áudio no material da disciplina para que sejam interpretadas como marcações relacionadas a dúvidas, convertendo-as a texto para que deste modo, possam ser compartilhadas. Esses exemplos mostram quão importante é poder contar com mecanismos que permitam a revisão automatizada e detalhada de tarefas executadas ao interagir com dispositivos computacionais.

Um cenário claro de uso mecanismo de revisão é o relacionado à captura de informação baseadas em tinta eletrônica. Para prover alternativas de acesso à informação capturada Cattelan et al. (2008b) definem o conceito de Inkteractors: operadores sobre a tinta eletrônica que permitem extrair informações relativas à interação dos usuários. Os operadores de tinta tratam a situação em que vários usuários remotos possam utilizar uma mesma sessão de lousa eletrônica 
para escrever ou fazer desenhos. Eles propõem um conjunto de operadores que auxiliam as tarefas de autoria e representação da informação capturada, ao considerar as interações dos usuários como um todo ou de usuários em separado.

O trabalho de Cattelan et al. (2008b) facilita o acesso às informações capturadas da sessão relacionadas às ações que foram feitas com os dispositivos de caneta eletrônica. Esse enfoque facilita a geração de versões de documentos multimídia e permite o acesso de forma direta nos pontos de interesse aos usuários, sem que eles tenham que rever toda a animação do documento, ou no pior dos casos, que só tenham uma versão final estática dos traços. Contudo, a proposta de Cattelan só foi definida para operadores de tinta, não tendo sido considerados outros tipos de mídia. Poderia ser proposta uma formalização de outros tipos de operadores que estendam o conceito dos Inkteractors para outras mídias de forma genérica. Assim, ao generalizar os Inkteractors para outros tipos de mídia, o processo de autoria e de acesso ao conteúdo seria enriquecido com a presença dos operadores de interação, que a sua vez, vão gerar um maior número de eventos semânticamente relacionados com as interações contidas nas mídias. Além disso, poderiam ser combinados os diversos tipos de operadores dando lugar a operadores mais complexos, que podem contribuir com novos conceitos semânticos de acesso e autoria.

Propõe-se que as informações capturadas de sessões síncronas colaborativas possam ser usadas na geração automática de documentos multimídia interativos (interactive multimedia document - iMMD). O iMMD gerado pode ser enriquecido com vários tipos de eventos (por exemplo, mudanças de slides, mensagens de chat, as interações baseadas em tinta) que serão chamados de Interactors, permitindo aos usuários navegar no documento gerado automaticamente através de pontos de acesso em uma linha do tempo, por exemplo. A fim de reforçar o baixo acoplamento entre o ambiente de captura e o iMMDs, cada sessão é exportada do ambiente para um documento de intercâmbio de informação, encapsulando as mídias capturadas junto com sues respectivos índices de interação, adotando uma abordagem centrada em documentos.

\subsection{Objetivos}

O objetivo geral deste trabalho foi a generalização e a proposta dos Interactors: operadores de interação de usuários baseado na informação capturadas nas mídias, definindo novos operadores e estendendo operadores de tinta eletrônica. Os seguintes objetivos específicos foram propostos: 
- Definir e propor os novos operadores de interação que auxiliem no processo de autoria, visualização e acesso de sessões capturadas.

- Viabilizar mecanismos de visualização de eventos semânticos de interação em documentos gerados a partir das interações dos usuários contidas nas mídias, sejam estes eventos de natureza implícitas ou explícitas.

- Aportar novos recursos para a experiência interativa do usuário durante a revisão da sessão, com operadores que possam ser aplicados a diferentes tipos de mídias, enriquecendo o documento da sessao de forma automática, oferecendo novas formas de acesso a partir de sequências lógicas de operadores criadas pelos usuários e com significado para eles.

- Validar os Interactors no contexto de engenharia de documentos ao serem utilizados para a geração automática de documentos multimídia interativos.

\subsection{Desenvolvimento do Trabalho}

Em um primeiro momento, foi feito um estudo dos conceitos relacionados ao trabalho proposto. Foi estudado tema das aplicações de Captura \& Acesso, considerando os principais domínios, os trabalhos relacionados e as técnicas de visualização empregadas.

A partir dessas análises foi estudada a metodologia centrada em documentos que faz parte da abordagem propostas na engenharia de documentos. Portanto, foram estudados os métodos de geração automática de documentos multimídia e os trabalhos relacionados com documentos de intercâmbio de informação utilizados para a captura de eventos do usuário. Dessas análises surgiu a primeira versão do documento de intercâmbio de informação.

Em seguida, foi escolhido o domínio e o contexto em que seria instanciado o modelo para futuras avaliações e provas de conceito. A partir desse ponto, foi escolhido o contexto de TV digital, e em particular, foram estudados os conceitos relacionados ao Sistema Brasileiro de TV digital.

Também, foi realizada uma revisão sistemática da área com a finalidade de conhecer o estado da arte dos métodos, técnicas e abordagens usadas em aplicações de Captura \& Acesso sob o ponto de vista das interações/informações contidas nas mídias. Como mecanismo de visualização, adotou-se a geração automática de vídeos interativos, mediante o uso de documentos multimídia.

Com base em estudos prévios, foram definidos novos operadores de interação denominados como Interactors como a generalização dos Inktractors reportados 
na literatura. A partir desse ponto, foi definido o processo de geração de eventos de interação a partir dos Interactos.

Foi utilizada a metodologia de desenvolvimento centrado no usuário ${ }^{1}$ para a realização dos protótipos usados nos testes e avaliações. Dentre as avaliações realizadas, foram realizados estudos com usuários para avaliar o nível de entendimento e aceitação dos Interactors, além de avaliações de usabilidade com especialistas.

\subsection{Resultados e limitações}

Formalizou-se o conceito de Interactors como operadores de interação baseados em mídias, estendendo-se e redefinindo-se os Inkteractors e, o mais importante, definindo-se novos operadores. Também foi discutido um processo de criação de conteúdo multimídia que exploram a possibilidade de usar os operadores de interação para indexar pontos de interesse no caso das sessões síncronas capturadas.

Foi proposto um documento de intercâmbio de informação que pode ser associado nas nas várias fases do processo. Instâncias desse documento podem ser enriquecidas e geradas de forma automática a partir sessões capturadas. As principais vantagens de adotar um documento estruturado como mecanismo de intercâmbio de informação é o baixo acoplamento e a capacidade do modelo de ser estendido e aplicado a diferentes cenários e ferramentas.

Para avaliação do trabalho, foram desenvolvidos protótipos aplicados em cenários de webconferência e videopalestra, mediante a geração automática de iMMD que contém os eventos de interação capturados. Para tal fim, os documentos multimídia foram enriquecidos com diversos tipos de índices obtidos a partir dos Interactors. Esses índices foram usados pelos usuários para se apoiar nas tarefas de navegação e visualização dos dados. Os resultados sugerem que os Interactors são meios efetivos para auxiliar a revisão de sessões colaborativas capturadas. Contudo, notou-se alguns problemas relacionados a uso do menu de navegação da aplicação e alguns pontos relacionados a usabilidade da ferramenta. Em geral, os usuários reconheceram a facilidade e efetividade do conceito dos Interactors após se familiarizarem com a ferramenta.

Por último, foi observado que é possível obter novas versões do documento multimídia ao se combinar os operadores de interação. Além disso, mediante o uso de operações lógicas entre operadores, existe a oportunidade de explorar novos métodos que permitam a combinação dos Interactors para visualizar e

\footnotetext{
${ }^{1}$ User Centered Desing
} 
acessar o documento, e a autoria sobre os dados da sessão gerando versões resumidas, personalizadas ou específicas da captura original.

\subsection{Estrutura do Documento}

Este trabalho está organizado da seguinte forma: No Capítulo 2 são apresentadas os conceitos fundamentais para o entendimento do trabalho. Sua primeira seção apresenta os conceitos das aplicações de Captura \& Acesso, seguido por uma descrição de engenharia de documentos, de televisão digital e os resultados de uma revisão sistemática da literatura relacionada aos operadores de interação. Por último, as considerações finais discutem as relações desses conceitos com o trabalho desenvolvido.

O Capítulo 3 apresenta o modelo proposto neste trabalho. A formalização dos operadores, o modelo de ciclo de vida de geração de conteúdo multimídia baseado em eventos de interação e a lógica de operadores que pode ser usada para fortalecer os processos de busca e autoria sobre os documentos. Os casos de estudo, os protótipos, as avaliações e os resultados a partir do modelo, são apresentados no Capítulo 4. Finalmente, o Capítulo 5 sumariza as contribuições do trabalho e aponta para os trabalhos futuros. 



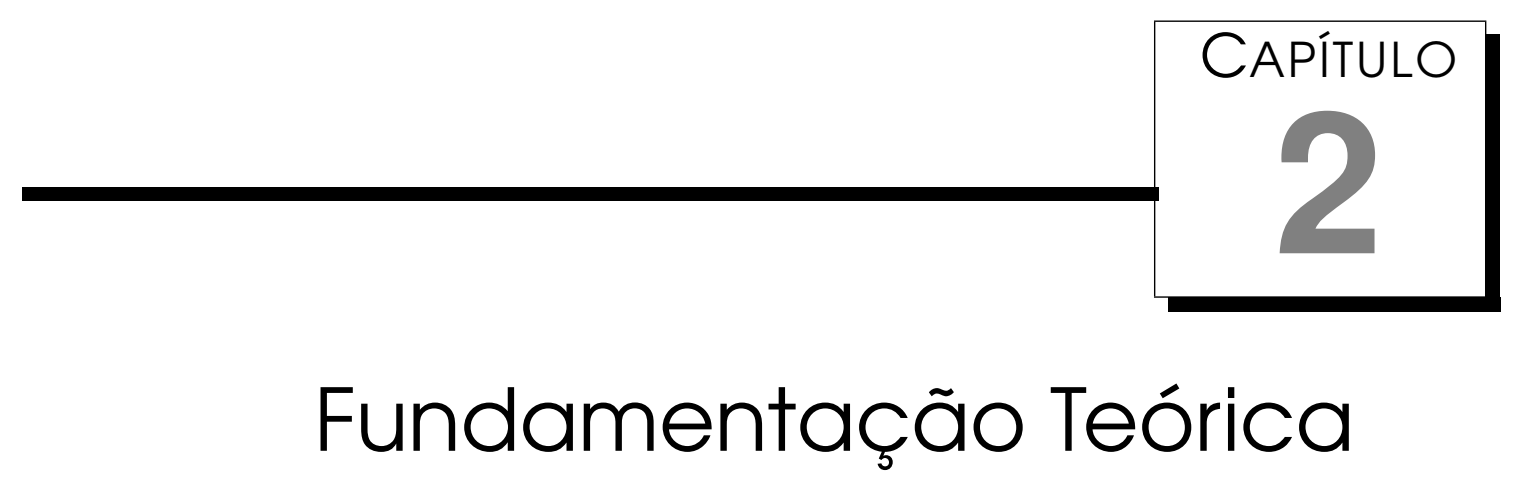

$\mathrm{N}$ este capítulo são apresentados os conceitos relacionados ao modelo de eventos de interação do usuário baseado em mídias. O primeiro conceito a ser abordado trata sobre as aplicações de Captura automática e Acesso de dados $(\mathrm{C} \& \mathrm{~A})^{1}$, as quais automatizam o processo de captura de atividades cotidianas para posteriormente permitir o acesso ao conteúdo capturado. Algumas dessas aplicações oferecem a possibilidade de capturar vários tipos de dados, como no caso dos ambientes instrumentados ou ferramentas de videoconferência, que podem ser sincronizados mediante o uso de documentos multimídia para, dessa forma, permitir o acesso à sessão.

Os documentos multimídia, além de facilitarem o acesso aos dados, oferecem as possibilidades de comunicação, recuperação, visualização e extensão do conteúdo ao longo do tempo. No momento em que é feito algum tipo de processamento ou transformação para definir, projetar e implementar esses documentos, fazemos referência à abordagem da Engenharia de Documentos (ED). Os conceitos de ED englobam todo o ciclo de vida dos documentos, desde as fases de definição e criação até as fases de consumo (acesso) e extensão da informação. Portanto, a partir de uma sessão capturada podem ser geradas diferentes versões de documentos multimídia que podem ser visualizadas em diferentes plataformas e dispositivos (TV-celular, Web-tabletPC, entre outros) permitindo dessa forma a interatividade com o usuário. Particularmente, para efeitos de validação e prova de conceito do modelo, este trabalho está contextualizado no ambiente 
da Televisão Digital (TVD), especificamente no Sistema Brasileiro de TV Digital (SBTVD), sem deixar de fora outros possiveis cenários.

O capítulo está organizado da seguinte forma: Os principais conceitos das aplicações de C\&A são apresentados na Seção 2.1; a definição de Engenharia de Documentos junto aos conceitos de hipertexto e de documentos multimídias é apresentados na Seção 2.2; a Seção 2.3 define as particularidade do contexto no qual foi validado o modelo; Finalmente a Seção 2.5 reúne as considerações finais do capítulo.

\subsection{Aplicações de Captura \& Acesso}

As aplicações de Captura \& Acesso (C\&A), conforme o nome indica, são aplicações que facilitam a captura automática de diferentes tipos de informações, como áudio, vídeo, texto, interações, entre outras, e que posteriormente permitem acessar os dados de forma rápida e fácil (Abowd et al., 2002). Estas aplicações têm a tarefa de registrar, de forma transparente para o usuário, as experiências vivenciadas em tempo real, fazendo uso de diferentes tecnologias para documentar e armazenar o histórico do que aconteceu na sessão.

A Captura é compreendida como o momento em que algum tipo de elemento de interação (dispositivos, programas, etc.) gera dados que depois serão indexados ao longo do tempo. Depois de finalizada a sessão, dependendo do volume de informação armazenada, a tarefa de revisão do conteúdo pode chegar a ser uma tarefa difícil de cumprir. O problema a resolver durante a fase de Acesso é o de prover ao usuário mecanismos de recuperação de informação para que possa encontrar de forma simples aquilo que está procurando ou que está precisando. Por isso, áreas como hipermídia, engenharia de documentos, interação usuário-computador, entre outras, têm bastante relevância na forma como vai ser apresentada a informação ao usuário.

As aplicações de C\&A são necessárias dadas as dificuldades humana em registrar e recuperar, com detalhe e precisão, grandes quantidades de informação, seja por sobrecarga cognitiva, falta de atenção ou esquecimento. Por esta razão, os domínios em que são úteis estas aplicações podem estender-se desde documentar experiências humanas em ambientes de reuniões como o sistema DUMMBO (Brotherton et al., 1999) ou o sistema LiteMinutes (Chiu et al., 2001) até, em ambientes de hospitais como o ActiveTheatre (Hansen e Bardram, 2005), e educacionais como os sistemas eClass (Brotherton e Abowd, 2004), SmartClassroom (Shi et al., 2003) e iClass (Pimentel et al., 2007a). 


\section{Captura}

A fase de captura consiste em armazenar toda a informação correspondente aos dispositivos e artefatos da sessão ao vivo. Existem informações contidas nas mídias que podem ser extraídas de forma derivada (implícita) ou explícita (Geyer et al., 2005; Chen e Liu, 2006). Os mecanismos mais usados nas aplicações de C\&A são aqueles que, fazendo uso de dispositivos especializados, se possibilitam capturar algum tipo de informação relacionada com o contexto da aplicação. Entre estes dispositivos estão as canetas digitais, os microfones, os sensores, entre outros. Esta forma de captura de informação será denominada neste trabalho como captura de informação explícita. Quando se trata de fazer um processamento posterior dos dados capturados para encontrar novas informações, será denominado como o processo de extração de informação de maneira derivada ou explícita sobre os dados. Reconhecimento de objetos no fluxo do vídeo (Schneiderman e Kanade, 2000), identificação de cenas (Manzato et al., 2009), conversão de falas em texto (Behera et al., 2007) ou segmentação do áudio para extração de sentenças-chaves (Kawahara et al., 2004), e algoritmos de reconhecimento de texto em imagens (Harvel et al., 2004) são exemplos deste tipo de pós-processamento.

\section{Acesso}

A fase de Acesso consiste em prover aos usuários diferentes modos de recuperação da informação. O objetivo é ajudar o usuário no processo de busca e visualização, dada a dificuldade de localizar um ponto específico da sessão capturada, sem ter que assistir a todo o material gravado. É importante destacar que as mídias capturadas têm que estar orquestradas na sequência em que foram capturadas, para, dessa forma, não perder a informação adicional contida na sinergia dos dados armazenados. Portanto, a sincronização é uma peça chave a ser considerar nesta fase. Algumas tecnologias, como Advanced Streaming Format (ASF) ${ }^{2}$, Synchronized Multimedia Integration Language (SMIL) ${ }^{3}$, Nested Context Language $(\mathrm{NCL})^{4}$ ou Hypertext Markup Language versão 5 (HTML5) ${ }^{5}$, são apenas exemplos de ferramentas que fornecem recursos de sincronização e interação aos usuários.

2Microsoft Corporation

3Recomendação da World Wide Web Consortium (W3C)

4Recomendação União Internacional de Telecomunicações - serviços Telemáticos (UIT-T) para a construção de aplicações multimídia destinadas ao a 5Capitulo de revisão do grupo de trabalho da W3C 


\subsubsection{Fases do Problema de Captura \& Acesso}

Abowd et al. (1998) sugerem dividir o problema de C\&A em quatro fases:

- Pré-Produção: Está relacionada com os ajustes prévios à fase de gravação (captura). Nesta fase são carregadas as informações relevantes do contexto da experiência em geral.

- Gravação ao Vivo: Ocorrem a sincronização e a captura dos fluxos de informações relevantes previamente estipulados e o seu armazenamento.

- Pós-Produção: É quando acontece a integração dos fluxos de informação capturados com seu devido processamento.

- Acesso: Esta é a fase em que os usuários finais vão visualizar e acessar a informação capturada por meio de algum mecanismo de recuperação.

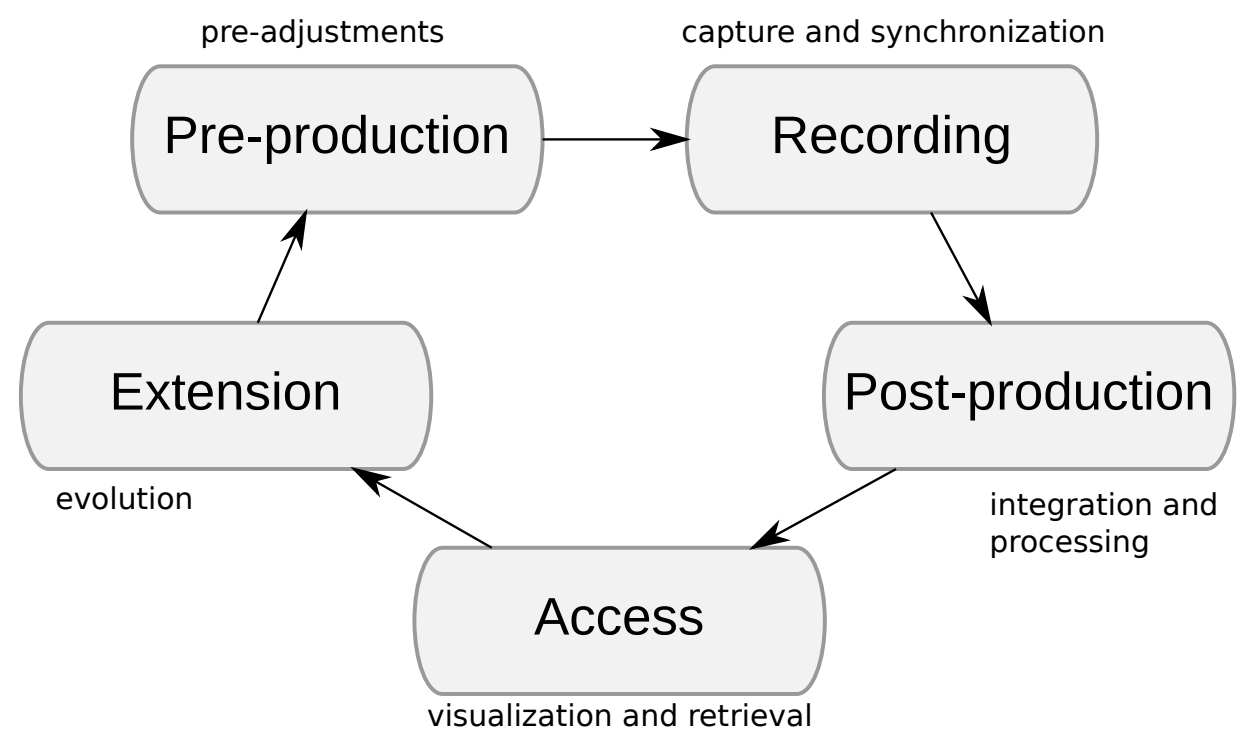

Figura 2.1: Ciclo de vida de geração de multimídia. Extraído de Vega-Oliveros et al. (2010a)

Outros autores na literatura utilizam esta estruturação com algumas adaptações. Richter et al. (2001) propõem uma integração da segunda e terceira fases, sem nítida distinção dos processos de captura, sincronização e integração dos fluxos de mídia. Pimentel et al. (2001) agregam uma quinta fase, a de extensão, que explora o conceito de informação hipermídia evolutiva, como ilustra a Figura 2.1. Esta nova fase permite dar continuidade ao processo de captura por meio da interação dos usuários, complementando o inter-relacionamento das informações capturadas e visualizadas a qualquer momento, seja antes, durante e após experiência ao vivo (Cattelan, 2009). 


\subsubsection{Classificação da Captura de Eventos de Interação}

Uma classificação de índices, ou eventos de interação, para mídias capturadas é proposta por Minneman et al. (1995), que categorizam os índices em quatro classes principais: anotações intencionais, realizadas explicitamente pelos participantes enquanto acontece a reunião (Shamma et al., 2009); índices de efeito colateral, produzidos pela captura da interação do usuário-mídia ou do usuáriodispositivo, como mudança de slides e/ou ativação do som do microfone (Terken e Sturm, 2010); índices derivados, automaticamente obtidos de análises baseadas em conteúdo, como por exemplo, para identificar quem fala (Friedland et al., 2010) ou detectar nas mídias eventos de interação usuário-usuário (Behera et al., 2007; Junuzovic et al., 2008); e índices pós-hoc, que consistem na interação usuário-mídia realizada durante a revisão da sessão capturada (Teixeira et al., 2010a).

Uma extensão à taxonomia apresentada é a proposta por Geyer et al. (2005) que define os índices nas categorias online e offline, os quais são construídos durante e depois da respectiva reunião. Eles também definem os índices do tipo explícitos e derivados (implícitos), que são obtidos das análises dos correspondentes elementos de mídia. Trabalhos similares têm sido propostos por Chen e Liu (2006) e por Bouamrane e Luz (2007). Chen e Liu (2006) definem as correlações entre as mídias como implícitas -encontrando informações cruzadas entre os objetos de mídia para análises futura e explícitas fazendo referência às correlações que são pré-orquestradas durante a fase de captura e autoria da apresentação - para serem sincronizadas em um documento multimídia. No caso de Bouamrane e Luz (2007), eles fazem uma formalização entre os eventos de interação usuário-mídia priorizando os índices no momento da produção ou de consumo do conteúdo.

Como foi apresentado na Seção2.1.1, Abowd et al. (1998) e tempo depois Pimentel et al. (2001) propõem o modelo de cinco fases do ciclo de vida da criação de conteúdo multimídia nos sistemas de C\&A: cada fase do ciclo de vida apresenta oportunidade para processar eventos baseados nos diferentes tipos de interações. Na primeira fase, a de pré-produção, anotações intencionais offline podem ser aplicadas para realizar segmentação e recomendação do conteúdo (Macedo et al., 2010). Durante a segunda fase, a de gravação ao vivo, anotações online e eventos colaterais são normalmente construídos (Branham et al., 2010). Os eventos ou índices offline podem acontecer na terceira fase, a de pós-produção, como a geração de índices derivados (Behera et al., 2007). No momento da revisão, os eventos de interação usuário-mídia são especificamente obtidos durante a quarta fase, a de acesso, na qual as revisões do usuário podem 
gerar novos elementos de mídia, por exemplo, anotações ou a discriminação de intervalos (Teixeira et al., 2010b). As interações usuário-mídia podem ser usadas para enriquecer e gerar novas versões dos elementos de mídia originais (Cattelan et al., 2008b; Teixeira et al., 2010a), usadas na quinta fase, a de extensão.

A partir dessas categorias, foi notado que a dimensão central do trabalho está no tipo de interações que são indexadas (usuário-mídias, usuário-dispositivo, ou usuário-usuário) e na fase do ciclo de vida do conteúdo multimídia (Hardman, 2005; Kirk et al., 2007) nas quais as interações são geradas.

\subsubsection{Exemplo de Domínios de Captura \& Acesso}

Atualmente as aplicações de Captura \& Acesso auxiliam um grande número de atividades humanas. Estes sistemas servem como apoio nos ambientes onde a memória humana apresenta limitações para recuperar detalhes de eventos e experiências, facilitando o acesso aos registros capturados de modo que possa ser reconstituída a experiência. Segundo Truong e Abowd (2004), as pesquisas na área de C\&A em relação ao ambiente em que vão ser usadas podem ser classificadas em três tipos de domínios: de sala de aula (educação); de salas de reunião; e de propósito geral.

Nesta seção é apresentada uma descrição teórica de cada um dos domínios apresentados junto com alguns dos principais trabalhos reportados na literatura.

\section{Domínio de Sala de Aula (educação)}

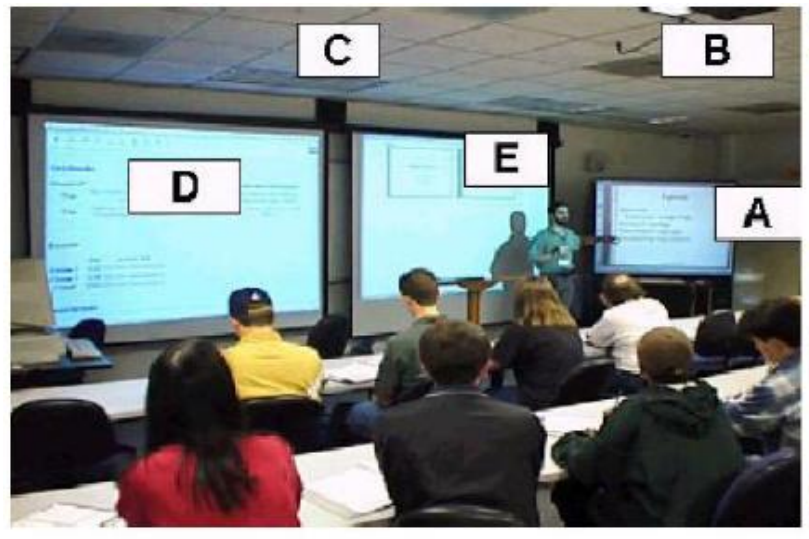

(a)

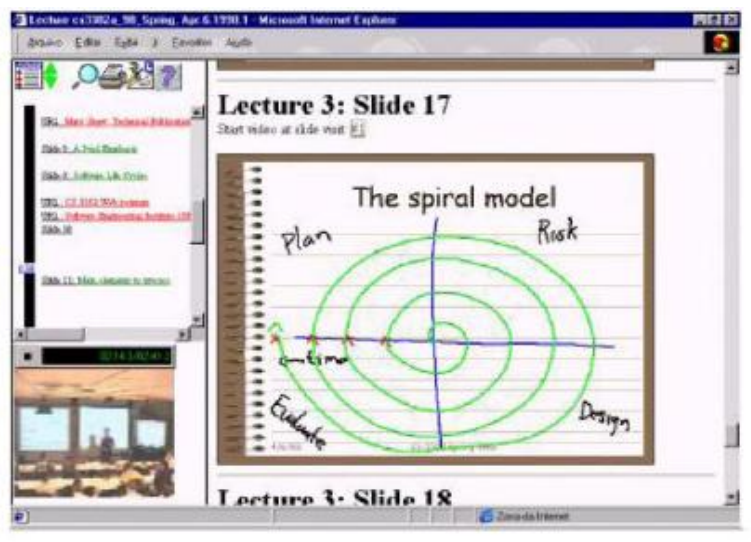

(b)

Figura 2.2: Captura \& Acesso no ambiente de sala de aula do sistema eClass (Brotherton e Abowd, 2004): (a) sala de aula instrumentada utilizada no sistema eClass (b) hiperdocumento gerado automaticamente pelo sistema. 
Tradicionalmente o cenário de sala de aula tem sido um bom exemplo para captura automática das atividades conduzidas pelo professor, beneficiando desta forma o processo de aprendizagem dos alunos. A sala de aula pode ser convertida em um ambiente instrumentado com dispositivos ubíquos que permita visualizar e armazenar a informação do contexto da sessão. Ferramentas tais como projetores, câmeras, microfones de ambiente, lousas eletrônicas, televisores e tabletsPC (Figura 2.2a), além das interfaces que integram os diferentes fluxos de mídia capturados pelos dispositivos (Figura 2.2b), exemplificam o tipo de infra-estrutura usada para automatizar as atividades da aula.
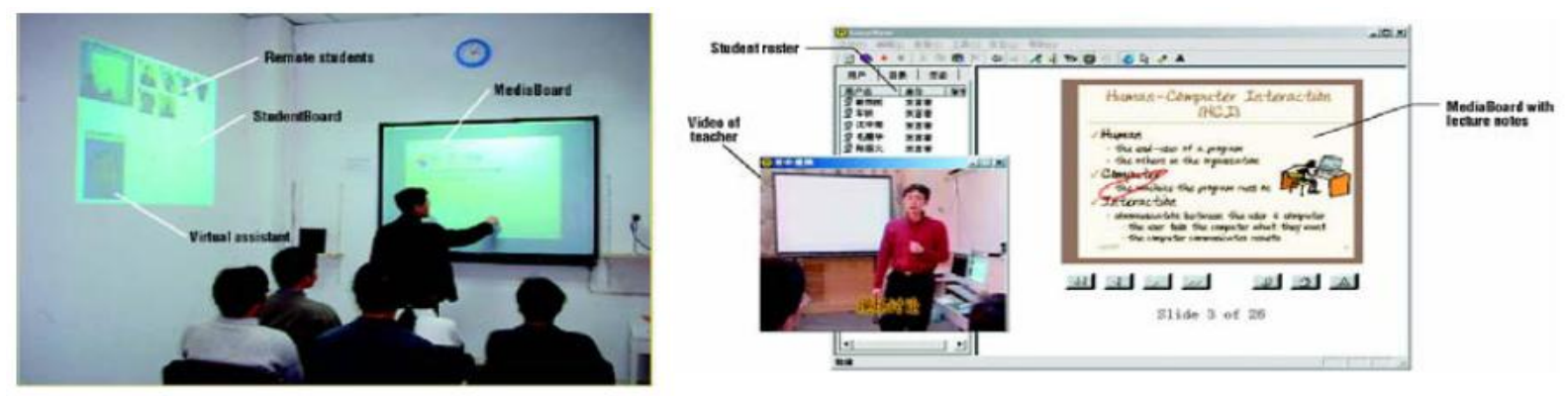

Figura 2.3: Captura \& Acesso no ambiente de sala de aula do sistema

SmartClassroom (Shi et al., 2003): (esquerda) captura e dispositivos da sala de aula; (direita) documento hipermídia gerado pelos sistema

Trabalhos como o eClass/Classroom 2000 (Abowd et al., 1998) (Figura 2.2) caracterizam o cenário de uma aula tradicional para um auditório tradicional, onde o conteúdo capturado inclui os slides da aula e as anotações feitas sobre estes. Seguindo essa mesma linha, trabalhos reportados como o iClass (Pimentel et al., 2007a) buscam investigar diferentes mecanismos para apoiar a captura e o acesso de informações de aulas tradicionais e missões de campo.

Sistemas acadêmicos como SmartClassroom (Shi et al., 2003) suportam sessões distribuídas ao vivo, permitindo aos alunos visualizar de forma síncrona os slides do professor, as anotações do professor com tinta eletrônica, além do áudio e do vídeo da sessão (Figura 2.3). Outros sistemas, como o sistema StuPad (Truong et al., 2001), foram desenvolvidos pensando no uso de dispositivos pessoais (tablets, o PDAs, entre outros), os quais permitem que o aluno faça suas próprias observações anotando o conteúdo apresentado pelo professor.

Estudos recentes do domínio educacional abordam diferentes enfoques, desde o tema dos sistemas LMS (Nodenot et al., 2006), até as ferramentas para auxiliar na preparação de apresentações pessoais (Kong e Muppala, 2007).Enfoques mais conservadores de trabalhos relacionados com aulas tipo palestras (Mertens et al., 2006; Chen e Li, 2007; Wang et al., 2008), alguns propondo novos paradigmas como aulas fora do contexto da sala e usando dispositivos móveis (Al-Imam e 
Lank, 2007; Pimentel et al., 2007a; Behera et al., 2007; Di et al., 2009), e outros mais individuais mediante aulas particulares para o aprendizado de uma língua estrangeira (Chen e Liu, 2006, 2009).

Também, foram encontrados trabalhos de linha mais estrita, como o monitoramento da atenção e do progresso acadêmico de alunos (Shakshuki e Halliday, 2008) até os mais criativos e didáticos, como o sistema de ensino para crianças usando hiper-histórias com interfaces 2D e 3D (Garzotto e Forfori, 2006).

Finalmente, existem alguns trabalhos cujo contexto de atuação é o domínio de sala de aulas, mas o objetivo da captura é diferente ao de suporte do ensino. Um exemplo é o sistema proposto por Kientz et al. (2007), que foi desenvolvido para facilitar a coleta de dados, feita por avaliadores, do comportamento de crianças autistas em salas de aulas, com o objetivo de observar seu desenvolvimento quanto à interação com outras crianças e com os professores.

\section{Domínio de reuniões}

Muitas pesquisas na área de C\&A têm sido focadas no estudo de aplicações para o domínio de reuniões, como apresenta o trabalho de Yu e Nakamura (2010). Este tipo de ambiente exige, dada a dinâmica das reuniões, aplicações com mecanismos colaborativos que permitam a interação entre os participantes, usando como modo de comunicação os dispositivos pessoais dos usuários. Para oferecer uma melhor experiência de interação aos usuários é preciso projetar sistemas de reuniões inteligentes.

As reuniões inteligentes têm como principal objetivo armazenar, analisar e sumarizar as informações capturadas com o intuito de aprimorar os processos de organização e visualização do conteúdo (Yu e Nakamura, 2010). Alguns dos primeiros trabalhos na área foram os de Pedersen et al. (1993), como o sistema Trivoli, e o de Streitz et al. (1994), com o sistema DOLPHIN, os quais eram aplicações do tipo lousa eletrônica na qual os usuários podiam interagir remotamente de forma síncrona. As aplicações foram evoluindo até conseguir capturar sincronamente vários tipos de mídias em sessões remotas ou não. Os sistemas iniciais deste tipo foram o LiteMinutes (Chiu et al., 2001) e o MuVIE (Lee et al., 2002). No caso de LiteMinutes, a aplicação automatiza a captura das anotações de áudio, vídeo e tinta digital de uma reunião online previamente programada. A sincronização é feita por meio de marcas do horário de forma semissupervisionada, já que um redator revisa o material para corrigir possíveis erros. O conteúdo gerado é publicado em uma pagina web e o endereço é enviado aos participantes para que possam rever a sessão. 
Por outra parte, o sistema MuVIE é uma aplicação de reuniões do tipo local que não precisa ser previamente agendada. A captura é feita por um único equipamento que aninha quatro câmeras de forma circular a ser colocado no centro da sala de reunião, de modo a capturar panoramicamente o áudio e o vídeo da reunião. Os participantes podem acessar em tempo real o conteúdo capturado, navegando por vários tipos de índices como transcrição automática do áudio em texto, quadros-chaves e detecção de objetos. Muitos trabalhos têm surgido a partir de então e os estudos relacionados ao domínio de reuniões e trabalho de escritório têm evoluído em pontos específicos. Como novas abordagens, existe uma preocupação com a indexação de documentos físicos e eletrônicos, (Everitt et al., 2008; Li et al., 2010) e com as relações dos documentos para o estudo de outras maneiras de busca e visualização, como o proposto por Rigamonti et al. (2007) com a criação de uma rede social de documentos. Outros trabalhos tiveram uma maior preocupação no momento da captura e nas alternativas de visualização, como no caso das câmeras panorâmicas e onidirecionais (Santos e Santos, 2006) junto com novas metodologias de organização e acesso à informação (Rui et al., 2006).

Por outra parte, estão os trabalhos mais recentes no tema de captura de reuniões, os quais, considerando os objetos de mídia que podem ser capturados durante a sessão, propõem sistemas de processamento de emoções para identificar o nível de interesse da pessoa em uma leitura (Asteriadis et al., 2009), as relações sociais ou os padrões de interação (Yu et al., 2010b,a) ou também o comportamento dos participantes para o monitoramento da dinâmica da reunião (Terken e Sturm, 2010).

\section{Domínio de propósito geral}

Os dois domínios anteriormente apresentados representam o maior número de pesquisas na área. Contudo, existem outros trabalhos que podem pertencer a uma grande variedade de domínios que também pesquisam os temas concernentes às aplicações C\&A, como seria no caso do estudo das crianças autistas apresentado por Kientz et al. (2007) no caso das áreas de ciências humanas e biológicas. Nessa ordem, trabalhos como o de Bulterman (2003) fornecem um ambiente interativo de anotações que pode ser usado no domínio de sistemas de informação médica, para a criação e visualização de anotações nas fichas dos pacientes, ou também no caso de ActiveTheatre (Hansen e Bardram, 2005) que está projetado para a captura de informações em ambientes de centros cirúrgicos, no qual os médicos, mediante o uso de canetas eletrônicas, podem fazer anotações na mesa de operações e a aplicação, integrando-se com os sistemas 
corporativos do hospital, faz uma recuperação de informações de contexto para fornecê-las aos médicos.

Mudando um pouco de contexto, encontramos trabalhos como o de Goularte et al. (2004) com o sistema M4Note, o qual serve como um anotador multimodal de vídeo, áudio e tinta digital, no contexto de captura de dados em saídas de campo, permitindo aos usuários fazer autoria sobre o material capturado. Também foram encontrados trabalhos interessantes aplicados a diversos temas, como diários pessoais (Chen e Jones, 2010), robôs pessoais (Solar, 2007), discussões médicas (Bulcão-Neto et al., 2008b,a) entre outros.

\subsection{Engenharia de Documentos}

"A escrita dá permanência ao conhecimento dos homens e lhes possibilita comunicar-se a grandes distâncias... Sem a arte de escrever não seria possível a existência das sociedades complexas das grandes civilizações" (Diringer, 1986)

Cada dia que passa, milhões de documentos são criados no mundo, analisando situações e transformando-as em modelos de abstração. Imagens, diagramas, réplicas a escala, vídeos, entre outros, são exemplos de modelos de abstração. Estes modelos são um conjunto de metadados relacionado a um contexto ou processo mental, que descrevem alguma informação pertinente. Para cada tipo de modelo de documentos, seja qual for o contexto (indústria, comércio, educação, entre outros), é preciso descrever os processos e os dados relevantes de modo que a estrutura dos documentos que sejam gerados satisfaça os requerimentos dos diferentes perfis. Por exemplo, os detalhes de um produto em uma ordem de compra enviada para um fornecedor contém menos descrições que as exigidas em uma ordem de compra enviada ao comprador; ou as considerações que um professor faz de uma disciplina são informações que, dependendo do grupo alvo (colegas, monitores, alunos), pode variar a pertinência ou importância de algumas informações.

A engenharia de documentos é definida como uma linha de pesquisa em que se estudam os sistemas que manipulam os documentos sem importar o tipo de conteúdo ou mídia (Lins, 2008). As pesquisas procuram aperfeiçoar a capacidade de criar, administrar, armazenar, compactar, acessar, extrair e dar manutenção aos documentos, fazendo uso de novas ferramentas e processos. Os trabalhos orientados nesta área estão focados nos processos de produção, manutenção e consumo de documentos (Glushko e McGrath, 2002). 
Alguns trabalhos (Chiu et al., 2001; Cheok e Li, 2008), oferecem soluções para problemas específicos com modelos específicos, cujo vocabulário só pode ser usado naquele contexto, tornando difícil a extensão e a integração com outros modelos. Esta situação é conhecida como o acoplamento entre o modelo de informação junto com a estrutura ou arquitetura do sistema, e varia em diferentes níveis. As boas práticas em engenharia de documentos enfatizam no reuso de modelos e padrões, conseguindo desta maneira um baixo acoplamento com os sistemas. Dentro da área é recomendado o uso de implementações de vocabulários da família XML (Extensible Markup Language)(Pimentel et al., 2000; Glushko e McGrath, 2002; Macedo et al., 2004; Hansen e Bardram, 2005; Glushko, Robert J. and Mcgrath, T., 2008) tanto quanto o uso de esquemas de XML como formato de codificação de novos modelos.

\subsubsection{Documentos Hipertexto}

O conceito de Hiperdocumento ou hipertexto nasce das pesquisas feitas por Vannevar Bush, Theodor Nelson e Douglas Engelbart, em relação ao problema da leitura sequencial e à sobrecarga de informação durante os anos da pós guerra (Nielsen, 1995). Segundo Theodore Nelson ${ }^{6}$, um hipertexto é um documento cuja estrutura está composta por blocos de textos e links que estão conectados com outros blocos (hiperdocumentos) em torno de um determinado conceito, recuperando a informação de maneira dinâmica, permitindo navegar na estrutura de forma não linear (poli-seqüencial). Isto significa que o usuário pode navegar através dos conceitos (âncoras) do documento, conectando-se com outros documentos relacionados a esses conceitos (links), conseguindo, dessa forma, um acesso simultâneo à informação de modo interativo e não linear.

Os hiperdocumentos expandiram as fronteiras para o processamento da informação, oferecendo novas formas de pensar, organizar e comunicar as idéias. A estrutura permite acessar e manipular a informação de modo a melhorar a visualização e a elaboração de novos documentos. Contudo, é preciso oferecer mecanismos que facilitem a criação de documentos que representem da melhor maneira os dados existentes. No caso em que a criação seja automática, o problema se estende a fornecer aos usuários as ferramentas de autoria para que possam gerar novos conteúdos.

Finalmente, dependendo de como tenha sido modelado o hiperdocumento, o usuário pode ficar perdido enquanto estiver navegando. Isto pode acontecer devido ao fato de que o usuário não tem uma idéia clara das conexões semânticas do sistema ficando perdido enquanto navega no documento ou também porque

6"What is HyperText- W3C Site:http://www.w3.org/WhatIs.html. Último acesso 19 Fevereiro 2011 
o usuário não sabe para onde olhar ou o que escolher a partir da posição no documento onde está. Portanto, a desorientação, a sobrecarga cognitiva, a qualidade da interface e a interatividade são alguns dos principais problemas que enfrentam os sistemas baseados em hiperdocumentos.

\subsubsection{Documentos Multimídia ou Hipermídia}

Quando um hiperdocumento permite a manipulação e o acesso simultâneo a vários tipos de informações (tais como imagens, vídeos, áudio, diagramas, entre outros) que estejam inter-relacionadas de tal forma que o usuário possa visualizá-las e navegar no próprio documento, se está falando de documentos multimídias ou hipermídia (Nielsen, 1995).

Segundo Nielsen (1995), o primeiro sistema hipermídia conhecido foi o dos Mapas de Aspen, que era uma aplicação de viagem que permitia aos usuários simular um passeio pela cidade de Aspen na tela do computador (algo assim como a primeira versão do Street view que oferece a empresa Google). O sistema usava como mecanismo de captura um carro que levava quatro câmaras no teto, cada uma com um ângulo de rotação de $90^{\circ}$ em ralação à outra, que percorria a cidade tirando fotos a cada três metros. O sistema hipermídia permitia fazer buscas específicas de ruas e "dirigir" pela cidade. Este tipo de enfoque pode ser usado nas aplicações de C\&A, no qual a informação capturada da sessão transformada em um documento hipermídia que permita recuperar e visualizar facilmente os dados mediante algum modo sincronizados.

São muitos os possíveis cenários entre dos vistos na Seção 2.1.3, nos quais se faz necessário transformar a informação capturada em um hiperdocumento. Por exemplo, no domínio de sala de aula, um professor poderia querer que o conteúdo de sua disciplina fosse discutido por ele em companhia dos alunos durante várias sessões, fazendo com que a aula fosse mais participativa e que as contribuições, perguntas e comentários feitos pelos alunos fossem armazenados. Com um sistema hipermídia, o professor poderia, posteriormente, rever as intervenções dos seus estudantes para depois complementar o material da aula adicionando novas informações e compartilhá-lo com os alunos.

Também existem trabalhos que destacam a importância de gerar formatos padronizados de documentos multimídia, como resultado da captura de experiências ao vivo (Macedo et al., 2004; Pimentel et al., 2007a). Por exemplo, Cesar et al. (2006b) argumentam sobre os benefícios de usar a linguagem SMIL como documento multimídia estruturado na Televisão Digital Interativa (TVDI) ou em dispositivos móveis (Bulterman, D. C. A. and Rutledge, Lloyd , 2008), podendo 
também ser usado o NCL, permitindo assim uma melhor experiência para o telespectador ao possibilitar-lhe compartilhar, editar e anotar sobre o conteúdo.

Em referência ao $\mathrm{SBTVD}^{7}$, existem trabalhos que mostram as vantagens de usar a linguagem NCL como documento multimídia de sincronização de mídias (Soares et al., 2006; Moreno et al., 2008; Soares et al., 2009a; Brandão et al., 2010; Guimarães et al., 2010) além dos mecanismos de interação que oferece a linguagem. No caso de Macedo et al. (2008), quem descreve uma infraestrutura de captura, acesso, sincronização, armazenamento e recuperação de informação para uma aplicação Web de sala de aula chamada xINCA, usa como base documentos XML para depois transformá-los em formatos de apresentação SMIL e XHTML (eXtensible Hypertext Markup Language).

Finalmente, é importante destacar que existem trabalhos que exploram modos de recuperação e geração de informação relacionada ao conteúdo, para facilitar a busca de dados relevantes na apresentação. Algumas pesquisas estão focadas na autoria de documentos multimídia interativos, a qual tem crescido nos últimos anos com o surgimento da necessidade de geração de novas versões sobre os conteúdos e do acesso à informação armazenada. Trabalhos referentes às áreas de multimídia (Bulterman, 2007; Bulterman e Hardman, 2005; Sgouros e Margaritis, 2007), de engenharia de documentos (Cesar et al., 2006a; Costa et al., 2006; Mikác et al., 2008), de TV digital (Cattelan et al., 2008a; Cesar et al., 2008; Guimarães et al., 2008; Pimentel et al., 2008) e de Computação Ubíqua (Cesar et al., 2006a; Wu et al., 2007; Sgouros e Margaritis, 2007) convergem na busca de soluções para o problema de autoria, mostrando claramente a importância deste tema.

\section{Documentos SMIL}

SMIL, Synchronized multimedia integration language, foi o primeiro membro dos padrões abertos da família XML desenvolvido e recomendado pela $\mathrm{W}^{3} \mathrm{C}^{8} \mathrm{e}$ encontra-se atualmente em sua terceira verão (SMIL 3.0) (Bulterman, D. C. A. and Rutledge, Lloyd , 2008). É uma linguagem declarativa de marcação para especificar documentos multimídia e pode ser usada para o desenvolvimento de documentos multimídia sincronizados no tempo, criando interfaces interativas para PCs ou para dispositivos móveis (Zucker e Bulterman, 2007).

A linguagem SMIL é usada para especificar as diferentes inter-relações dentre os objetos multimídia baseadas no tempo. Esta linguagem auto-descritiva não decodifica as mídias, simplesmente referencia ao formatador o lugar onde podem

7Sistema Brasileiro de Televisão Digital

8World Wide Web Consortium 
ser encontradas. O documento descreve as regras que sincronizam os objetos de mídia entre sim, especificando os pontos em que cada mídia vai ser ativada, além da posição na tela em que serão apresentadas, no caso das mídias gráficas. A ativação é feita através de disparadores de tempo ativados pelas regras de sincronização descritas no documento e pelas interações dos usuários (Zucker e Bulterman, 2007).

A linguagem também possibilita a definição de comportamentos alternativos para a apresentação do conteúdo de um documento. Esses comportamentos estão baseados em fatores específicos do contexto de exibição, como são as preferências do usuário e o dispositivo onde será tocado o documento. Finalmente, a linguagem tem como desvantagem o fato de não permitir a especificação de interação entre objetos baseados no sincronismo espacial, ou seja, aquele que acontece quando se deseja movimentar um objeto em uma região específica.

\section{Documentos NCL}

A linguagem NCL, Nested Content Language, é uma linguagem declarativa pertencente a família de linguagens XML que define uma separação bem demarcada entre o conteúdo e a estrutura da aplicação (Barbosa e Soares, 2008). O NCL segue o paradigma de modularização recomendado pela W3C que também e utilizado por outras linguagens do mesmo tipo. O documento NCL pode ser definido como um conjunto de elementos XML sintaticamente relacionados que se combinam para formar uma unidade funcional.

Em linguagens de marcação no geral é comum ter um formato bem definido do documento, especificando algumas tags e atributos que devem estar presente em todos os documentos. Além disso, pelo fato de NCL ser uma linguagem de marcação, existe a possibilidade de essas tags virem em qualquer ordem, desde que obedeçam à hierarquia predefinida pela linguagem. Um aplicativo ou documento NCL apenas define como os objetos de mídia são estruturados e relacionados, no tempo e no espaço, mas não restringe os tipos de objetos de mídia possíveis (Barbosa e Soares, 2008; Soares et al., 2007).

\subsection{Televisão Digital}

A televisão é um dos dispositivos de entretenimento mais importantes na maioria das residências de diferentes países (Berglund, 2004). Por exemplo, no Reino Unido, 99\% dos domicílios tinham televisão (TV) em 2000 (ONS, 2002) enquanto que no Brasil a TV estava presente em 87,2\% (IBGE, 2000). 
Tal importância faz com que seja pertinente considerar novos modelos de mercado, que ofereçam melhores conteúdos e novos serviços de valor agregado para a TV. É assim como a atual fase de digitalização da TV aberta pela qual diversos países do mundo têm passado, em especial o Brasil, traz mudanças na forma como o telespectador recebe o conteúdo multimídia, tais como melhoria da qualidade de imagem e som, possibilidade de multiprogramação e aplicações interativas.

Na transmissão analógica da TV existem vários problemas que são solucionados pela digitalização do sinal. Alguns desses problemas (Cejudo et al., 2009) são:

- Na TV terrestre cada canal ocupa um espaço da banda (espectro) usando Freqüência muito alta, do inglês Very-High-Frequency (VHF) ou Freqüência ultra alta, do inglês Ultra-High-Frequency (UHF). Isso leva a ter um menor número de canais devido a limitação do espectro de frequências.

- O sinal precisa de maior potência para ser transmitido. Não é possível oferecer serviços multimídia e nem transmissão de dados.

- A imagem apresenta baixa qualidade (720x480 pixels, proporção 4:3) e apenas dois canais para som. Tem efeitos de "chuviscado" e de dupla imagem.

- As alterações no nível do sinal causam efeitos de ruído, responsáveis pelos "chuviscos" na imagem, e interferências que limitam a capacidade do sistema (Barbosa e Soares, 2008).

A melhora na qualidade da imagen e do som foi possível graças ao uso, por parte dos padrões de transmissão para TV digital, de códigos corretores de erros do nível do sinal digital. Outro fator decisivo na melhoria da qualidade de áudio e vídeo é a utilização de técnicas de compressão de dados nos sinais, sendo possivel transmitir mais dados, ou seja, uma maior resolução de vídeo e mais canais de áudio, obedecendo à mesma limitação imposta pelo meio físico.

Seguindo a mesma lógica, a possibilidade de compressão permite ainda que por um mesmo meio físico possam ser transmitidos até 4 programas com vídeo na definição padrão (SDTV, do inglês Standard Definition Television) em vez de apenas 1 programa em Alta definição (HDTV, do inglês High-Definition Television) (Barbosa e Soares, 2008). Esse esquema de transmissão é conhecido como multiprogramação e possibilita uma maior oferta de programas para o usuário.

A mudança mais significativa, entretanto, é o aumento da quantidade e qualidade de serviços que podem ser oferecidos através da televisão devido ao datacasting, permitindo à possibilidade de transmissão de dados multiplexados com 
o áudio e vídeo (Montez e Becker, 2004). Esta característica redefine o conceito da TV de consumo brodcasting convertendo-a em um terminal multimídia, passando a ser mais participativa para os usuários.

Para que a TV possa acessar a transmissão digital terrestre, é preciso um sintonizador que faça a recepção do conteúdo digital. Este dispositivo pode estar embarcado na TV ou pode ser um aparelho anexo chamado STB. No caso do dispositivo embarcado, presente só nas TVs novas, este oferece pouco poder de processamento, restringe-se a simplesmente decodificar-sintonizar o sinal digital e em relação ao custo benefício não representa uma boa escolha. O STB e as possibilidades que oferece, vão ser explicados a seguir.

\subsubsection{Equipamento de Conversão de TV Digital}

Existe um bom número de TVs do mundo que só pode processar o sinal analógico (Piccolo e Baranauskas, 2006). Para que possam receber o sinal digital, enquanto não são atualizadas por modelos mais novos, é necessário usar um STB(Set-Top Box) ou receptor que faça a conversão do sinal digital ao analógico para a TV e que execute as aplicações (serviços) oferecidas pelos canais ou empresas do setor.

O STB possui uma arquitetura muito semelhante à arquitetura de um $\mathrm{PC}^{9}$. Tem processador, memória RAM, disco rígido ou memória flash, portas de entrada e saída (conexão a rede) e um sistema operacional mais simples que o de um computador. As aplicações são executadas sobre um middleware, o qual é a camada que intermedia toda a comunicação entre as aplicações e os serviços oferecidos pelo sistema operacional do receptor, através de uma interface padronizada.

O middleware possui um papel importante, pois permite que as aplicações sejam executadas em qualquer receptor que suporte o middlerware para o qual ela foi desenvolvida, abstraindo as diferenças e particularidades dos decodificadores (Montez e Becker, 2004; Barbosa e Soares, 2008). O middleware definido pelo padrão brasileiro é o Ginga, explicado na Seção 2.3.2.

\subsubsection{Sistema Brasileiro de TV digital}

No Brasil, em dezembro de 2007 começou o cronograma de implantação da TV digital que vai até 2016. O Ginga, definido como middleware do Sistema Brasileiro de TV Digital (ABNT, 2007), foi desenvolvido principalmente por pesquisadores de duas universidades, a Pontifícia Universidade Católica de Rio de 
Janeiro (PUC-Rio) e a Universidade Federal da Paraíba (UFPB). O Ginga Common Core (Ginga-CC) possui dois ambientes de execução de aplicações: o Ginga-J, responsável pelo processamento de aplicações procedurais, e o Ginga-NCL, responsável pelo processamento de aplicações declarativas (Soares et al., 2007).

Uma aplicação procedural possui seu conteúdo imperativo, mas pode conter também conteúdos declarativos. O mesmo vale para aplicações declarativas, que possuem seu conteúdo descritivo, mas podem fazer uso de scripts ou referenciar aplicações procedurais em Java (Soares et al., 2007; ABNT, 2007).

\section{Ginga-J}

O Ginga-J é o ambiente de execução de aplicações procedurais do middleware Ginga, o qual está baseado na tecnologia Java. Este ambiente, que foi adotado como recomendação de linguagem procedural para televisão digital terrestre (ITU $\mathrm{J} 202^{10}$ ), possui um elemento chave para que as aplicações possam executar sem importar o hardware do STB ou o software (sistema operacional,middleware) que é a máquina virtual Java. Esta máquina virtual conhecida como Java DTV foi desenvolvida pela Sun Microsystem em conjunto com companhias e institutos de pesquisa do Brasil.

Neste trabalho não será tratado em mais detalhes o ambiente Ginga-J, porque o interesse do presente projeto centra-se na autoria e manipulação de documentos multimídia interativos, que para o caso do Ginga seria seu ambiente declarativo conhecido como Ginga-NCL.

\section{Ginga-NCL}

O Ginga-NCL é um subsistema lógico do middleware Ginga responsável pelo processamento de documentos NCL. Os principais componentes do Ginga-NCL são a máquina de interpretação do conteúdo declarativo (formatador NCL), o exibidor XHTML, que inclui interpretadores CSS (Cascading Style Sheets) e ECMAScript, e a máquina de apresentação Lua, que é responsável pela interpretação dos scripts Lua (ABNT, 2007).

O formatador NCL é responsável por receber documentos NCL e controlar sua apresentação respeitando as relações definidas entre os objetos de mídias (Soares et al., 2007). São os exibidores de mídia presentes no formatador que define quais são os tipos de mídias suportadas (ABNT, 2007). Durante a apresentação dos objetos de mídia, diversos eventos são gerados (Soares et al., 2007). Os eventos podem ser do tipo apresentação, seleção, atribuição ou composição 
(ABNT, 2007). Documentos NCL possuem conectores, que são responsáveis por fazer uma ligação entre eventos e ações (Barbosa e Soares, 2008). Um exemplo seria um conector que faz com que o evento de pressionamento de um botão do controle remoto resulte na ação de inicialização de apresentação de um vídeo.

\section{NCLua}

Lua é uma linguagem de scripting rápida e leve, projetada para estender aplicações e dar suporte à programação procedimental em geral, oferecendo facilidades para a descrição de dados (Brandão et al., 2010). Foi criada em 1993 por Roberto Ierusalimschy, Luiz Henrique de Figueiredo e Waldemar Celes, membros do Grupo de Tecnologia em Computação Gráfica (Tecgraf) da PUC-Rio. Da versão 5.0 em diante, utiliza a licença MIT, compatível com a GNU General Public License (GPL). É uma linguagem de extensão que funciona embarcada em um programa hospedeiro, podendo ler e escrever suas variáveis e até fazer uso de funções de C. Além disso, está ganhando muito reconhecimento no mundo todo dado seu pequeno "runtime" e sua simples interface de programação (API, do inglês Application Programming Interface), sendo usada em muitos jogos eletrônicos e recentemente na TVDI.

Lua é a linguagem adotada pelo módulo Ginga-NCL para fortalecer seu ambiente declarativo, permitindo o desenvolvimento de objetos imperativos com códigos procedurais interpretados por Lua. Dessa forma, estende-se o paradigma ao modelo declarativo+procedural dando lugar a uma ferramenta que provê uma descrição de dados baseada em tabelas, além de ser uma linguagem tipada dinamicamente, com gerenciamento automático de memória, coleta de lixo e interpretada a partir de uma máquina virtual baseada em registradores (bytecodes).

O interpretador NCLua utilizado no motor de apresentações do NCL deve ser capaz de entender a API padrão do Lua, incluindo os módulos basic, string, table, math, package, io, os, debug e coroutine (ABNT, 2007). Além dos módulos padrões, a API Ginga-NCLua prevê a implementação dos seguintes módulos adicionais obrigatórios, com seu carregamento automático antes da execução de qualquer script (ABNT, 2007):

- Módulo Canvas: oferece uma API para manipulação de imagens e desenho de primitivas gráficas;

- Módulo Event: permite que aplicações NCLua comuniquem-se com o middleware através de eventos e que scripts Lua manipulem objetos declarativos dos documentos NCL, adicionando, modificando e removendo informações. Os eventos do módulo têm a ver com key, NCL, EDIT e TCP; 
- Módulo Settings: provê uma forma simples de acessar as variáveis de ambiente do sistema e também as variáveis definidas em objetos do tipo "applitacion/x-ginga-settings";

- Módulo Persistent: permite a manipulação de uma tabela de dados persistentes que podem ser acessados por diferentes objetos imperativos.

Os operadores de interação, que frequentemente foram usados nas aplicações de C\&A nos últimos cinco anos, que abrem um leque de possíveis formas de acesso e de busca de informações, são apresentados a seguir.

\subsection{Operadores de Interação}

Foi realizada uma revisão sistemática (Apêndice A) que teve como objetivo analisar o estado da arte dos métodos, técnicas e abordagens usadas nas aplicações de Captura \& Acesso que facilitem o acesso sob o ponto de vista das interações/informações contidas nas mídias, levando em consideração a geração automática de vídeos interativos, fazendo uso de documentos multimídia interativos.

Além de identificar os estudos, a revisão sistemática também teve como objetivo a classificação desses por tipos de operadores que geram eventos de interação relacionados às mídias e pelos mecanismos de visualização e acesso frequentemente usados. Os eventos de interação e a classificação dos operadores são apresentados na Seção 2.4.1; e a classificação dos estudos baseados nos mecanismos de visualização é apresentada na Seção 2.4.2.

\subsubsection{Classificação Por Operadores de Interação}

A partir dos estudos primários da revisão sistemática foi feita uma classificação baseada no tipo de eventos gerados pelas técnicas ou métodos (que são chamados neste trabalho como operadores) utilizados nas aplicações de C\&A. No Apêndice B.2 são reportados estudos com os respectivos operadores de interação usados ou propostos para a geração de informações explícitas (derivadas) sobre os dados capturados. No trabalho desenvolvido na revisão sistemática, eses eventos foram generalizados em operadores e classificados a partir do ponto de vista do tipo de mídia ao qual se aplicam.

Na Figura 2.4 estão sumarizados todos os operadores de interação que foram utilizados em cada um dos estudos, agrupados segundo o tipo de mídia a que se aplicam. Temos, por exemplo, que o sistema DocMIR (Behera et al., 2007) 


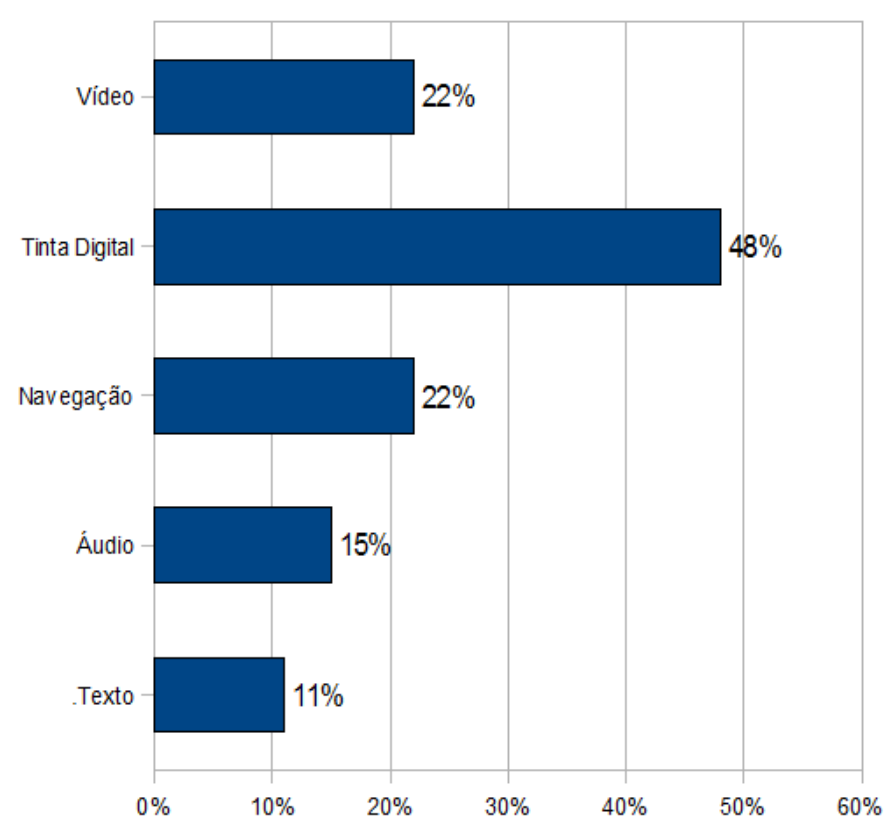

Figura 2.4: Distribuição dos operadores de interação usados nos estudos primários segundo o tipo de mídia

faz identificação de palavras-chaves de uma pista de áudio, reconhecimento de texto em imagens, identificação de mudança de slides, de formas e de contornos e melhoramento da qualidade da imagem em um dado vídeo. Diferentemente em outros trabalhos que é realizado o análise com base em uma tipo de mídia especifica, como operadores de tinta digital (Westermann e Jain, 2006; Cattelan et al., 2008b; Li et al., 2010) ou de áudio (Reynolds e Torres-Carrasquillo, 2005; Chen e Li, 2007; Friedland et al., 2010).

Nos trabalhos encontrados na literatura, foi observado que os operadores de interação mais usados são aqueles que fazem uso de tinta digital, com 48\% de uso. Seguem os operadores de interação de vídeo e de navegação, ambos com $22 \%$ de uso. No caso das mídias menos exploradas, foi evidenciado um baixo uso de operadores de áudio e de texto, com um 15\% e 11\% respectivamente. Esses operadores de interação podem ser úteis como mecanismos de geração e acesso a sessões capturadas, como é evidenciado nas pesquisas feitas por Pimentel et al. (2000), Chen e Li (2007) e Behera et al. (2007).

\subsubsection{Classificação Por Mecanismos de Visualização}

Uma grande parte dos trabalhos reportados na literatura usa como forma de visualização, softwares específicos (players) para os dados capturados e o contexto em que estava inserido o projeto, como no caso dos trabalhos FaericWorld (Rigamonti et al., 2007), SHALEX (Shakshuki e Halliday, 2008) e o PocketPad 
(Al-Imam e Lank, 2007). Alguns outros usam as técnicas tradicionais de visualização de dados capturados, como são os vídeos lineais com animações FLASH (Mertens et al., 2006; Garzotto e Forfori, 2006), ou documentos estáticos como documentos web (Wang et al., 2008), SVG (Mertens et al., 2006) ou PDF (BulcãoNeto et al., 2008a).

Quanto ao uso de documentos multimídia interativos (Apêndice B.3), apenas $27 \%$ dos trabalhos selecionados utilizaram esses documentos como forma de visualização da sessão. Foi visto que $75 \%$ dos estudos que usaram documentos multimídia adotaram a linguagem SMIL para suas aplicações. Alguns poucos trabalhos reportaram novas linguagem para o desenvolvimento de aplicações multimídias interativas, como o caso de Ferati et al. (2009) com a linguagem AIDM, o caso de Nodenot et al. (2006) com o modelo chamado de CP, ou o caso de Behera et al. (2007), com a proposta de uma linguagem de marcação de informações multimodais chamada de IM2. Em menor proporção estão os trabalhos que usam dois ou mais tipos de documentos multimídia como mecanismo de visualização, como é o caso de Cattelan et al. (2008a) que gera documentos NCL e SMIL.

Dessa forma, foi evidenciado que a grande maioria dos pesquisadores preferem utilizar ou desenvolver softwares específicos para visualizar os dados, ou também, as abordagens tradicionais, como a geração de vídeos ou animações com o formato $f l v$ de FLASH por exemplo, ou visualizar os dados de maneira estática, como SVG, PDF, HTML entre outros.

\subsection{Considerações Finais}

Aplicações de captura automática e acesso aos dados podem ser bastante úteis em diversos cenários. Existem informações relacionadas à fase de captura que podem ser extraídas de forma implícita ou explícita. Os mecanismos mais usados nas aplicações de C\&A são aqueles que, fazendo uso de dispositivos especializados, armazenam algum tipo de informação relacionada com o contexto. Entre esses dispositivos estão canetas digitais, microfones, sensores e outros. Essa forma de captura de informação é denominada neste trabalho como captura de informação explícita.

Um processamento a posteriori dos dados capturados para encontrar novas informações foi denomindo neste trabalho como extração de dados de maneira implícita ou derivada sobre os dados. Por exemplo, algoritmos de reconhecimento de objetos no fluxo do vídeo, identificação de cenas, transcrição automática do áudio em texto, entre outros. 
Portanto, é importante contar com tecnologias que auxiliem $i$ ) na sincronização dos fluxos de informação capturados; ii) na geração de novas versões dependendo da informação requerida ou do perfil do usuário; iii) na visualização efetiva da sessão capturada e $i v$ ) na otimização dos mecanismos de acesso a pontos específicos de interesse. Por tal motivo, foi mostrado que, mediante o uso de documentos hipermídia e em especial de documentos multimídia interativos como NCL ou SMIL, essas tarefas podem ser realizadas de modo mais fácil e direto.

Contudo, existem muitas informações relacionadas à interação dos usuários que oferecem novas formas de indexação e visualização dos dados. Por exemplo, eventos relativos à interação baseada em caneta eletrônica, mudança na cor dos traços, mudança entre as ferramentas de desenho, entre outros, podem ser gerados automaticamente fazendo uso de operadores de interação, ou processando algoritmos que reconheçam a interação do usuário já seja de forma implícita ou explícita. Tais operadores poderiam ser usados para gerar visões personalizadas da sessão capturada e para retroalimentar o sistema com as ações do usuário.

Nas análises dos estudos primários relacionados ao domínio de aplicação, foi constatado que o número de trabalhos pertencentes ao domínio educacional é o mais representativo dentre os trabalhos selecionados. Também, foi constatada a baixa quantidade de trabalhos relacionados com recuperação de informação e indexação de eventos de interação por mecanismos de pós-processamento. Isto mostra que a grande maioria dos trabalhos usa dispositivos para indexar as interações dos usuários, dado o baixo enfoque de captura explícita dos dados. Junto a isto, foi visto que apenas $27 \%$ dos estudos usaram como maneira de visualização documentos multimídias interativos, e destes $75 \%$ usaram a linguagem SMIL como ferramenta de visualização.

Finalmente, existe uma grande proporção de trabalhos relacionados a operadores de tinta digital, fazendo com que este seja a base dos primeiros estudos em processamento de eventos de interação do usuário. Foi constatado que mídias como áudio e texto apresentam poucos estudos primários, $15 \%$ e $11 \%$ respectivamente. Isto pode ser devido à complexidade do processamento sobre esse tipo de dados, usando técnicas/ferramentas de outras áreas e até propondo novas formas de processamento, colocando de manifesto os poucos trabalhos relacionados na área. 


\section{$-3$ \\ Interactors: Eventos de Interação Baseados em Mídias}

$\mathrm{F}$ erramentas de comunicação síncrona permitem a usuários remotos colaborar entre si por medio da troca texto, imagens, áudio, e vídeo em para visualizar uma sessão capturada, a alternativa comumente adotada é gerar o vídeo linear com o conteúdo das mídias trocadas. Essa abordagem limita a revisão da sessão ao exigir que se assista ao vídeo usando os comandos tradicionais de navegação de vídeo sobre a linha de tempo (tocar, pausar, avançar, retroceder).

Nos cenários em que a ferramenta de comunicação sincrona gera de forma automática documentos multimídia interativos como resultado da captura, a literatura reporta a oportunidade de explorar operadores que, modelando as interações do usuário associadas com dispositivos de caneta eletrônica, como por exemplo, as lousas inteligentes (smartboards), permitem a revisão dos traços de tinta digital capturados durante a sessão como um documento interativo (Cattelan et al., 2008b). Esta abordagem foi estendida para permitir que os navegadores (browsers) sejam construídos através da geração automática de documentos multimídia interativos (iMMD) envolvendo múltiplos tipos de mídias (Vega-Oliveros et al., 2011a).

O iMMD gerado é, portanto, enriquecido com vários tipos de índices mapeados no tempo. Esses índices são gerados por operadores de interação baseados 
em tinta digital ${ }^{1}$ ou operadores de interação baseados em áudio ${ }^{2}$, por exemplo. Esses operadores são chamados Interactors, como a generalização de "operadores baseados na interação do usuário com uma respectiva mídia”. O resultado é um iMMD que contém vários pontos de acesso, com significado semântico, sobre a linha de tempo do documento, por exemplo.

Para gerar um iMMD associado com uma sessão capturada, é usada a abordagem do documento de intercâmbio de informação especificado em XML, que sincroniza os fluxos de mídia capturados e oferece diferentes maneiras de acesso à linha de tempo (Vega-Oliveros et al., 2010b). Este capítulo está organizado da seguinte forma: uma primeira abordagem de operadores de tinta digital reportada na literatura é apresentada na Seção 3.1; a extensão e a formalização dos operadores de interação baseados em mídias aparecem na Seção 3.2; o processo proposto e as fases do ciclo de vida dos eventos de interação são apresentado na Seção 3.3; algumas propriedades emergentes da abordagem relacionadas com a teoria de conjuntos são descritas na Seção 3.4; por último, uma discussão da proposta e das primeiras contribuições é apresentada na Seção 3.5.

\subsection{Operadores de Interação: abordagem inicial}

Fazer anotações em um documento eletrônico, tomando a metáfora do papel, permite que o usuário tenha uma experiência interativa próxima de uma interação natural. Mecanismos de interação para autoria de anotações em multimídia têm sido alavancados pela presença cada vez mais difundida de dispositivos computacionais com interfaces baseadas em tinta digital - Tablets PCs, Celulares, PDAs, lousas eletrônicas, entre outros. Tais sistemas processam a entrada de dados via caneta eletrônica, armazenando os dados relacionados à informação da tinta digital, como marcações de tempo, cor, espessura e posição.

A vantagem dos documentos eletrônicos está na facilidade de edição (apagar, mover ou redimensionar os traços (strokes)) além da possibilidade da criar documentos remotos que permitam realizar as tarefas de edição de modo colaborativo, via Internet.

Contudo, as formas tradicionais de visualizar documentos eletrônicos (anotado com tinta digital) apresentam algumas falhas. Em geral, são representados como documentos estáticos que só mostram o estágio final, por exemplo, uma imagem. A desvantagem das representações estáticas é que ignoram as versões intermediárias do documento e apenas o resultado final é apresentado. Por outro

\footnotetext{
${ }^{1}$ Inkteractors (Cattelan et al., 2008b).

${ }^{2}$ AudioInteractors (Vega-Oliveros et al., 2010a).
} 
lado, também são feitas as representações dos documentos como se fossem uma animação, na qual é possível reproduzir os traços da caneta eletrônica como um processo contínuo. Porem, a animação requer de tempo para sua apresentação e exige que o usuário fique assistindo até alcançar o ponto que lhe interessa no documento (uma linha de tempo poderia acelerar o processo, mas não permite que o usuário atinja o ponto desejado de forma não linear).

Foi vista a importância de oferecer mecanismos que facilitem a revisão automatizada das anotações feitas pelo usuário com os dispositivos computacionais baseados em caneta eletrônica. Para tal fim, o conceito dos Inkteractors (Pimentel et al., 2005; Cattelan et al., 2008b) entra em cena para auxiliar o usuário na autoria, geração e acesso aos dados capturados com tinta digital.

Os Inkteractors foram definidos como os operadores que consideram as informações geradas a partir da interação do usuário com a caneta eletrônica (Pimentel et al., 2005). Cattelan et al. (2008b), formalizou um conjunto de operadores que considera as informações relacionadas aos atributos da interação (cor, espessura, marcações de tempo, entre outros), para gerar automaticamente documentos derivados correspondentes a estágios intermediários da interação como um todo. Originalmente foram divididos em quatro categorias, que são apresentadas a seguir:

Baseados em tempo. Cada traço desenhado recebe marcações de tempo (timestamps) relativas ao começo da atividade de anotação. Essa informação temporal permite a definição de operadores simples, porém interessantes:

- TimeSlice(t): considerando a linha de tempo da atividade de escrita, esse operador gera, periodicamente, snapshots derivados dos artefatos anotados, isto é, a cada $t$ segundos um novo snapshot é gerado.

- IdleTime(t): gera snapshots dos artefatos anotados imediatamente antes de períodos de inatividade na escrita, isto é, sempre que o usuário não usa a caneta por pelo menos $t$ segundos. A Figura 3.1 ilustra um exemplo em que dois slides são gerados automaticamente: um contendo apenas o enunciado do problema e o outro contendo também a solução.

Baseados em atributos. Muitos atributos dos traços podem ser automaticamente coletados durante a escrita, incluindo cor, espessura, tipo de traço (escrita livre, forma geométrica, etc.). Tais atributos podem ser utilizados como parâmetros para os Inkteractors:

- ChangeOnAttributes(1): gera snapshots de um artefato anotado sempre que um atributo entre traços consecutivos muda. Os atributos a serem monitorados são especificados na lista $l$. 


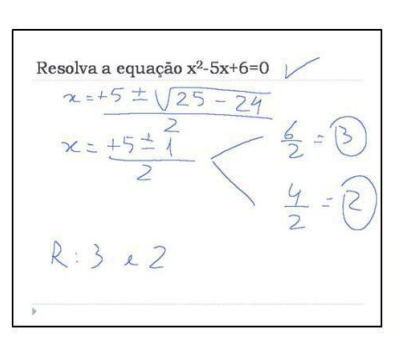

versão original

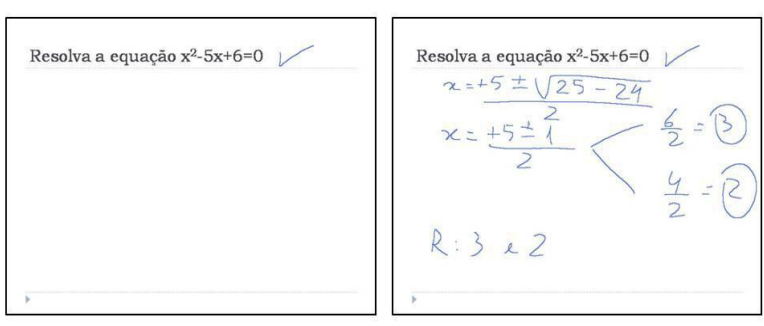

versão derivada

Figura 3.1: Resultado da aplicação do operador IdleTime 0 em um slide com a resolução de um exercício: o enunciado do problema e a solução correspondente são automaticamente separados. (Adaptada de (Cattelan et al., 2008b))

- FilterByAttribute(1; v): gera snapshots de um artefato anotado selecionando apenas os traços cujos atributos especificados na lista $l$ assumam os valores especificados na lista $n$-dimensional $v$, onde $n$ é o número de parâmetros em $l$.

Baseados em ações. Ao interagir com o sistema de captura, o usuário pode executar varias ações sobre os traços desenhados, como mover, apagar ou alterar a cor, por exemplo. O histórico de tais ações é mantido implicitamente na representação dos traços, bem como quem realizou cada ações. Os seguintes operadores foram definidos a partir de ações do usuário:

- ChangeOnAuthor(): gera snapshots derivados do artefato anotado cada vez que o autor do próximo traço é diferente do autor do traço atual. Por exemplo, no caso de dois usuários disputando um "jogo da velha"em uma whiteboard distribuída, é possível reconstruir as jogadas de cada usuário, como mostra a Figura 3.2

- FilterByAuthor(1): gera snapshots derivados do artefato anotado incluindo apenas os traços desenhados pelos autores especificados na lista $l$.

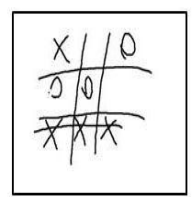

versão original

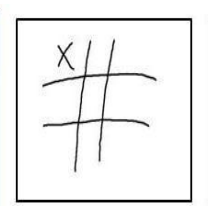

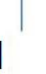

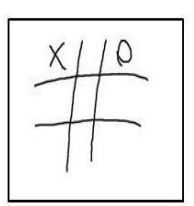

versão derivada

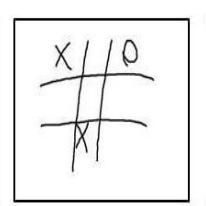

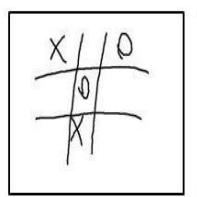
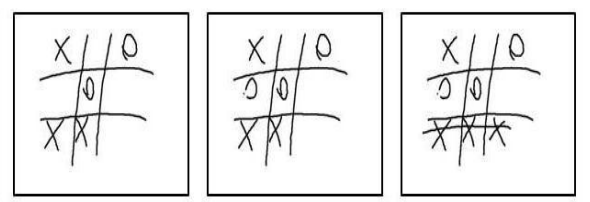

Figura 3.2: Resultado da aplicação do operador ChangeOnAuthor() em um documento editado colaborativamente: usuários alternando jogadas em uma disputa de "jogo da velha". (Adaptada de (Cattelan et al., 2008b))

Baseados em posição. A superfície de anotação e os traços são representados como um conjunto de pontos em coordenadas cartesianas. Os limites de 
fronteira (valores mínimos e máximos ocupados nos eixos X e Y) também são registrados para cada traço. Essa informação sobre a posição relativa dos traços permite as seguintes operações:

- ChangeOnArea(a; b): gera snapshots derivados do artefato anotado quando a interação com a caneta acontece na área selecionada $a$. O parâmetro booleano $b$ indica que deve-se considerar qualquer traço interceptando $a$ ou apenas traços cujos limites de fronteira estejam totalmente contidos em $a$.

- FilterByArea(a; b): filtra os traços anotados em uma área selecionada $a$. O parâmetro booleano $b$ indica caso deva-se considerar qualquer traço interceptando a ou apenas traços cujos limites de fronteira estejam totalmente contidos em $a$.

\subsection{Generalização dos Operadores de Interação: Interactors}

Nesta seção o conceito de Interactors é estendido e generalizado desde a abordagem dos Inkteractors, ao tratar-se de eventos de interação gerados a partir de operadores baseados em mídias, para a criação de documentos multimídia interativos, do inglês Interactive Multimidia Documents a partir das mídias capturadas (Vega-Oliveros et al., 2011a).

A proposta dos Interactors está em categorizar os diferentes tipos de índices e mecanismos de extração agrupando-os no conceito de mídia, abstraindo as tecnologias ou dispositivos de captura. O conceito determina as características dos tipos de eventos de interação que podem ser gerados e não nos métodos ou algoritmos precisos para tal fim. Neste sentido, Whittaker et al. (2007) propõem categorizar os navegadores (ou neste caso também operadores) de acordo com o tipo de índice disponível: navegadores baseados no áudio, focados em geral na detecção de pausas, aumento do volume, na ênfase, entre outros; navegadores de vídeos, explorando a detecção de cenas chaves e do estado ou comportamento do usuário no vídeo; navegadores de artefatos, que estão relacionados com a interação do usuário com algum tipo de dispositivo; e navegadores de discurso, concentrados na transcrição de falas e percepção de emoções.

Definição 1 (Interactor): Um Interactor é uma técnica ou operação que é aplicável a um tipo específico de mídia (operador baseado em mídia) e consiste em um conjunto de ao menos um evento de interação.

Quando foram realizados experimentos com os Interactors, notou-se que o tempo, ao invés de ser caracterizado como uma categoria isolada, também podia 
ser usado em conjunto com outras categorias de recursos. Baseando-se nesta premissa, foi proposta uma extensão no sentido de considerar os vários tipos de mídias e dois novos requisitos:

- (i) a necessidade de uma lista de momentos de tempo para ser retornada por um operador; e

- (ii) a necessidade de incluir o intervalo de tempo no qual a mídia está sendo processada.

Neste contexto, definiu-se o momento, como o instante de tempo em que acontece a ação na sessão, e o intervalo de tempo, como um segmento delimitado por dois momentos.

Alguns exemplos de operadores baseados em mídia são (Definição 1): Board Interactors (por exemplo, transição de slides) (Behera et al., 2007; Adcock et al., 2010); Ink Interactors (por exemplo, anotações baseadas em tinta produzida por dispositivos baseados em caneta) (Cattelan et al., 2008b; Chen e Liu, 2009; Motti et al., 2009); Text-based Interactors (relacionados com a troca de mensagens de texto e anotações) (Chen e Liu, 2006; Macedo et al., 2010); e Audio-based Interactors (por exemplo, relacionado com a detecção de momentos de silêncio) (Terken e Sturm, 2010; Vega-Oliveros et al., 2010a). A formalização dos operadores orientados a mídias é descrita a seguir:

\subsubsection{Redefinição dos Inkteractors}

Os Interactors baseados em tinta se estenderam, foram revisados e redefinidos para cumprissem os novos requisitos. Os Inkteractors são um tipo especial de Interactors obtidos pelo processamento das interações dos usuários com tinta digital - que é comum quando a informação é capturada de reuniões, salas de aula ou museus, por exemplo, mediante o uso de dispositivos que usam caneta eletrônica, como whiteboards e tablets. Estes operadores podem ser aplicados sobre os traços de tinta digital permitindo a geração e reprodução de documentos contendo versões alternativas do processo original de interação do usuário. A seguir, são apresentadas as especificações originais de alguns Inkteractors que têm sido atualizadas para abarcar os novos requisitos.

Baseados em tempo. Usado para filtrar ou expandir os elementos de mídia baseados apenas em restrições de tempo.

- timeSlice(time StartTime, time EndTime): retorna uma lista de traços de tinta digital gerados em um intervalo de tempo específico - isto pode ser usado para gerar uma imagem que agrega os traços realizados, por exemplo; 
Baseados em atributos. considera os atributos dos traços, como cor, espessura, tipo de traço (tinta com forma livre, forma geométrica, etc).

- changeOnAttribute(atributo A, tempo StartTime, tempo EndTime): retorna uma lista dos momentos de tempo em que os traços de tinta foram alterados de acordo com o atributo A, dentro do intervalo definido por StartTime e EndTime - isso pode ser usado para gerar índices na linha de tempo correspondente à mudança na cor ou no traço, por exemplo;

- filterByAttributeValue(atributo $A$, valor $V$, tempo StartTime, tempo EndTime): retorna uma lista de momentos de tempo em que os traços de tinta foram alterados, de tal forma que o atributo $A$ é igual ao valor $V$ dentro do intervalo de tempo definido por StartTime e EndTime - isto pode ser usado, por exemplo, para gerar um índice na linha de tempo correspondente aos momentos em que uma cor específica foi usada.

Baseados em ações. Enquanto interage com a ferramenta de captura, um usuário pode realizar várias ações com tinta digital, como desenhar, apagar, alterar a cor e assim por diante. O histórico dessas anotações é mantido juntamente com a representação de traços, bem como o autor que realizou cada uma delas.

- changeOnAuthor(tempo StartTime, tempo EndTime): retorna uma lista dos momentos de tempo na qual houve uma mudança na autoria dos traços, dentro de um intervalo de tempo definido por StartTime e EndTime - isto pode ser usado para gerar índices na linha de tempo correspondente a uma alteração na autoria do traço, a qual pode ser de interesse em sistemas distribuídos, nos quais vários usuários podem desenhar em uma superfície comum;

- filterByAuthor(id ID, tempo StartTime, tempo EndTime): retorna uma lista dos momentos de tempo em que houve uma mudança na autoria dos traços, na qual o autor é identificado por $I D$, dentro de um dado intervalo de tempo - isso pode ser usado para gerar índices na linha de tempo correspondentes aos momentos em que o autor fez um traço depois de alguém.

Baseados em posição. O Desenho dos traços são representados como um conjunto de pontos em coordenadas cartesianas, limites de fronteiras, i.e., valores mínimos e máximos nos eixos $\mathrm{X}$ e $\mathrm{Y}$, são armazenados para cada traço.

- changeOnArea(coord $X$, coord $Y$, tempo StartTime, tempo EndTime): retorna uma lista dos momentos de tempo na qual houve uma mudança em uma área especificada; 
- filterByArea(coord $X$, coord $Y$, tempo StartTime, tempo EndTime): retorna uma lista dos traços desenhados em uma dada superfície durante um intervalo de tempo específico.

\subsubsection{Audiolnteractors}

Os AudioInteractors são um tipo especial de Interactors que geram eventos de interação a partir de análises do conteúdo do áudio que contém a fala do usuário (Vega-Oliveros et al., 2010a). Os AudioInteractors estão categorizados como baseados no tempo, baseados em atributos e baseados em ações. A seguir é apresentada cada uma destas categorias com sua respectiva especificação.

Baseados em tempo. São aqueles eventos de interação obtidos na detecção de padrões sobre o arquivo digital de áudio. Podem ser usados, por exemplo, para a identificação de momentos ou intervalos de tempo na gravação de quando acontece alguma ação com determinada voz.

- silenceMoments(time Tmin, time StartTime, time EndTime): retorna a lista dos momentos no tempo em que não havia nenhuma voz em ao menos Tmin unidades de tempo de durante o intervalo de tempo definido por StartTime EndTime.

- spokenMoments(time Tmin, time StartTime, time EndTime): retorna uma lista dos momentos na gravação logo antes de alguém ter falado pelo menos Tmin unidades de tempo durante o intervalo de tempo definido por StartTime e EndTime.

Baseados em atributos. Existem atributos no áudio digital (frequência, tom, ruído, amplitude) que podem ser explorados para detectar pontos de interesse entre os elementos de mídia. Algumas operações baseadas em atributos, podendo ser estendidas a muitas outras, são mostradas a seguir.

- voiceIncrease(time StartTime, time EndTime): retorna a lista dos momentos no tempo em que houve um aumento consistente no volume da voz durante um determinado intervalo de tempo.

- conversation(time StartTime, time EndTime): em relação ao intervalo T de tempo no arquivo de áudio, retorna o número potencial de participantes que falaram durante esse intervalo.

- outstandingMoments(time StartTime, time EndTime): retorna uma lista dos instantes no tempo em que houve momentos fora do comum no áudio. Os 
momentos fora do comum são definidos como todos aqueles em que várias pessoas estão falando ao mesmo tempo com algum aumento considerável no volume das vozes.

Existem vários métodos de análises do conteúdo que podem ser usados para derivar os índices dos AudioInteractors. Por exemplo, o operador baseado em tempo silenceMoments() que pode ser computado usando transformadas wavelet (Guido et al., 2006), particularmente a transformada Haar, como foi detalhado por Vega-Oliveros et al. (2010a). Uma categoria importante dos AudioInteractors não muito explorada é aquela associada à interação explícita do usuário com o controle do microfone.

Baseados em ações. São aqueles obtidos a partir da captura dos momentos em que o usuário ativa alguma função própria do microfone, como nos exemplos:

- enterAudioMute(time StartTime, time EndTime): retorna uma lista dos instantes de tempo, dentro do intervalo dado, em que a função do mute foi ativada.

- exitAudioMute(time StartTime, time EndTime): igual à de cima, mas com a função de mute desativada.

\subsubsection{TextInteractors}

Os TextInteractors são um tipo específico de Interactors definidos como aqueles que identificam a interação usuário-usuário no intercâmbio de mensagens de texto: as mensagens escritas podem, por exemplo, ser trocadas em uma sessão de chat. Foram divididos em duas categorias:

Baseados em atributos. São muitos os atributos que podem ser coletados nas mensagens de texto durante a captura, como a fonte, tipo, cor, entre outros.

- changeOnAttribute(attribute $A$, time StartTime, time EndTime): retorna a lista dos instantes de tempo em que mudaram as menssanges de texto de acordo com o atributo $A$, dentro do intervalo de tempo definido por StartTime e EndTime - o que pode ser usado, a título de exemplo, para gerar índices na linha de tempo correspondente às mudanças em um dado atributo (por exemplo: os momentos em que foi mudada a cor da fonte da mensagem);

- filterByAttributeValue(attribute $A$, value $V$, time StartTime, time EndTime): retorna a lista dos instantes de tempo em que as mensagens de texto mudaram, só que em relação ao atributo $A$ com valor igual a $V$, dentro do 
intervalo de tempo definido por StartTime e EndTime - o que poderia ser usado, a título de exemplo, para gerar um índice na linha de tempo correspondente aos instantes de tempo em que a cor do texto mudou para azul.

Baseados em tempo. Obtidos através da detecção de intervalos de tempo da troca de mensagens ou de sua inexistência.

- silenceMoments(time Tmin, time StartTime, time EndTime): retorna uma lista dos instantes de tempo em que não houve nenhuma troca de mensagens por mais de $T$ ( $T>$ Tmin) unidades de tempo, durante o intervalo de tempo definido por StartTime e EndTime.

- textMoments(time Tmin, time StartTime, time EndTime): retorna uma lista dos instantes de tempo logo antes de alguém digitar alguma mensagem por pelo menos Tmin unidades de tempo durante o intervalo de tempo definido por StartTime and EndTime.

\subsubsection{Boardinteractors}

Há muitas situações em que os usuários podem usar lousas eletrônicas para fazer apresentações de slides em reuniões e palestras, por exemplo. Alguns sistemas de webconferência oferecem lousas inteligentes para apresentar slides para serem discutidos pelo grupo; a aplicação Webcast ${ }^{3}$ oferece lousas eletrônicas para os apresentadores para que possam enviar suas palestras junto com os slides e o áudio, por exemplo.

Existem também aplicações nas quais os slides são o único recurso de informação da apresentação, como por exemplo, no caso de Slideshare ${ }^{4}$. Dada a ampla utilização das lousas eletrônicas, independente das anotações baseadas em tinta digital, foi observada a necessidade de definir operadores diretamente relacionados com elas. Estes são também divididos em duas categorias:

Baseados em tempo. Obtidos através do monitoramento da interação de Usuário-imagem na fase de captura. Os operadores podem ser usados para construir uma linha do tempo com os instantes de tempo correspondentes à apresentação de um slide específico.

- changeBoard(time StartTime, time EndTime): retorna uma lista dos instantes do tempo em que houve uma mudança de slide no intervalo de tempo

\footnotetext{
${ }^{3}$ http://www.webopedia.com/TERM/W/Webcast.html

${ }^{4}$ http://www.slideshare.net
} 
especificado - o que pode ser usado para gerar a correspondente linha de tempo;

- idleBoard(time T, time StartTime, time EndTime): retorna uma lista dos instantes do tempo em que não houve nenhuma mudança de slide por pelo menos $T$ segundos no intervalo de tempo especificado.

Baseados em atributos. Existem uma série de atributos nos slides (por exemplo um slide que tenha texto, imagem, animação, etc) que podem ser usados para detectar slides de interesse.

- changeOnAttribute(attribute $A$, time StartTime, time EndTime): retorna uma lista de instantes de tempo em que houve alguma alteração relacionada com o atributo A no intervalo de tempo definido por StartTime e EndTime - isso pode ser usado para gerar índices em uma linha de tempo correspondentes à mudança do atributo (por exemplo, os momentos em que houve um mudança de um slide contendo texto para um slide contendo uma animação);

- filterByAttributeValue(attribute $A$, value $V$, time StartTime, time EndTime): retorna uma lista de instantes de tempo em que houve alguma alteração no atributo $A$ para um valor igual a $V$, no intervalo de tempo definido por StartTime e EndTime - isso pode ser usado, por exemplo, para gerar/indexar na linha de tempo os momentos em que o atributo contém um valor determinado (por exemplo, os instantes de tempo em que o slide contém uma animação)

\subsubsection{Videolnteractors}

Em palestras publicadas na web, como as disponíveis na MIT OpenCourseWare e Google Tech Talks, os slides são capturados através da gravação de um vídeo do conteúdo projetado. A fim de permitir uma recuperação adequada do conteúdo, sistemas como Talkminer (Adcock et al., 2010) analisam o vídeo capturado segmentando-os em quadros-chave que representam mudanças nos slides apresentados. Com o intuito de tais cenários, nesta seção se definem os $V i$ deoInteractors como um operador obtido mediante a identificação das interações usuário-imagem: as imagens podem ser, por exemplo, um conjunto de slides ou um conjunto de fotos. Os VideoInteractors estão divididos em duas categorias:

Baseados em tempo. Obtidos através do monitoramento da interação Usuárioimagem na fase de captura. Os operadores podem ser usados para selecionar instantes ou intervalos em que uma imagem foi revisitada. 
- blankMoments(time Tmin): os momentos em que uma imagem foi apresentada durante $T$ ( $T>$ Tmin) unidades de tempo.

- imageMoments(time Tmin): retorna os instantes de tempo bem no momento em que o usuário estivesse presente na imagem durante $T$ ( $T>T$ min $)$ unidades de tempo.

- imageIntervals(time Tmin): retorna os intervalos de tempo nos quais um usuário estever presente na imagem durante $T(T>T$ min $)$ unidades de tempo.

Baseados em atributos. Há atributos que são das imagens (tipo, tamanho, etc.) que podem ser explorados para detectar imagens de interesse.

- imageSize(int Size): retorna os instantes de tempo em que uma imagem de um dado tamanho foi apresentada.

- others: também se podem definir os operadores com base em características das imagens, tais como bordas e cantos (por JPEG), e do nível de canal alfa (por PNG).

\subsection{Ciclo de Vida dos Eventos de Interação}

Nesta seção é apresentado o processo de ciclo de vida de operadores para gerar documentos multimídia interativos (interactive multimedia documents iMMD) a partir das mídias capturadas. O iMMD é gerado a partir de um documento de intercâmbio de dados baseado em XML, que descreve as mídias capturadas com seus respectivos eventos de interação (por exemplo: mudança de slide, eventos baseados em tinta, mensagens de chat) que são chamadas aqui de Interactors.

Adotar documentos de transferência baseados em XML permite à proposta que possa ser instanciada para diferentes ambientes de captura, independentemente das particularidades da implementação. Demonstra-se a abordagem proposta considerando-se que o documento automaticamente gerado é visto por clientes de TV interativa cujo principal mecanismo de interação é via controle remoto. Como tal, o iMMD gerado segue as diretrizes de design e mecanismos de interação especialmente adaptados para esses dispositivos. O ciclo de vida dos eventos de interação junto ao processo proposto e apresentado na Figura 3.3.

Os dados da sessão, que foram capturados e sincronizados pelo ambiente na fase de gravação, são exportados para um documento intercâmbio que inclui 


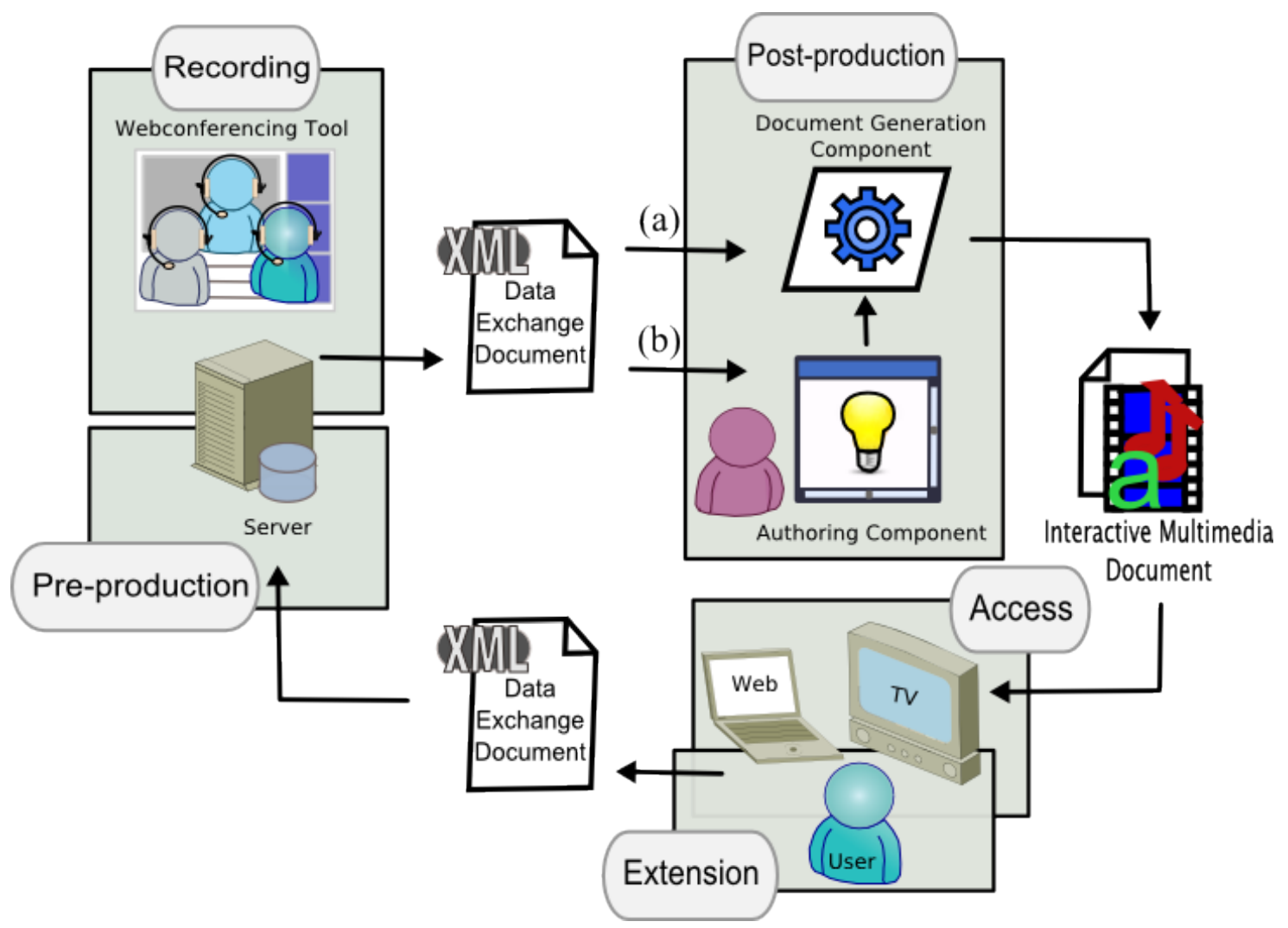

Figura 3.3: Processo proposto de ciclo de vida de eventos para a geração de documentos multimídia via operadores de interação baseados em mídias.

os links nos vários elementos de mídias capturadas e as interações registradas para cada elemento de mídia. O documento de intercâmbio de dados alimenta a fase pós-produção na qual (a) o documento pode ser diretamente transformado em um iMMD pelo componente de geração do documentos, ou (b) o documento pode passar por um processo de autoria pelo produtor de conteúdo multimídia e depois transformado em um iMMD. O iMMD gerado pode ser transmitido (por exemplo, via TV broadcasting ou Internet) ou transportado para a correspondente plataforma do cliente, como set-top boxes ou tablet PC, para que assim possa ser revisto pelo usuário na fase de acesso.

A abordagem oferece mecanismos de navegação e acesso ao iMMD da sessão capturada envolvendo múltiplas mídias (Vega-Oliveros et al., 2010b). O iMMD é enriquecido com diferentes tipos de índices relacionados às mídias, chamados de eventos de interação, que podem ser generalizados como "o conjunto de eventos baseados na interação do usuário com as mídias, gerados a partir de alguma operação sobre os dados (operadores)". Como resultado temos, um iMMD com muitos índices de acesso com um significado semântico apresentados na linha de tempo, os quais facilitam a busca de pontos de interesse para o usuário, por exemplo. Os usuários também podem interagir com o documento multimídia fazendo anotações e enriquecendo-o na fase de extensão. Essas informações são 
armazenadas e exportadas para um novo documento de intercâmbio de dados que contém as anotações e os eventos de interação do usuário.

Finalmente, no momento em que os usuários tenham terminado de revisar o documento multimídia, os novos documentos de intercâmbio podem ser transmitidos para o servidor como mecanismo de retorno (feedback) das interações do usuário. As novas informações podem ser processadas no servidor a fim de produzir uma variedade de serviços, como os de mineração de dados para a extração de dados referentes aos alunos, como resumos estatísticos, ou material de entrada para novas versões. Neste ponto, esta-se no final de um ciclo de vida e no começo de outro, na fase de pré-produção. Esta abordagem é uma extensão do ciclo de vida da hipermídia evolutiva (Pimentel et al., 2001), pois foi incorporado a abordagem de estruturação de informação e comunicação centrada em documentos, permitindo o processo contínuo de enriquecimento do conteúdo, através da captura da interação do usuário.

\subsection{A Teoria de Conjuntos e os Eventos de Interação}

No momento da formalização dos Interactors, foi notado que o tempo, mais que uma característica isolada, pode determinar uma conjunção entre as outras categorias ou características. Dado este ponto, foi visto que os eventos de interação podem ser interpretados como acontecimentos, com um intervalo de tempo definido, que podem ser mapeados como elementos de um supraconjunto relacionado ao tempo total da sessão capturada.

Definição 2 (Sessão): Uma sessão é um conjunto não vazio de mídias, sincronizadas e correlacionadas, ao qual pode ser aplicado para cada mídia pelo menos um tipo de Interactor para gerar índices chamados de eventos de interação.

Dada uma sessão capturada que contém [j] elementos de mídia e $X_{j}$ Interactors carregados por mídia, se definiu, o conjunto de eventos de interação como o mapeamento $T L(a, b)$ onde $a \leq j$ é o elemento de mídia capturado, e [b] é o Interactor carregado. Por definição, um Interactor pode mapear um número indeterminado de eventos de interação. Desse modo, para um elemento de mídia específico [i], o mapeamento $T L(i, b)$, [b] um Interactor carregado com $b \geq 0$, representa o conjunto total de eventos de interação para o elemento de mídia $[i]$. Adicionalmente, existe a restrição de que um Interactor não pode ser usado para qualquer tipo e mídia (por exemplo, o atributo de cor da tinta digital não se aplica ao áudio). 
Os eventos de interação carregados em uma sessão capturada podem ser vistos desde o enfoque de alguns conceitos da teoria de conjuntos. Um primeiro conceito é o conjunto vazio, definido como um conjunto que não possui elementos. No caso particular de uma sessão, isto significa a ausência de eventos de interação ou a não seleção/aplicação de nenhum Interactor. Na literatura é comumente representado pelo símbolo $\emptyset$, mas neste trabalho será definido como o conjunto $\{N U L L\}$. É importante destacar que o conjunto vazio está contido em todos os subconjuntos (Interactors) da sessão.

Naturalmente, após a definição do conjunto $\{N U L L\}$, está o conceito do conjunto universo, que é o conjunto que contém todos os elementos (eventos) e conjuntos (Interactors) do contexto da sessão capturada. Na literatura, o conjunto universo é representado pela letra $U$, mas neste trabalho será definido como o conjunto $\{F U L L\}$.

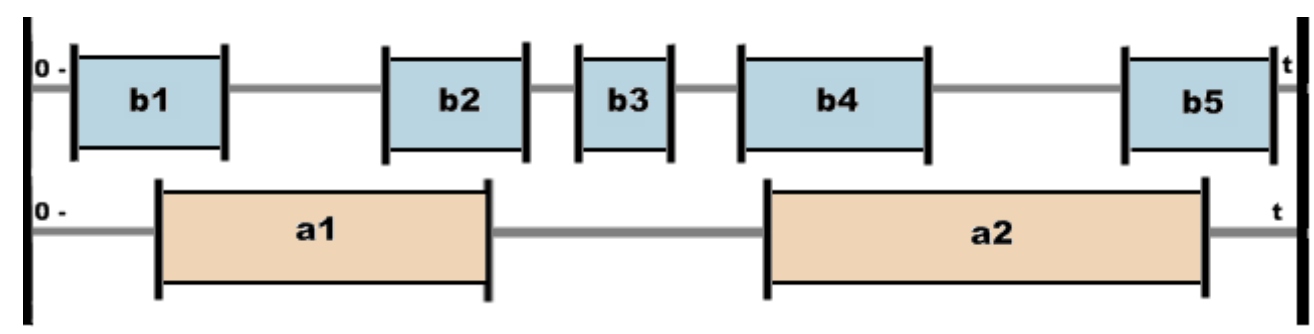

Figura 3.4: Imagem ilustrando dois conjuntos de Interactors mapeados na linha de tempo (Vega-Oliveros et al., 2011a)

A Figura 3.4 ilustra dois tipos de Interactors, o conjunto A e B, onde cada evento de interação está sincronizado no tempo em relação à sessão capturada e tem mapeado o intervalo e o tempo de duração como a largura e posição do evento na linha de tempo.

A união de $A$ e $B$, denotada por $A \cup B$, representa o conjunto que contém todos aqueles elementos que estão em $A$ ou em $B$ ou em ambos. No caso dos Interactors, consiste em todos os eventos de interação que pertençam tanto a $A$ ou $B$. Portanto $A \cup B=\{x: x \in A \vee x \in B\}$ onde $x$ são eventos de interação. A título de exemplo, no caso da Figura3.4, tem-se que $A \cup B=\{a 1, a 2, b 1, b 2, b 3, b 4, b 5\}$.

Definição 3 (operação OR): A operação lógica OR é definida como o resultado da união entre dois conjuntos de eventos de interação, o que significa que $A$ OR $B \equiv A \cup B$.

No caso da interseção de $A$ e $B$, denotada por $A \cap B$, ela representa o conjunto que contém aqueles elementos que estão em $A$ e $B$ ao mesmo tempo. No caso dos Interactors, o conjunto dos eventos de interação que pertencem a $A \cap B$ são unicamente aqueles eventos que estão em $A$ e cujo intervalo de tempo se 
sobrepõe com pelo menos um evento do conjunto $B$. Em outras palavras, significa que somente são aceitos aqueles eventos de $A$ em cujo intervalo e tempo de ocorrência aconteceu ao menos um evento do tipo $B$ e vice-versa. Portanto $A \cap B=\{x: x \in A \wedge x \in B\}$ onde $x$ são eventos de interação. A modo de exemplo, no caso da Figura3.4, tem-se $A \cap B=\{a 1, a 2, b 1, b 2, b 4, b 5\}$.

Definição 4 (operação AND): A operação lógica AND é definida como o resultado da interseção entre dois conjuntos de eventos de interação, o que significa que $A$ AND $B \equiv A \cap B$.

A diferença entre $A$ e $B$, denotada por $A-B$ representa o conjunto de elementos que pertencem a $A$ e que não estão em $B$. No caso dos Interactors, são aqueles eventos de interação que estão no conjunto $A$ e cujos intervalos de tempo não se sobrepõem com nenhum evento que esteja no conjunto $B$. Portanto $A-B=\{x: x \in A \wedge x \notin B\}$ onde $x$ são eventos de interação. A título de exemplo, no caso da Figura3.4, tem-se que $B-A=\{b 3\}$.

Definição 5 (operação NOT): A operação lógica NOT é definida como o resultado da diferença entre dois conjuntos de eventos de interação, o que significa que $A$ NOT $B \equiv A-B$.

A partir do conceito de diferença surge também outra operação conhecida como o complemento de um conjunto, que se define como a diferença entre $\{F U L L\}-A$, chamada de complemento de $A$ e denotada por $\bar{A}$. Portanto $\bar{A}=$ $\{F U L L\}$ NOT $A \equiv\{\forall x: x \in\{F U L L\} \wedge x \notin A\}$ onde $x$ são eventos de interação.

Também é possível ressaltar algumas propriedades emergentes das operações sobre conjuntos que se aplicam no caso dos eventos de interação formalizados neste Capítulo.

- Complemento. Qualquer que seja o conjunto A, tem-se que: $A \cup \bar{A}=\{F U L L\}$ e $A \cap \bar{A}=\{N U L L\}$

- Elemento Neutro. Qualquer que seja o conjunto A, tem-se que: $A \cup\{N U L L\}=A$ e $A \cap\{F U L L\}=A$

- Idempotência. Qualquer que seja o conjunto A, tem-se que: $A \cup A=A$ and $A \cap A=A$

- Associativa. Quaisquer que sejam os conjuntos A, B e C, tem-se que: $A \cup(B \cup C)=(A \cup B) \cup C$ and $A \cap(B \cap C)=(A \cap B) \cap C$

- Commutativa. Quaisquer que sejam os conjuntos A e B, tem-se que: $A \cup B=B \cup A$ and $A \cap B=B \cap A$ 


\subsection{Considerações Finais}

Este capítulo apresentou a generalização do conceito dos Interactors como operadores de interação baseados em mídias, estendendo-se e redefinindo-se os Inkteractors e, o mais importante, definindo-se novos operadores relacionados a áudio, vídeo, texto e board Interactors. Também foi apresentado o modelo de ciclo de vida dos eventos de interação, destacando-se a possibilidade de usar os operadores de interação para indexar pontos de interesse no caso das sessões síncronas capturadas.

Uma característica importante do modelo proposto é a abordagem centrada em documentos, mediante o uso de um documento de intercâmbio de informação que pode ser enriquecido em várias fases do ciclo de vida e serve como dado de entrada em muitas outras. Com esse documento podem ser gerados de forma automática documentos multimídia interativos que são usados para rever as sessões capturadas. As principais vantagens de adotar um documento estruturado como mecanismo de intercâmbio de informação são o baixo acoplamento e a capacidade do modelo de ser estendido e aplicado a diferentes cenários e ferramentas.

É possível obter novas versões do documento multimídia ao se combinar os operadores de interação. Inclusive, mediante o uso de operações lógicas entre operadores, existe a oportunidade de explorar novos métodos que permitem aos usuários combinar os Interactors para visualizar e acessar o documento durante a navegação ou que permitem editar os dados da sessão gerando versões resumidas, personalizadas ou específicas em comparação com a captura original.

O capítulo a seguir descreve como resultados desta dissertação: os protótipos e os testes que foram realizados para avaliar a abordagem. 



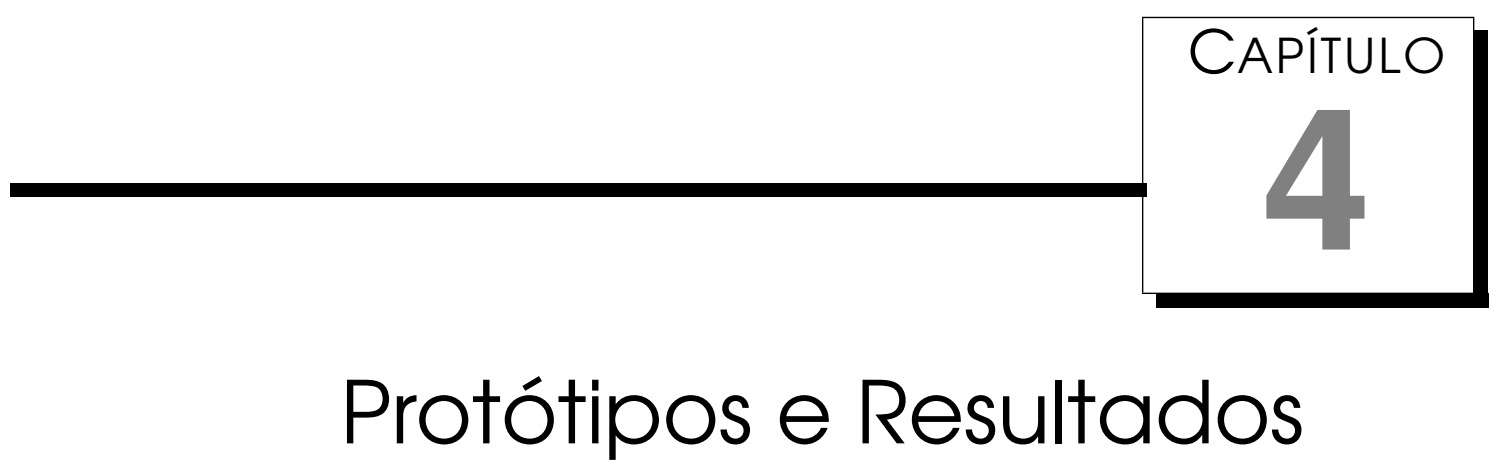

$\mathrm{E}$ m alguns cenários, tais como videoconferências ou educação a distância, é importante registrar os encontros para fazer posteriores análises. Uma alternativa adotada é a de gerar um documento multimídia como resultado da sessão capturada. A abordagem atual para a criação de tais documentos é a de criar apresentações lineares editando alguns dos aspectos do documento, como incluir e excluir mídias, o estilo ou layout, a sincronização espacial e temporal e as opções interativas para os usuários. Essa abordagem não permite de forma espontânea a criação e geração automática de versões personalizadas, a navegação e o acesso a pontos de interesse relacionados com informação contida nas mídias, nem retroalimentar o conteúdo considerando às anotações dos usuários.

Neste capítulo são apresentados os resultados obtidos ao experimentar o uso Interactors na criação, visualização e acesso de documentos multimídia interativos. Esses Interactors são representados por vários tipos de índices obtidos a partir da análise das interações usuário-mídia ou da captura das interações usuário-dispositivo. Com esses índices é possivel criar mecanismos que permitam gerar automaticamente iMMD (documento multimídia interativo, do inglês Interactive Multimidia Document), navegar pelo conteúdo do documento usando operações lógicas, editar o documento com base na semântica dos eventos, e enriquecer o documento adicionando novos conteúdos ou eventos.

Para fins do desenvolvimento, foi definido um documento de intercâmbio de informação XML como parte da estratégia do modelo, que i) descreve os eventos de interação gerados mediante a aplicação do conceito dos Interactors; ii) serve 
como dado de entrada para geração automaticamente de iMMD e iii) pode ser usado como mecanismo de armazenamento e extensão do conteúdo da sessão, cuja informação pode ser enviada a um servidor para futuros processamentos.

A estrutura do capítulo está organizada como segue: a apresentação geral da ferramenta em uso empregada para à captura das sessões é apresentada na Seção 4.1; O estudo da geração automática de documentos, a prova de conceito e o componente de geração são apresentados na Seção 4.2; a proposta de um novo mecanismo de acesso e de visualização, assim como os resultados da avaliação com especialistas e dos testes com usuários são apresentados na Seção 4.3; a formalização do documento de intercâmbio de informação, que é peça fundamental no modelo de ciclo de vida da geração de conteúdo multimídia, é apresentada na Seção 4.4; finalmente, as reflexões e considerações finais referentes aos resultados obtidos e reportados neste capítulo são apresentadas na Seção 4.5 .

\subsection{Descrição do Ambiente de Captura}

O DiGaE (Distributhed Gathering Environment) é um ambiente captura de reuniões colaborativas que pode ser usado em salas instrumentadas ou no modo de webconferência. Os requisitos funcionais do sistema DiGaE compreendem: fornecimento de dados de áudio, vídeo, texto e a interação com as ferramentas de Whiteboard, para desenho; e Bate-Papo, para troca de mensagens.

O usuário pode acessar uma sessão corrente compartilhando canais de áudiovídeo e texto, recebendo dados dos outros usuários (por exemplo, mediante o uso da ferramenta de Bate-Papo ou acessando a Whiteboard) e ver as interações que estão ocorrendo na sala. A ferramenta permite ao usuário modificar seu status (online ou offline) além de listar as sessões agendadas das quais ele faz parte. Além disso, o usuário pode cadastrar uma nova sessão, especificando seu tema, descrição, data, hora, local, usuários que participarão e também quais ferramentas serão usadas. Existe também a opção de consultar sessões agendadas para editá-las ou excluí-las.

Guando usado em salas instrumentadas, o DiGaE oferece suporte para sincronização do vídeo das câmeras, o áudio dos microfones, as lousas eletrônicas, vídeoprojetores e leitores de RFID que podem ser usados para a identificação de participante. Quando é usado para webconferências, uma configuração especial chamada de DiGaE Home provê uma ferramenta web que captura os fluxos de áudio e vídeo das webcam do computadores ou laptops, assim como outros tipos de tecnologia como sessões de chat e o software de lousa eletrônica. 


\subsection{Geração Automática de Documentos Multimídia Interativos}

Em alguns cenários é importante que as sessões sincronas colaborativas sejam armazenadas para sua posterior revisão. Particularmente, no caso de ferramentas de webconferências, a abordagem normalmente adotada para gravação de uma reunião é realizada por meio da geração de um vídeo linear com o conteúdo das mídias trocadas. Nesta seção é apresentada a abordagem de geração automática de documentos multimídia interativos como resultado de uma sessão de vídeo conferência capturada com a ferramenta DiGaE. Para esta finalidade é detalhada a geração de um documento multimídia interativo por meio de operadores de interação usuário-mídia (por exemplo: mudança de slides, mensagens de chat, interações baseadas em tinta, eventos de áudio) chamados de Interactors, possibilitando aos usuários navegar no documento gerado por pontos de interesse/acesso nas mídias capturadas. Define-se a abordagem de Interactors e os demonstra-os no contexto de uma ferramenta em uso.
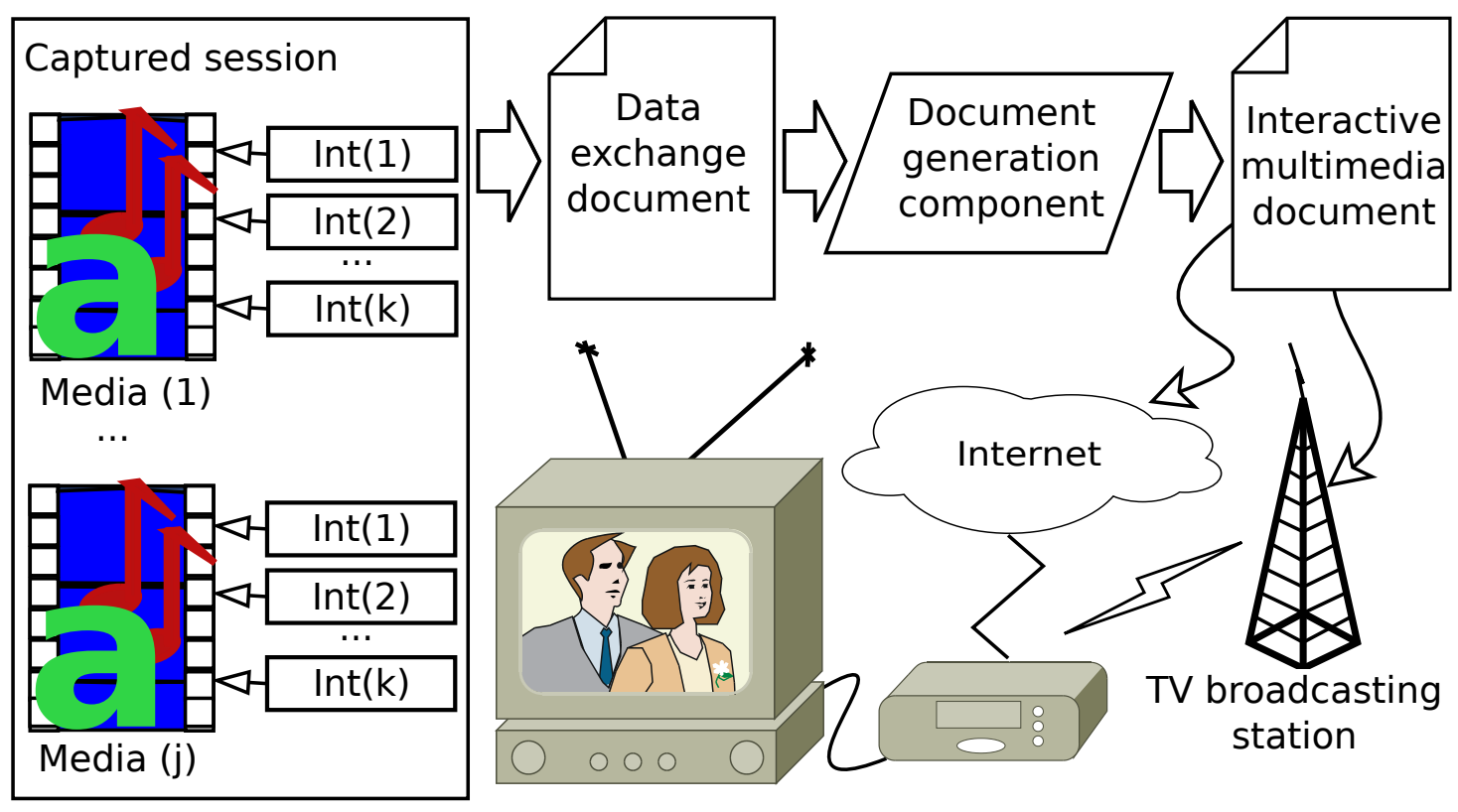

Figura 4.1: Diagrama inicial dos interactors para geração automática de documentos multimídia interativos

O diagrama inicial de Interactors proposto para gerar documentos multimídia interativos das mídias capturadas é apresentado na Figura 4.1. O iMMD é gerado a partir de um documento XML de intercâmbio que se adiciona às mídias capturadas com seus respectivos eventos de interação (por exemplo: mudança de slide, eventos baseados em tinta, mensagens de chat) que são chamadas aqui de Interactors. Adotando um documento de intercâmbio baseado em XML 
é possível instanciar o modelo proposto para diferentes ambientes de captura, independente das particularidades de suas implementações. Demonstra-se a abordagem proposta considerando-se que o documento automaticamente gerado é visto por clientes de TV interativa cujo principal mecanismo de interação é via controle remoto. O iMMD gerado segue as diretrizes de design e mecanismos de interação especialmente adaptados para estes dispositivos (de Miranda et al., 2008).

Os dados da sessão capturados pela ferramenta são exportados para um documento de intercâmbio de informação que inclui links para vários elementos de mídia e as interações registradas para cada elemento de mídia. O documento exportado de intercâmbio de informação alimenta o componente de geração de documentos, Generation Component, que o transforma em um iMMD. Após estes passos, o iMMD automaticamente gerado pode ser transmitido (por exemplo: via programa de TV ou canal de retorno) para os Set-Top Box (STB) e pode ser revisado pelos usuários na TV de forma interativa.

\subsubsection{Documento de Intercâmbio de Informação}

O modelo do documento de intercâmbio de dados padroniza: $i$ ) a descrição de vários elementos de mídia compreendidos em uma sessão; e ii) a descrição dos eventos de interação registrados e capturados pelo ambiente.

Este modelo é definido por meio de um XML Schema e pode ser usado por diferentes ambientes para exportar dados capturados, reforçando o baixo acoplamento entre o formato de armazenamento de subjacente da sessão e o iMMD gerado. Além disso, um documento estruturado facilita abordagens baseadas em transformação para gerar automaticamente iMMDs.

Um documento de intercâmbio (Figura 4.2) tem um elemento primário player que compreende vários elementos de mídia capturados pelo ambiente de reunião. Para fins de ilustração, o documento na Figura 4.2 descreve slides, conversações por chat, vídeo e áudio (linhas 3-12, 14-22, 24-30, 32-38, respectivamente); porem, vale ressaltar que o esquema XML prevê outros tipos de mídia que não estão representados neste documento. Cada elemento de mídia possui atributos para referências à fonte, que pode ser local ou remota. Um elemento de mídia é local quando as fontes são retribuídas pelo ambiente de captura, contendo o documento de intercâmbio de dados e todas as mídias capturadas; as mídias remotas são relevantes quando o documento de intercâmbio é obtido como resposta de um serviço web, por exemplo, exigindo que a mídia seja recuperada posteriormente por suas URLs. 


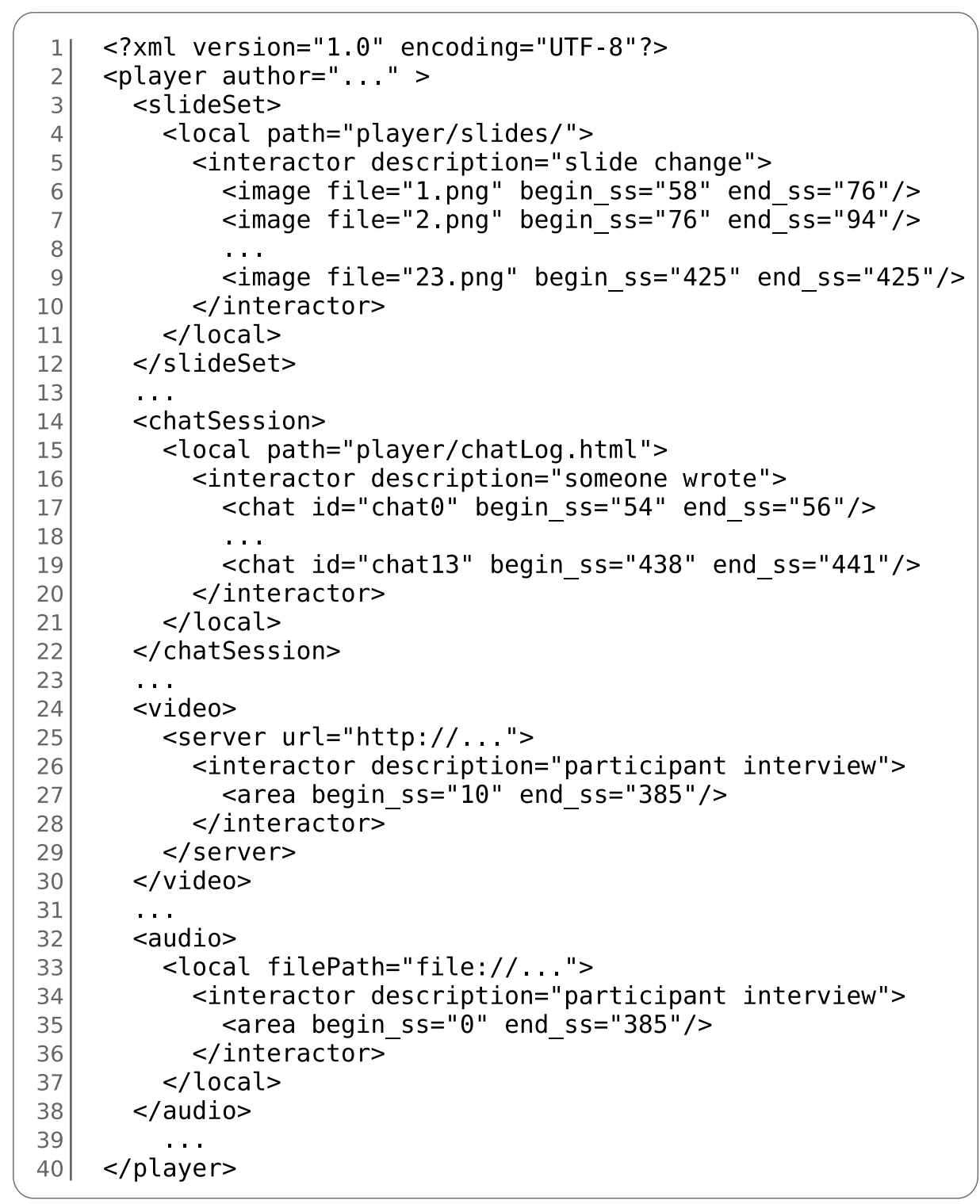

Figura 4.2: Extração ilustrando a estrutura global do documento de intercâmbio de informação

Além disso, cada elemento de mídia tem um conjunto de Interactors associados a ela. Por exemplo, os slides podem ter uma série de operadores do tipo slide change associados a eles (linhas 5-9), enquanto sessões de chat podem ter Interactors do tipo someone wrote (linhas 17-19). Para cada Interactor, o esquema provê uma identificação específica dos atributos de tempo. Interactors relacionados com elementos de mídia contínuos (como fluxos de áudio e vídeo) são identificados pelo nome e as datadas de seus momentos de início e fim. Por outro lado, Interactors relacionados com elementos de mídia discretos (capturados a partir de whiteboards, chats, câmeras fotográficas, scanners, etc.) são identificados pelo nome, ou substitutos, e são datados pelo período entre dois eventos capturados (attributes begin_ss and end_ss): por exemplo, o período entre duas mudanças de slides ou duas mensagens de texto. Todas estas mar- 
cas de tempo são relativas ao início da sessão e são usadas com o propósito de sincronização quando o iMMD é gerado.

\subsubsection{Document Generation Component}

A fim de criar um iMMD de uma sessão capturada, o componente gerador de documentos (Document Generation Component) realiza transformações no documento de intercâmbio exportado. Este componente agrupa os Interactors por tipo (por exemplo: mudança de slides, anotações em tinta, conversações por chat, etc.) e para cada grupo ele constrói uma linha de tempo principal, decorada com seus Interactors. As linhas de tempo geradas são montadas no iMMD com os elementos de mídia. Consequentemente, os Interactors atuam como operadores que permitem aos usuários navegar por pontos de interesse tal navegação é possível devido à ativação de um documento procedural (mais detalhes na Seção 4.2.2) o qual garante que todos os elementos de mídia são sincronizados quando um operador é emitido.

A atividade seguinte é a geração de um documento multimídia declarativo que atua como a interface do usuário para a revisão da sessão. Este documento declarativo descreve os atributos dos elementos de mídia (tais como tipo de mídia, local de origem, etc.), posição e tamanho de cada elemento de mídia na tela, conexões entre mídias e sincronização de acordo com os Interactors. Além disso, o documento declarativo inclui a linha de tempo que é gerada em uma atividade posterior. Em particular, esta linha de tempo é o elemento de ligação entre o documento declarativo e o documento procedural gerado depois.

\section{Documento Multimídia Interativo}

O documento multimídia interativo é o elemento que permite o acesso e análise da sessão capturada. O iMMD autogerado é composto por dois documentos distintos: o documento de revisão declarativo e o documento de controle procedural. Com o intuito de reforçar uma forte separação entre o documento declarativo e o procedural, a abordagem Padrão de desenho Modelo-VisualizadorControlador, do inglês Model-View-Controller (MVC) foi adotada (como ilustra a Figure 4.3).

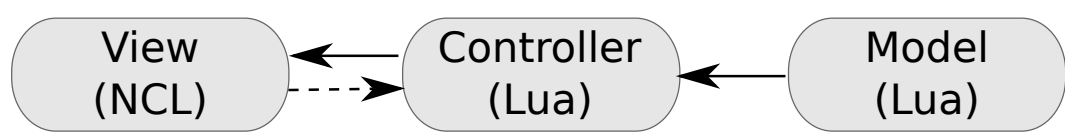

Figura 4.3: Estrutura global do iMMD. Linhas contínuas são notificações intradocumento e linhas tracejadas são eventos iniciados pelo usuário 
Construído em NCL, o documento declarativo é responsável pela especificação da renderização e da sincronização das mídias bem como do layout da apresentação multimídia. Construido em Lua, definiram-se dois documentos procedurais: i) o modelo ou timeline model, que mapeia os eventos de navegação (por exemplo: eventos iniciados pelo usuário, como apertar um botão do controle remoto) e os eventos de interação (por exemplo: pontos de interesse) dentro da mídia; e ii) o controlador ou timeline controller, que trata os eventos de navegação e consulta o modelo para atualizar o estado da apresentação.

Estruturalmente, o documento declarativo define um conjunto de âncoras que representam todos os operadores disponiveis contidos na linha de tempo (Figura 4.4) operadores que são usados para sincronizar a apresentação. Todas as mídias discretas como slides e mensagens de texto podem ser agrupadas em ordem cronológica em um único objeto NCL (Figura 4.4 linhas 11-18) que conecta e organiza sua própria sincronização. No caso de mídias contínuas, como áudio e vídeo, uma âncora separada é definida (linhas 3-9) para cada elemento de mídia. Além disso, a mesma âncora é definida para a linha de tempo (linhas 19-25).

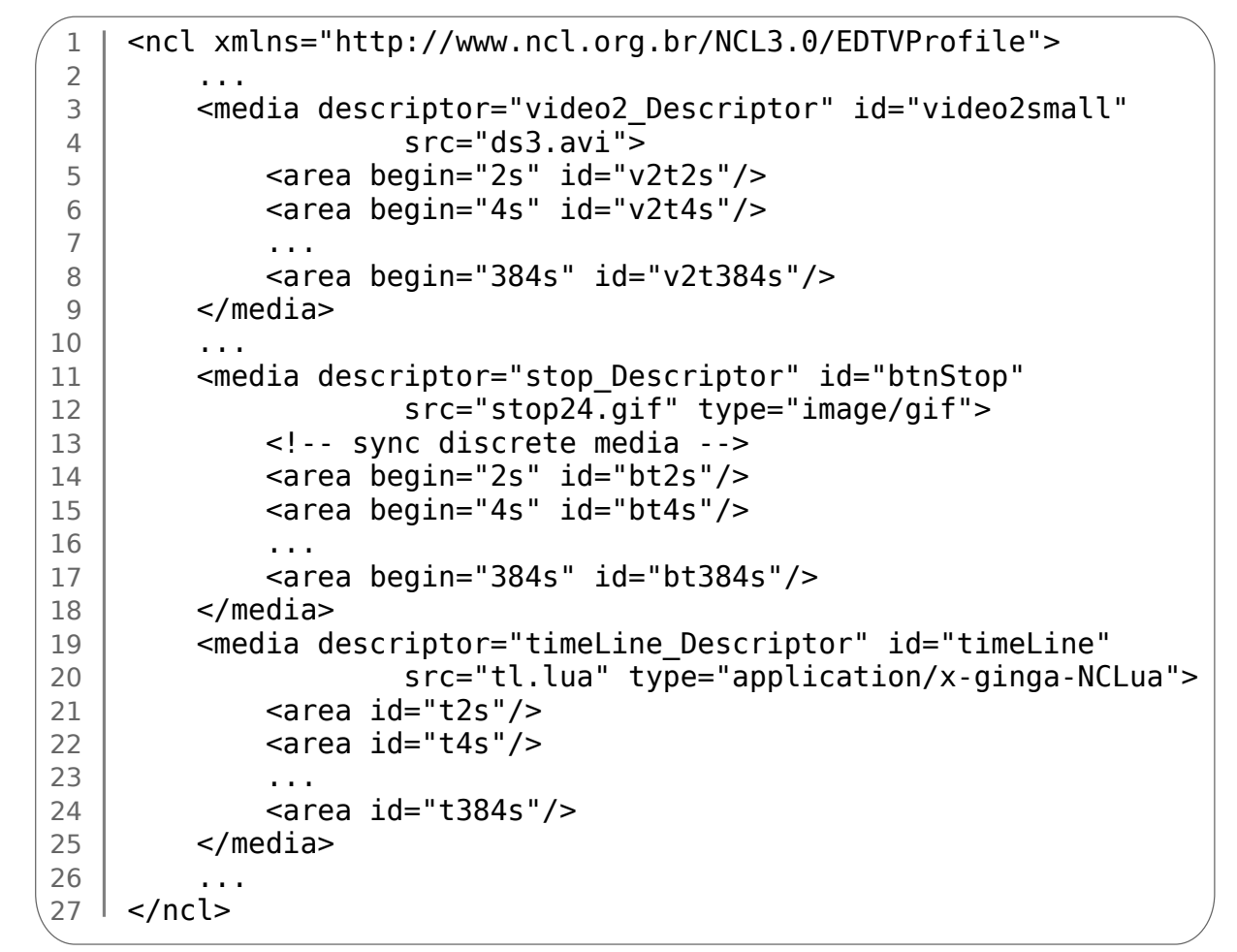

Figura 4.4: Extração do documento declarativo automaticamente gerado com foco nas âncoras 


\section{Documentos Procedurais}

Importado pelo documento declarativo (linhas 19-20), o documento procedural define um objeto Lua que cuidará do tratamento de eventos de navegação ministrado pelo usuário. Após receber esses eventos, este objeto opera sobre o documento declarativo para saltar ao ponto de interesse requisitado. Esta ação implica a ressincronização dos elementos de mídia via um sinal (evento Lua) que ativa uma das âncoras disponíveis no documento declarativo.

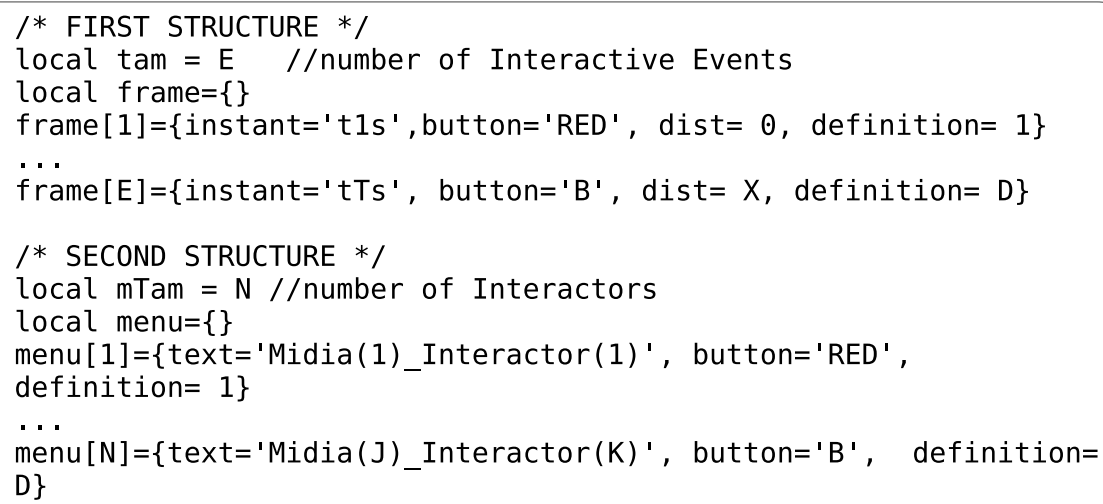

Figura 4.5: Extração do documento procedural automaticamente gerado que representa o modelo da aplicação (timeline model)

Os mapeamentos estabelecidos pelo modelo da linha de tempo (Figure 4.5) são gravados na estrutura frame por meio de registros armazenados dos momentos (instant) dos pontos de interesse, eventos de navegação (button) emitidos pelo usuário, normalizados pela posição de deslocamento (dist), em pontos ou pixels, e um identificador sequencial (definition) para cada evento armazenado.

O número total de Interactors é armazenado pela variável $\mathrm{mTam}$, sendo $\mathrm{mTam} \leq$ tam devido a que, por definição, um Interactor é um conjunto não-vazio de eventos de interação. A estrutura menu define a estrutura de dados usada para gerar a linha de tempo interativa empregada para navegar na sessão. Cada registro da estrutura menu está relacionado com os eventos da estrutura frame, usando como chaveamento o par $(B, d e f)$ no qual $B$ é um botão e def é o identificador, definition, de um evento de interação.

Ambas as estruturas de dados são utilizadas pelo controlador para ativar âncoras específicas do documento declarativo, em resposta à navegação, fornecido pelo usuário. Os principais métodos usados pelo controlador da linha de tempo estão definidos a seguir.

- Redraw (): cuida da atualização e do aspecto visual da linha de tempo no documento declarativo. Suas responsabilidades incluem a colocação de marcadores na linha de tempo correspondentes aos eventos de interação. 
- Stop () e Start (): estas funções são responsáveis por desencadear a ressincronização de uma âncora específica no documento declarativo.

- Handler (evt): recebe como parâmetro um evento de navegação do usuário (emitido via controle remoto) e reage de acordo com um mapeamento relacionado ao evento recebido com a sua ação correspondente.

- openMenu() e closemenu(): recebem eventos para mostrar/esconder a linha de tempo decorada quando um botão pré definido do controle remoto é pressionado.

Em resumo, o controlador da linha de tempo é responsável por receber os eventos do controle remoto do usuário, consultando o modelo da linha de tempo para que a âncora correspondente ao ponto de interesse requisitado pelo usuário seja ativada em resposta no documento declarativo para atualizar o estado de apresentação.

\subsubsection{Estudo de Caso: Cenário de VideoConferência}

A fim de ilustrar a abordagem para a geração de documentos multimídia interativos usando Interactors, esta seção reporta um caso de estudo realizado com um ambiente de captura em uso. Para o caso de estudo, uma prova de conceito do protótipo foi desenvolvida em NCLua.

Neste caso de estudo empregou-se o DiGaE Home, descrito na Seção 4.1, para capturar uma reunião com três participantes remotos que usaram o software Whiteboard para carregar um conjunto de slides e fazer anotações, uma sessão de chat para fornecer conteúdo textual complementar (como URLs) e captura de vídeo a partir das webcams. A dinâmica da reunião exigiu que os participantes se revezassem para realizar suas apresentações orais, fazendo anotações de tinta eletrônica nos slides e postando mensagens no chat. A sessão foi exportada para um documento de intercâmbio de dados XML que foi pós-processado e enriquecido com o AudioInteractor spokenMoments() sobre o vídeo capturado.

A Figura 4.6 detalha o layout geral do documento gerado. Nesta figura são ilustradas as principais regiões da interface, nomeadas como: 1) a região da whiteboard; 2) a região dos vídeos; 3) a região da linha de tempo; e 4) a região de chat. A Figura 4.6 representa o estado da apresentação após Interactors baseados em vídeo serem ativados (pressionando o botão amarelo no controle remoto). Como consequência, a linha de tempo é enfeitada com um Interactor relacionado com este elemento de mídia. Considerando que os controles remotos do SBTVD têm botões coloridos para interatividade, no iMMD gerado esses botões podem ser usados para trocar entre Interactors de mídias especificas que enfeitem a 


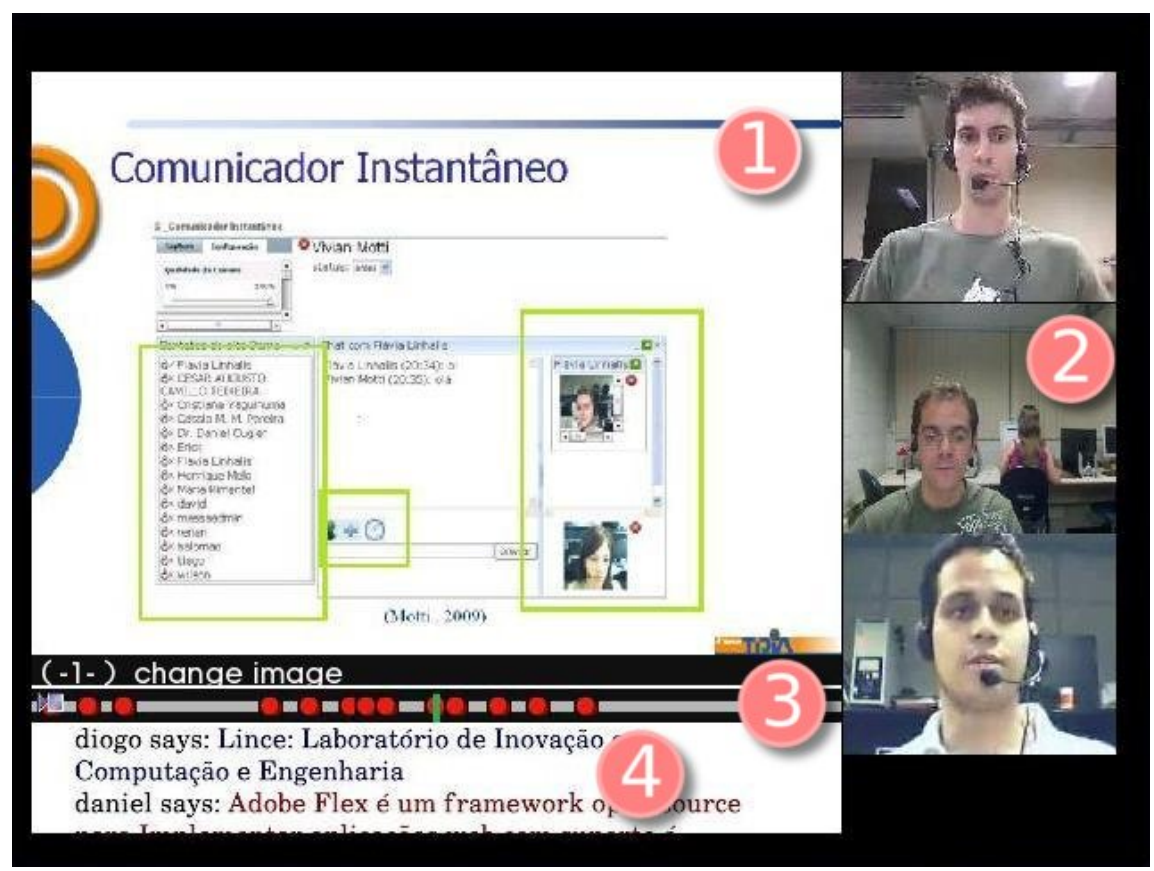

Figura 4.6: Imagem da interface do documento multimídia gerado

linha tempo (por exemplo, o botão vermelho habilita os Inkteractors, o amarelo habilita os relacionados aos vídeos, etc).

Como exemplo, na Figura 4.6 a linha de tempo está ornamentada com pontos de acesso cujo ícone está relacionado com o botão vermelho do controle remoto. Para navegar por pontos de interesse, o usuário emprega os botões de navegação direito/esquerdo do controle remoto mudando o foco e pressiona o botão ok quando o ponto desejado é encontrado. Além disso, uma caixa de texto está incluida na parte de cima da linha de tempo para indicar qual Interactor especificamente foi ativado (por exemplo, o change image ${ }^{1}$ Interactor na Figura 4.6); se mais Interactors estão disponíveis para o mesmo tipo de mídia, ambos os botões de navegação para cima/baixo, e também códigos numéricos, podem ser usados para selecioná-los como nas próximas figuras.

\subsection{Navegação e Acesso sobre Documentos Multimídia Gerados}

Nesta seção é abordada a questão de geração automática de navegadores baseados em documentos por meio de vários tipos de índices capturados durante as fases de gravação e pós-produção. Estes índices são usados para fornecer uma interface centrada no menu de navegação baseado em mídia e criar cadeias(strings) de composições lógica de operadores, a fim de melhorar o acesso a

\footnotetext{
${ }^{1}$ futuro ChangeBoard Interactor
} 
pontos de interesse, gerando-se linhas de tempo interativas. A abordagem centrada em documentos busca mudanças para os navegadores: em particular, a abordagem permite a revisão eficiente das gravações de reuniões por meio de dispositivos com restrições de hardware como são os STB de TV. Em termos de avaliação, foram investigados dois estudos de usuários e conduzidas inspeções de usabilidade e testes com usuários, a fim de verificar o modelo. Em geral, os resultados da avaliação sugerem que a abordagem proposta fornece um nível satisfatório de usabilidade e os usuários entendem o conceito de navegação por menu.

\subsubsection{Navegação via Menu de Operadores}

De acordo com as operações lógicas apresentados na Seção 3.4, considera-se a vantagem de criar strings de composições lógica de operadores que permitam navegar, visualizar e acessar pontos específicos de interesse das sessões capturadas. Propôs-se um menu de Interactors centralizado no tipo de mídia, e a oportunidade de usar as operações lógicas para permitir ao usuário criar consultas lógicas do conteúdo (Vega-Oliveros et al., 2011b).

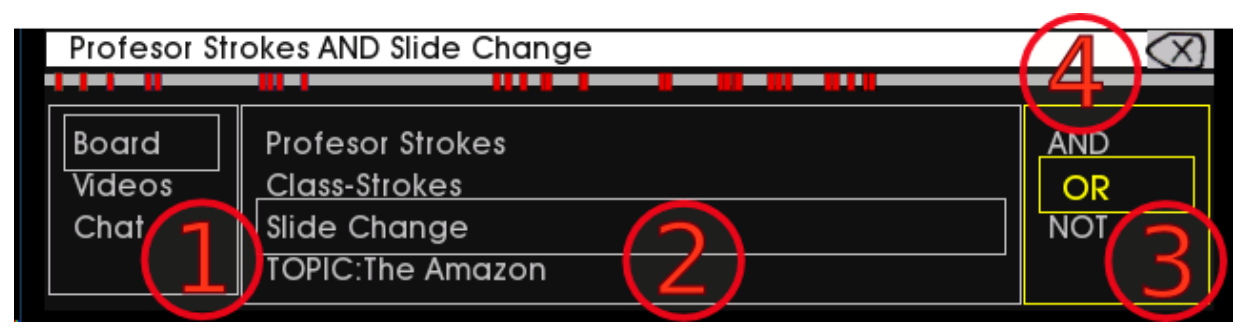

Figura 4.7: Screenshot ilustrando a abordagem do menu de Interactors para visualização e acesso de eventos

A Figura 4.7 mostra o layout do menu de Interactors. Nesta figura se ilustram as principais regiões da interface, nomeadas como segue: 1) a região de seleção de mídia; 2) a região de seleção de Interactor; 3) a região da seleção de operações lógicas; e 4) a região da linha de tempo.

Na região de seleção de mídia, os usuários podem selecionar a partir do tipo específico de mídia, o tipo de Interactor que desejam. Ao apertar o botão de navegação da "esquerda", na região de seleção de Interactors, os usuários poderão navegar em todos os operadores relacionados com a mídia escolhida. Em cada passo, eles podem voltar aos estágios anteriores. Na região das operações lógicas é onde os usuários escolherão e criarão a string lógica para buscar pontos específicos na sessão. Finalmente, na região da linha de tempo é onde o usuário poderá ver o a string de composição lógica dos Interactors criada, o resultado da composição que ornamenta a linha de tempo com os índices selecionados, e 
o botão de retrocesso para a edição da composição da string lógica. Para poder navegar entre pontos específicos de interesse, o usuário emprega os botões de navegação direita/esquerda do controle remoto para mover-se entre as regiões, os botões acima e abaixo para mudar o foco para a opção desejada e o botão ok para pressionar e selecionar.

Supondo o cenário em que foi capturada a sessão de uma videoconferência, um dos participantes deseja recordar o dia em que foi marcada a entrega de um relatório e os tópicos que devem ser abordados. O participante lembra que no momento em que foi definida a data e os tópicos do relatório, ele tinha saído da sala para ir ao toalete e que nesse momento, os colegas tinham feito uma piada e estavam rindo pela situação. Ao ser exportada a sessão para um iMMD, o participante pode navegar pela sessão usando o menu de Interactors. Ele escolhe a mídia de vídeo como base e imediatamente escolhe o AudioInteractor outstandingMoments que retorna os eventos de áudio relacionados a situações fora do comum dentro das pistas de áudio, isto com a finalidade de encontrar o momento em que os seus colegas estavam rindo. A participante pensa que, embora possa buscar por todos os marcadores retornados, pode fazer uma consulta ainda mais específica, já que ele se lembra de ter saído da sala nesse momento. Dessa forma, navega no menu e encontra o VideoInteractor imageMoments() que retorna os instantes de tempo em que o usuário estava presente no vídeo. Assim, ele pensa que "o momento em que foi dito a data da reunião foi o momento em que todos estavam rindo $\mathrm{E}$ eu NÃO estava na sala, pois tinha saído para o toalete”. Seguindo sua linha de pensamento, cria a composição lógica de operadores outstandingMoments() AND NOT jhon.imagemoments(), sendo que "jhon" é o nome que ele cadastrou na ferramenta de captura. Com esta string de busca ele conseguiu fazer retornar satisfatoriamente o ponto que estava procurando e recuperar a informação relacionada ao relatório.

\subsubsection{Casos de Estudo}

A fim de ilustrar a abordagem para navegar e buscar pela composição lógica dos Interactors, esta sessão apresenta dois casos de estudo realizados com um ambiente de captura em uso. Tanto para Webconferência como para cenários de Vídeoconferência, uma prova de conceito foi desenvolvida usando a linguagem NCL (declarativo) (Soares et al., 2009b) e Lua (procedural) (Brandão et al., 2010). Os participantes e a descrição do ambiente, o processo e o protótipo de cada caso de estudo são apresentados a seguir. 


\section{O ambiente de captura}

No estudo de Webconferência, foi empregado o ambiente DIGaE em uma reunião tipo seminário com um grupo de atendentes. Os participantes usaram o software Whiteboard para carregar o conjunto de slides e fazer anotações baseadas em tinta, uma sessão de chat para proporcionar a troca de mensagens de texto e os dispositivos de captura de vídeo e áudio. As interações usuário-lousa e usuário-tinta bem como mensagens textuais e arquivos de áudio-vídeo foram gravados. A dinâmica da reunião requereu que os atendentes se revezassem com respeito à fala, perguntando, desenhando e digitando textos.

No caso do cenário de videopalestra, foi empregada a ferramenta DiGaE Home para capturar uma aula com um professor usando o software Whiteboard para carregar um conjunto de slides e fazer anotações, uma sessão de chat para fornecer conteúdo textual complementar (como URLs ou anotações) e captura de vídeo da webcam. A dinâmica da captura foi como uma palestra magistral onde o professor fornecia o material por apresentação oral, fazendo anotações baseadas em tinta sobre os slides e postando mensagens no chat, sem ter o feedback dos alunos.

\section{Webconferências}

Seis voluntários participaram do experimento, cinco estavam em uma sala de reunião e outro estava em uma conexão remota. Os participantes eram estudantes universitários recrutados a partir do programa de ciência da computação de uma universidade de prestígio. Os participantes eram falantes nativos de português com conhecimento em inglês. Todos os participantes tinham experiência anterior em navegação web e controle remoto de TV. Antes do início da reunião, os participantes tiveram uma breve introdução sobre o ambiente de captura, os elementos da interface e o tema da reunião. O objetivo da reunião foi a apresentação do tema principal do participante remoto para os atendentes da sala. Os participantes da sala de reuniōes também podiam discutir, fazer perguntas, comentários e contribuir com o desenvolvimento da reunião. Após o fim da reunião, a sessão gravada foi processada e exportada para um iMMD em NCLua, uma vez que o documento enriquecido com os Interactors devia ser transformado em um formato multimídia interativo adequado para a reprodução. Os Interactors aplicados são listados na Tabela 4.1.

A Figura 4.8 mostra o resultado final do iMMD gerado do estudo da webconfêrencia. A interface contém: 1) a sessão da whiteboard; 2) os vídeos capturados; 3) a seessão do chat; e 4) a linha de tempo. 


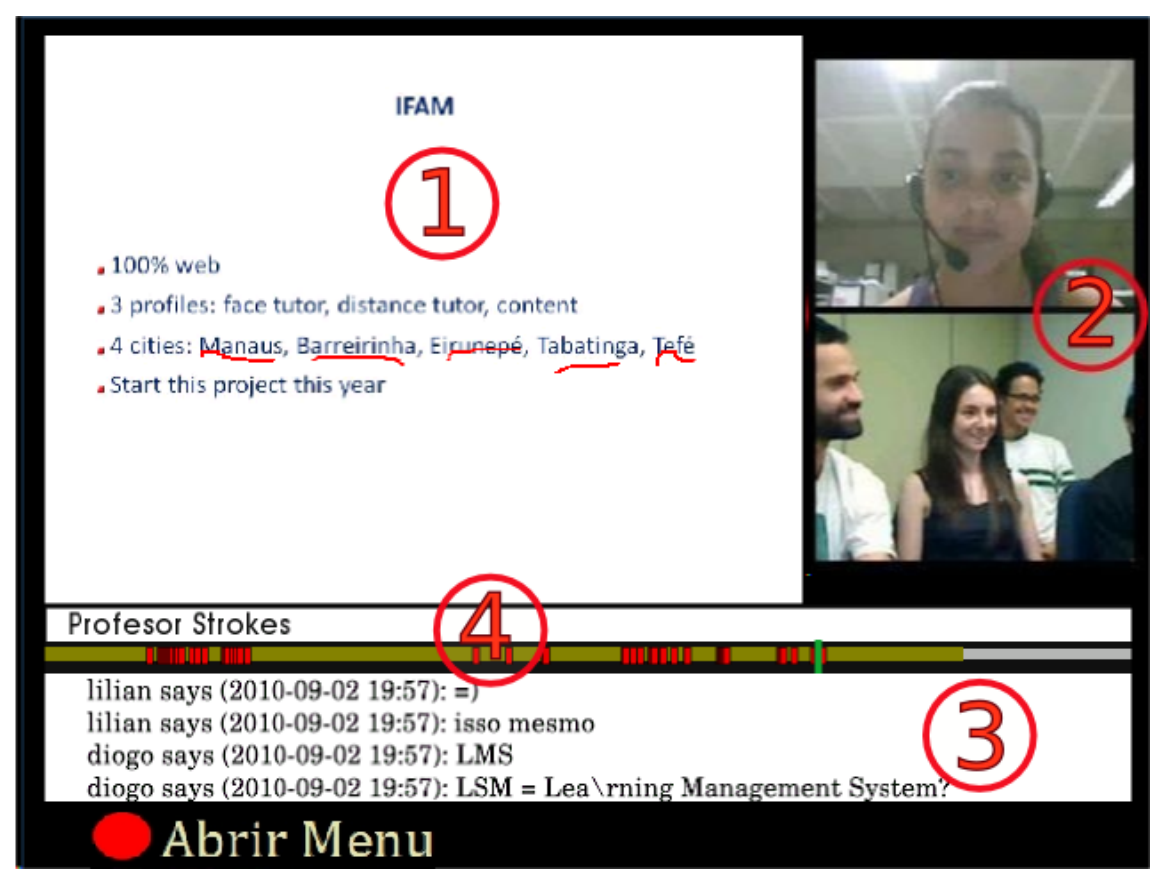

Figura 4.8: Estrutura do documento multimídia interativo final do cenário da webconferência ilustrando a linha de tempo decorada com o Interactor baseado em texto.

O botão vermelho (Figure 4.8) no canto inferior esquerdo, que significa "abrir menu”, pode ser usado para reabrir o menu de operadores para selecionar outro Interactor de string lógica para enfeitar a linha de tempo. A linha de tempo permite aos usuários navegar para diferentes pontos de interesse dentro de elementos de mídia. Por exemplo, a linha de tempo ornamentada na Figura 4.8 mostra os eventos de Interactor relacionados ao filterByAttributeValue() TextInteractor, com autor como atributo; após selecionar no menu e pressionar o botão ok (or enter), ele indica os momentos de tempo nos quais houve interação professor-texto durante a reunião. Quando um Interactor é selecionado o menu fecha automaticamente. Além disso, um rótulo é incluído acima da linha de tempo para indicar o Interactor específico que está ativo. Está claro que a apresentação atualiza o rótulo e os pontos de interesse correspondentes na linha de tempo. A fim de navegar para um ponto particular de interesse, os usuários empregam os botões de navegação direita/esquerda na interface de reprodução para se concentrar no ponto desejado, e pressiona o botão ok (ou enter) quando terminam.

\section{Videopalestras}

Este estudo pesquisou o problema da aprendizagem a distância em áreas isoladas no estado brasileiro do Amazonas. As cidades nesta área têm problemas de acesso devido às longas distâncias e aos muitos rios no estado. Foi considerado 
Tabela 4.1: Interactors usados nos protótipos

\begin{tabular}{l|l|c}
\hline Categoria & Operador & Atributos \\
\hline \hline Inkteractors & FilterByAuthor & autor \\
AudioInteractors & spokenMoments & - \\
TextInteractors & filterByAttributeValue & autores \\
BoardInteractors & filterByAttributeValue & titulos dos slides \\
BoardInteractors & changeBoard & - \\
\hline
\end{tabular}

também que em muitas cidades do interior, existem dificuldades de acesso à Internet, o que priva o uso de áudio e vídeo sincronizado. No entanto, a adoção de documentos multimídia estruturados abre benefícios para o enriquecimento de conteúdo, compartilhamento e transmissão sem a necessidade de uma conexão de banda larga.

De acordo com esta premissa, foi focado o estudo de videopalestras no cenário de educação a distância por TV, conhecida como t-learning, o que poderia ser um caminho para melhorar o acesso à educação na região. Um professor de uma escola de ensino técnico e dois grupos de estudantes de diferentes cidades, um na capital do estado, Manaus, e outro em Eirunepé, participaram do experimento. Os alunos foram participantes do curso de ensino à distância, com experiência previa no uso de Internet, no uso do controle remoto da TV, e falantes nativos de português com baixa proficiência em Inglês.

O professor preparou todo o material das aulas em um laptop pela ferramenta DiGaE home, com a qual gravou a palestra. Após isso, a sessão gravada foi enriquecida com os Interactors e exportada para um iMMD em linguagem SMIL, para sua reprodução no PC com o RealPlayer ou na WEB, e em NCLua, para reprodução no padrão de TV digital terrestre brasileira. Os alunos podiam assistir à videopalestra, em certos momentos, na escola usando a televisão, ou rever o material em casa na web. Os Interactors que foram aplicados nesse cenário estão listadas na Tabela 4.1

A Figura 4.9 mostra o layout do iMMD do vídeo da palestra com o menu de Interactors aberto: a sua reprodução é controlada por um player que oferece várias opções através do menu de Interactors e o teclado, quando a reprodução ocorre em uma plataforma baseada em computador, por exemplo, ou por um controle remoto quando a reprodução ocorre em uma plataforma baseada na televisão. O Interactor atualmente selecionado é "Mudança de Slide", e os botões para cima/para baixo poderiam ser usados para selecionar alguns dos outros BoardInteractors. A tecla esquerda e depois as teclas para cima/para baixo vão ajudar a trocar de mídia que especifica os Interactors; a tecla direita permite ao usuário escolher uma operação lógica para criar composições de sequências 


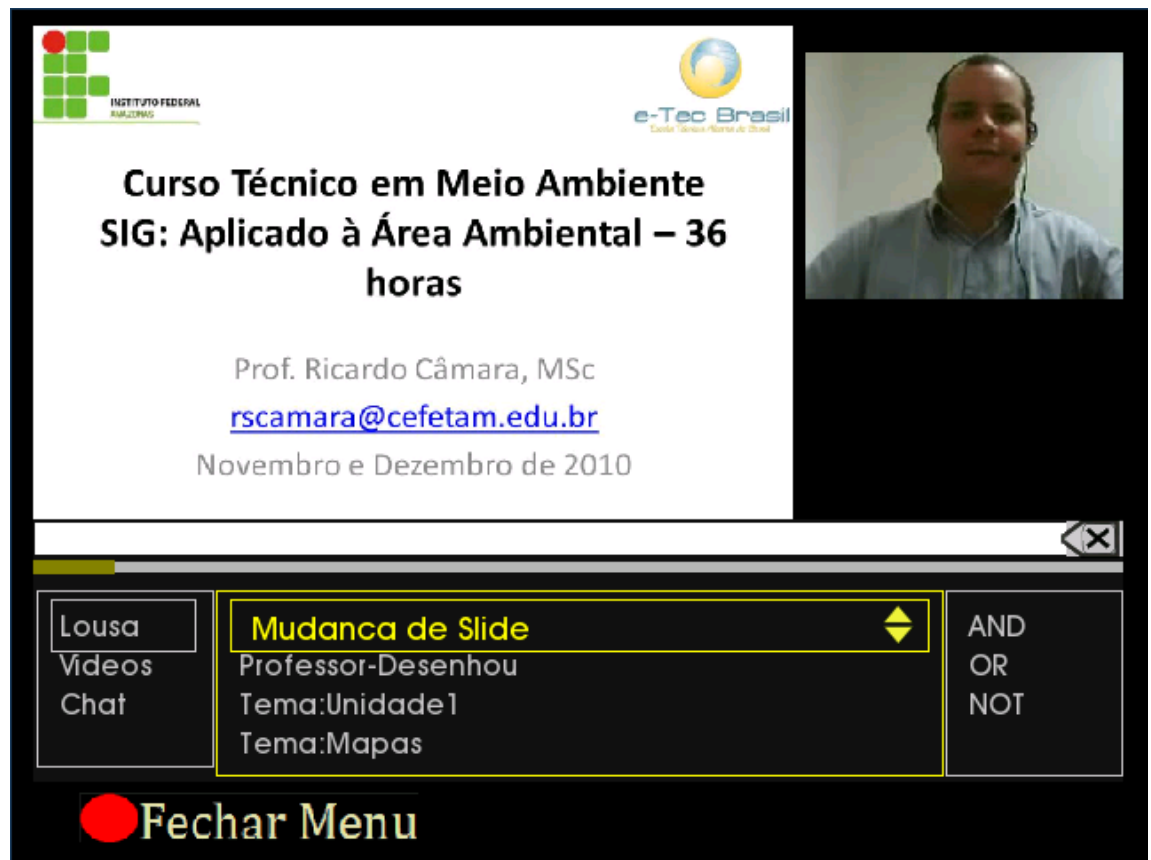

Figura 4.9: Screenshot ilustrando o menu de operadores aberto do documento multimídia interativo final gerado da vídeo palestra.

lógicas de Interactors. O botão vermelho no canto inferior esquerdo da Figura 4.9, permite que os usuários possam fechar o menu dos Interactors e retornar ao estado inicial da linha de tempo.

\subsubsection{Avaliações}

A avaliação visou medir a eficácia do menu de Interactors apoiando os usuários durante as tarefas de busca de fatos específicos em uma sessão de captura. Foi utilizado um método de inspeção e a avaliação de usabilidade para explorar questões relacionadas com a revisão de sessões gravadas que usam iMMD enriquecidos com vários tipos de índices de operadores baseados em mídias. Tudo isso, com o fim de encontrar contribuições para o processo iterativo de desenvolvimento e obter a introspecção de entendimento do conceito de operadores de interação baseados em mídias. Realizou-se o protocolo de pensar em voz alta (Wright e Monk, 1991), ou think-aloud em inglês, realizado no estudo de webconferência. Também foi aplicada a avaliação heurística utilizando as heurísticas gerais propostas por Nielsen e Mölich ${ }^{2}$ por seis especialistas.

\footnotetext{
${ }^{2}$ A lista original das 10 heurísticas da Nielsen e Mölich (1990) que foi aperfeiçoado por Nielsen (http : //www.useit.com/papers/heuristic/heuristiclist.html)
} 


\section{Think Aloud Tests}

Os testes foram realizados com quatro dos seis participantes que estiveram presentes na prova de conceito armazenada. Os participantes receberam uma breve introdução aos Interactors, os principais elementos da interface e uma lista de cinco perguntas simuladas sobre a reunião. Os usuários foram convidados a responder a cada pergunta navegando pela linha de tempo e o menu de Interactors. Através do teste, todos os eventos de navegação do usuário (pressionamento de teclas) foram capturados e registrados em um documento XML. Ao finalizar o teste, cada usuário participou de uma entrevista a respeito de sua compreensão do conceito e utilidade da ferramenta.

A maioria dos usuários se sentiu confortável com a possibilidade de navegar por pontos de interesse na sessão gravada e reconheceram a utilidade do menu de Interactors, exceto por algumas falhas. Nos testes, os usuários tinham dificuldades para associar a operação lógica e seu significado, especialmente no início da interação, quando os usuários não estavam muito conscientes das possibilidades da ferramenta. O que revela problemas de learnability/aprendizagem na interface.

Todos os usuários puderam reconhecer facilmente como navegar nos eventos de interação da linha de tempo e no menu de Interactors. No entanto, a maioria das pessoas observaram que para navegar entre os operadores do mesmo tipo, era necessário estar rolando no menu para assim encontrar a melhor escolha de Interactor. Isso poderia ser a causa de que, em 44\% do tempo, os participantes escolhessem o primeiro operador que permitiu atingir o ponto de interesse desejado e não aquele que poderia ser melhor, dada a semelhança de seu significado no contexto da pergunta. Nos testes, os usuários foram capazes de criar sequências lógicas envolvendo até três Interactors, mas não mais que isso. Finalmente, os usuários valorizaram a capacidade de encontrar pontos de interesse com rapidez.

\section{Avaliação Heurística}

A avaliação heurística é um método utilizado para detectar problemas de usabilidade nas interfaces. É realizado por um grupo de especialistas que utilizam um conjunto pré-definido de princípios e heurísticas. A avaliação foi realizada por seis especialistas: dois especialistas, um em design de interação e o outro um avaliador de experiência de usuário, especialistas em pesquisa e desenvolvimento de aplicações móveis; um especialista em design de interação em multimídia e projetos web; dois designers de interfaces especialistas em projetos de TV digital; e, finalmente, uma especialista em tecnologia de ensino à distância 
e aplicações de aprendizagem. Todos os especialistas são funcionários de companhias respeitáveis no mercado. As interfaces foram avaliadas considerando a lista das 10 heurísticas de Nielsen e Mölich (1990). Alguns comentários e observações mais marcantes manifestados pelos avaliadores são apresentados a seguir:

- "A linha do tempo ajuda o usuário a saber onde está, mas não está sendo informado o tempo total do vídeo e nem o minuto atual".

- Alguns revisores não perceberam, inicialmente, que havia mais opções na região de seleção de Interactors no menu do que aqueles apresentados na tela, uma sugestão seria a de ter uma barra de rolagem para indicar que há mais opções.

- "O conceito de combinação de marcadores está herdando conceitos de concatenação em banco de dados e isto não é parte da lógica popular".

- "Como faço em algum momento para chegar até o ícone de backspace".

- "Falta de uma descrição clara sobre quais teclas usar para iniciar, parar o vídeo...”.

- "O sistema não informa que precisa apertar enter para iniciar um ponto de interação na linha de tempo".

- "No caso de teclas mapeadas, precisam aparecer na barra de ajuda com o ícone e a legenda informando o que o usuário poderá executar”.

- "Não é necessário algum treinamento para ter acesso ao sistema".

- "O sistema é bem direto, apresentando somente as informações pertinentes”.

- "O fato de o sistema usar as opções textuais facilita ao usuário localizar o que ele procura”.

- "Usar operações booleanas como fazem os buscadores web melhoraria a experiência para os usuários já familiarizados”

- "Não percebi uma opção de ajuda".

Em termos de procedimentos, os resultados das avaliações realizadas pelos especialistas foram classificados como problemas sem importância, cosméticos, simples, críticos ou catastróficos. Os resultados e comentários dos especialistas 
foram agrupados e ordenados por severidade. Com base na análise dos dados, um plano de ação foi sugerido para aprimorar a interface. Os principais resultados, mostrados a partir dos problemas classificados como simples, até os problemas catastróficos, são apresentados como segue:

1. Simples - corrigi-los deveria estar com baixa prioridade.

(a) As operações lógicas não foram muito claras, além de estarem em inglês. Ações: Dependendo do público alvo da aplicação, esta tem que apresentar as operações lógicas de tal forma que sejam claras para o usuário. Pode-se Oferecer mecanismos de concatenação lógica implícita e mais simples.

(b) Prover a possibilidade de fazer mudanças dinâmicas no layout da aplicação. Ações: Dar ao usuário maior capacidade de interação com a ferramenta. Pode ser realizada autoria on-the fly ou oferecer opções previamente estabelecidas.

(c) O menu e os submenus estão sendo apresentados no mesmo nível. Ações: Destacar mais o menu de seleção de mídias, deixando claro na interface que menu de Interactors é um submenu.

(d) Mostrar de uma melhor forma ao usuário que existem mais opções de Interactors no submenu. Ações: Poderia ser usada uma barra de rolagem para indicar a presença de mais Interactors.

(e) A área de feedback da linha de tempo não é muito visível. Ações: Destacar mais a área de texto da linha de tempo para que o usuário perceba o status do sistema.

2. Críticos - importante serem corrigidos e de alta prioridade.

(a) Depois de abrir o Menu, as opções estão sem foco e desativadas. Ações: Habilitar opções default no menu de Interactors.

(b) O sistema não informa o tempo de reprodução e a duração da sessão. Ações: Adicionar um marcador do tempo atual da reprodução na linha de tempo.

3. Catastróficas - corrigi-los é mandatório e de altíssima prioridade.

(a) Prover os comandos de vídeo comuns como pausa, fast, forward. Ações: A linguagem não é que define esse tipo de operação e sim o player onde é tocada. Para o caso de SMIL, o RealPlayer faz todas essas operações. No caso de NCLua, por enquanto, teriam que ser programadas essas opções. 
(b) Um menu de ajuda da aplicação. Ações: Adicionar, no modelo da ferramenta, a opção de uma interface de ajuda própria para o contexto da TV.

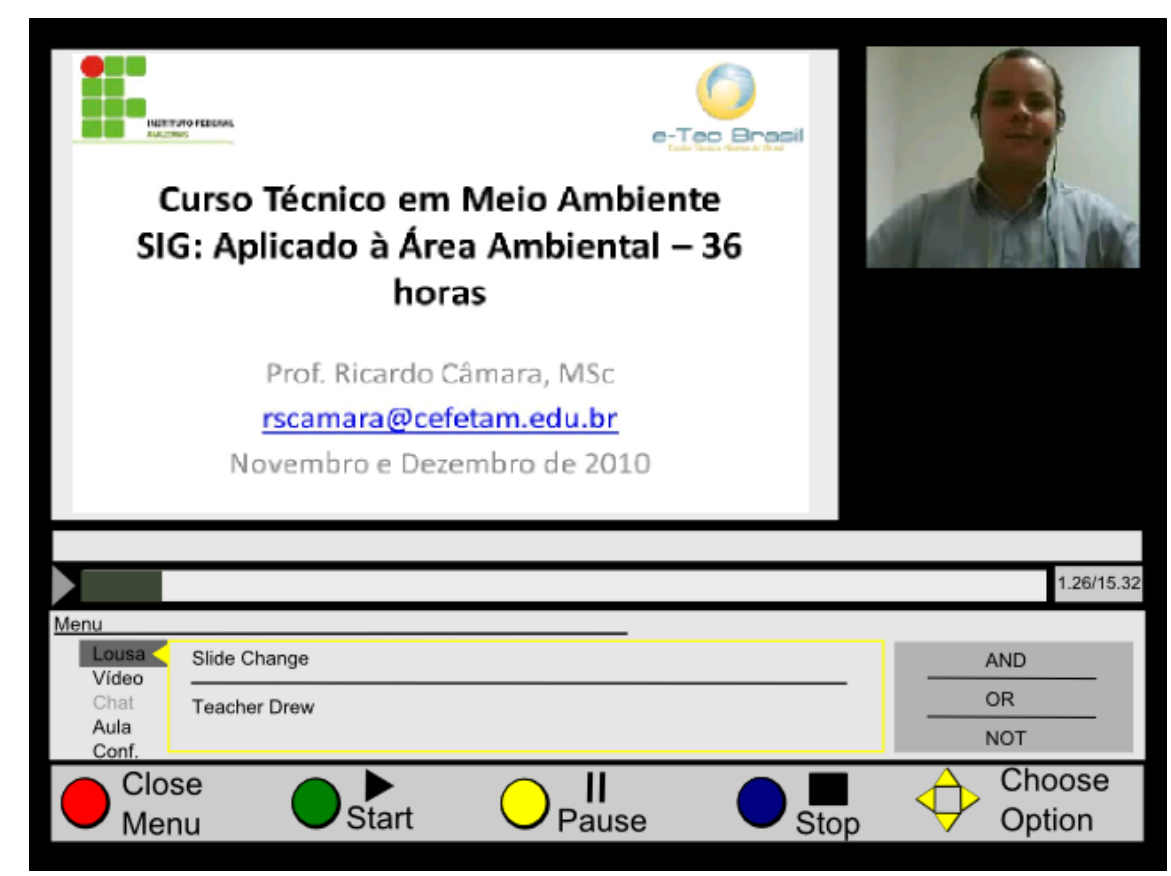

Figura 4.10: Screenshot ilustrando a interface proposta após os resultados da avaliação heurística

Após as análises das avaliações heurísticas, foi realizada uma nova proposta de reformulação da interface, de acordo com as sugestões dos especialistas para, dessa forma, resolver os principais problemas encontrados.

A Figura 4.10 mostra a interface proposta com as mudanças significativas sugeridas pela inspeção heurística. Em geral se tentou tornar mais visível a barra da linha de tempo e adicionar a descrição do tempo do vídeo. As opções do menu foram mais enfatizados, a fim de informar melhor a opção nível de navegação em que usuário está. Finalmente se tem a intenção de fornecer operações comuns de vídeo, e informar ao usuário o mapeamento das teclas.

\subsection{Formalização do Documento de Intercâmbio de Informação}

O documento de intercâmbio de informação permite o baixo acoplamento do modelo com a infraestrutura. A primeira versão do documento de intercâmbio, que foi apresentada na Seção 4.2.1, serviu como base para a exportação dos eventos de interação capturados pela ferramenta e como dado de entrada para 
o gerador automático de documentos multimídia interativos. Contudo, no modelo proposto de ciclo de vida dos eventos de interação, também foi definida a possibilidade de capturar as interações do usuário durante a fase de extensão, ou seja, enquanto o usuário visualiza/acessa o documento e faz anotações ou navega nele. Além disso, foi contemplada a possibilidade do usuário poder editar as sessões exportadas usando operações lógicas nos eventos de interação. Dessa maneira, o resultado seria uma autoria no conteúdo da sessão sem editar as mídias como tal.

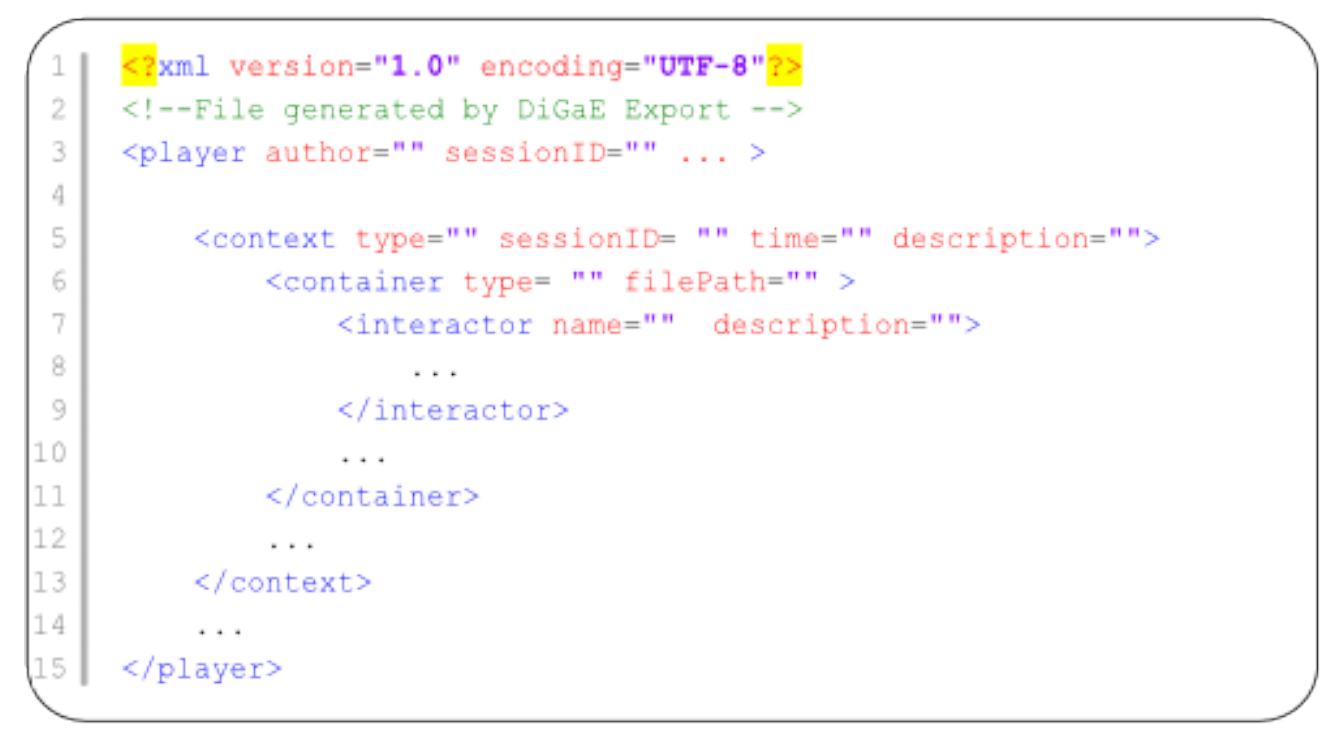

Figura 4.11: Principais elementos da estrutura do novo documento de intercâmbio de informação

Surge então a necessidade de estender e formalizar o documento de intercâmbio, para que possa ser usado nas outras fases do ciclo de vida e cumpra com os requerimentos do modelo. A Figura 4.11 apresenta a estrutura do documento de intercâmbio após a re estruturação. O elemento $<$ player $>$ continua sendo o elemento pai do documento, no qual são definidos os atributos de autor/author, (a ferramenta ou pessoa que gerou o documento), o identificador da sessão, entre outros.

Durante a formalização do documento, foram propostos novos elementos que abstraem alguns conceitos de maneira a estender o documento. A primeira mudança foi na abstração de todos os elementos de mídias, (SlideSet, ChatSession, audio, video) em um novo elemento chamado de <context > (linha 5-11). Este elemento tem como parâmetro obrigatório, (type), que representa o tipo de mídia ou contexto o qual está agrupando. Nesse sentido, podem ser definidos contextos do tipo bate-papo, lousa eletrônica, anotações, autoria entre outros, sem estar limitados a um cenário ou ferramenta. Também conta com os parâmetros de 
sessionID, que indicam a sessão à qual pertencem, time, data e hora em que foi instanciado e description.

O elemento <context $>$ tem como únicos filhos, elementos do tipo <container $>$. $\mathrm{O}<$ container $>$ determina as características ou informações específicas que são comuns a seu elementos-filho. Esse tipo de conceito estava presente no elemento <local> do primeiro modelo, indicando, por exemplo, todas as imagens dos slides que estavam em uma determinada pasta. A vantagem é que agora podem ser definidos vários grupos de elementos dentro de um determinado contexto, como por exemplo, gerar vários vídeos para um mesmo usuário em uma sessão de videoconferência, situação que não era suportada pelo documento de intercâmbio inicial.

$\mathrm{O}<$ container $>$, da mesma forma que o elemento <local>, contém todos os Interactors associados a esse contexto, que foram extraídos de uma mídia comum. Ao elemento < Interactor $>$ foi adicionando o parâmetro name, o qual serve para identificar, explicitamente o Interactor do qual se está tratando, facilitando os processos de transformação e localização no documento.

Foi realizadda uma videoconferência, como exemplo, entre três participantes para gerar os dados de entrada de um documento de intercâmbio de informação que ilustra a notação e estrutura do novo modelo. As partes do documento junto com as correspondentes fases do ciclo de vida, são descritas a seguir.

\subsubsection{Registro de Eventos da Fase de Captura}

Durante a fase de Captura dos dados, a sincronização tem um papel importante para o sucesso da transformação e aos acesso nos documentos multimídias automaticamente gerados. Nesse sentido, o documento de intercâmbio de informação detalha as informações precisas dos eventos de interação capturados, para assim conseguir a geração dos documentos baseada nas interações. A Figura 4.12 apresenta a descrição dos eventos de interação da sessão.

O primeiro contexto descrito (Figura 4.12) é o relacionado à lousa eletrônica (Board), (linhas 4-26). O contexto de lousa, da mesma forma que pode acontecer com outros contextos, pode abordar varias categorias de Interactors, devido à semântica emergente do contexto, que para este caso são os Inkteractors e os BoardInteractors. O contexto registrado a seguir é o relacionado ao bate-papo chat, o qual é descrito segundo o anteriormente explicado.

No caso do primeiro contexto de vídeo que aparece na Figura4.12(linhas 48-59), vemos que para o caso desse usuário foram gerados dos elementos $<$ container>, o que significa que foram gerados dois vídeos para esse usuá- 


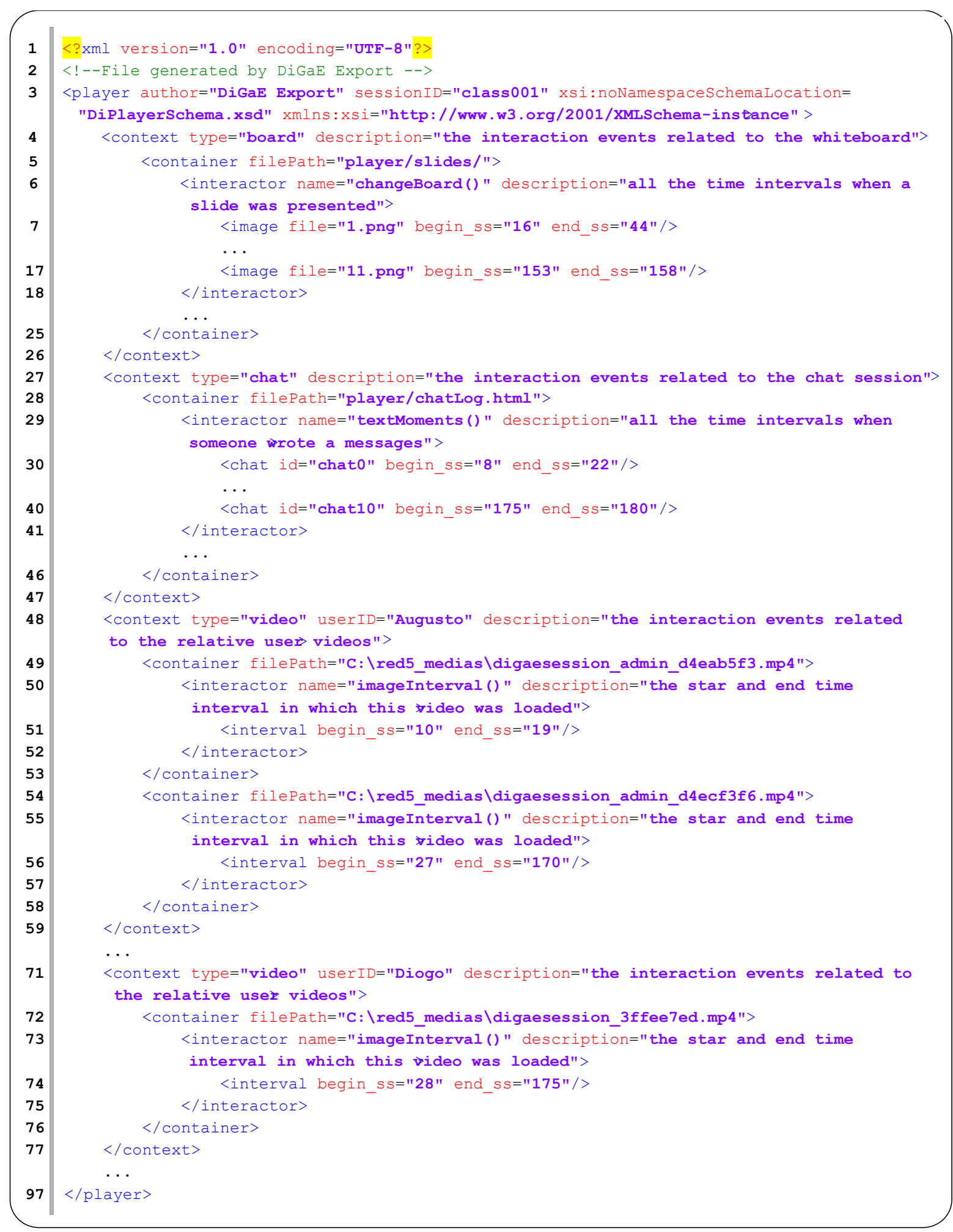

Figura 4.12: Exemplo de um documento de intercâmbio com os eventos de interação gerados na fase de captura.

rio: o primeiro, que durou só 9 segundos e o outro que começou 8 segundos depois de ter sido desabilitado o primeiro. 


\subsubsection{Registro de Eventos da Fase de Autoria e Pós-Processamento}

Como foi visto na Seção 3.3, existem duas opções que podem ser tomadas na fase de pós processamento para o documento de intercâmbio (Figura 4.1): (a), o documento de intercâmbio é automaticamente transformado para uma aplicação multimídia, ou $(b)$ o usuário pode editar a informação contida no documento de intercâmbio para depois gerar uma versão personalizada do documento multimídia.

As opções que o usuário tem, neste caso o produtor de multimídia, para modificar o documento de intercâmbio são: (i) modificar o layout da apresentação; (ii) enriquecer a sessão adicionando (ou removendo) operadores de interação; (iii) editar a apresentação da sessão com base no conteúdo da mesma, podendo decidir quais coisas quere que sejam apresentadas, quais quer que sejam puladas e quais que sejam retiradas da sessão; finalmente e não menos importante (iv) decidir o formato de apresentação da sessão.

Visando cumprir os requisitos estabelecidos para a autoria do documento de intercâmbio de informação, o qual implica diretamente na autoria do documento multimídia interativo, é proposta uma ferramenta que ainda não foi avaliada e está em fase de desenvolvimento, mas que para efeitos práticos serve como modelo para ilustrar o processo de autoria (Figura 4.13).

A primeira operação que o usuário poderia fazer na ferramenta de autoria é editar o layout do iMMD. Esse tipo de operação é comum nas ferramentas de autoria, mas não estão diretamente relacionada com a semântica dos dados capturados da sessão, portanto, esses eventos não são considerados como parte do documento XML. Uma opção diretamente relacionada com o documento de intercâmbio é a possibilidade de editar os Interactors da sessão (Figura 4.13(2)). Nesta parte, o produtor pode ver uma lista dos Interactors carregados no documento, e fazendo uso das opções, pode carregar um novo Interactor escolhendo de uma lista de possíveis operadores (algoritmos ou programas vinculados com a ferramenta) disponiveis para ele, junto com a mídia específica (Target) à qual será aplicado o operador. Por exemplo, o operador de momentos de silêncio pode ser aplicado ao vídeo user2. Os novos eventos de interação passam a enriquecer o documento de intercâmbio e diretamente a aplicação multimídia, o que se traduz na experiência do usuário.

A parte mais interessante das opções de autoria que a ferramenta oferece talvéz seja a relacionada com a possibilidade de editar a apresentação das mídias com base nas interações implícitas no conteúdo (Figura 4.13(3)). Nesta parte, o produtor pode decidir quais informações quer que sejam apresentadas ou não. Por exemplo, vetar os comentários ou mensagens de um usuário em um determi- 


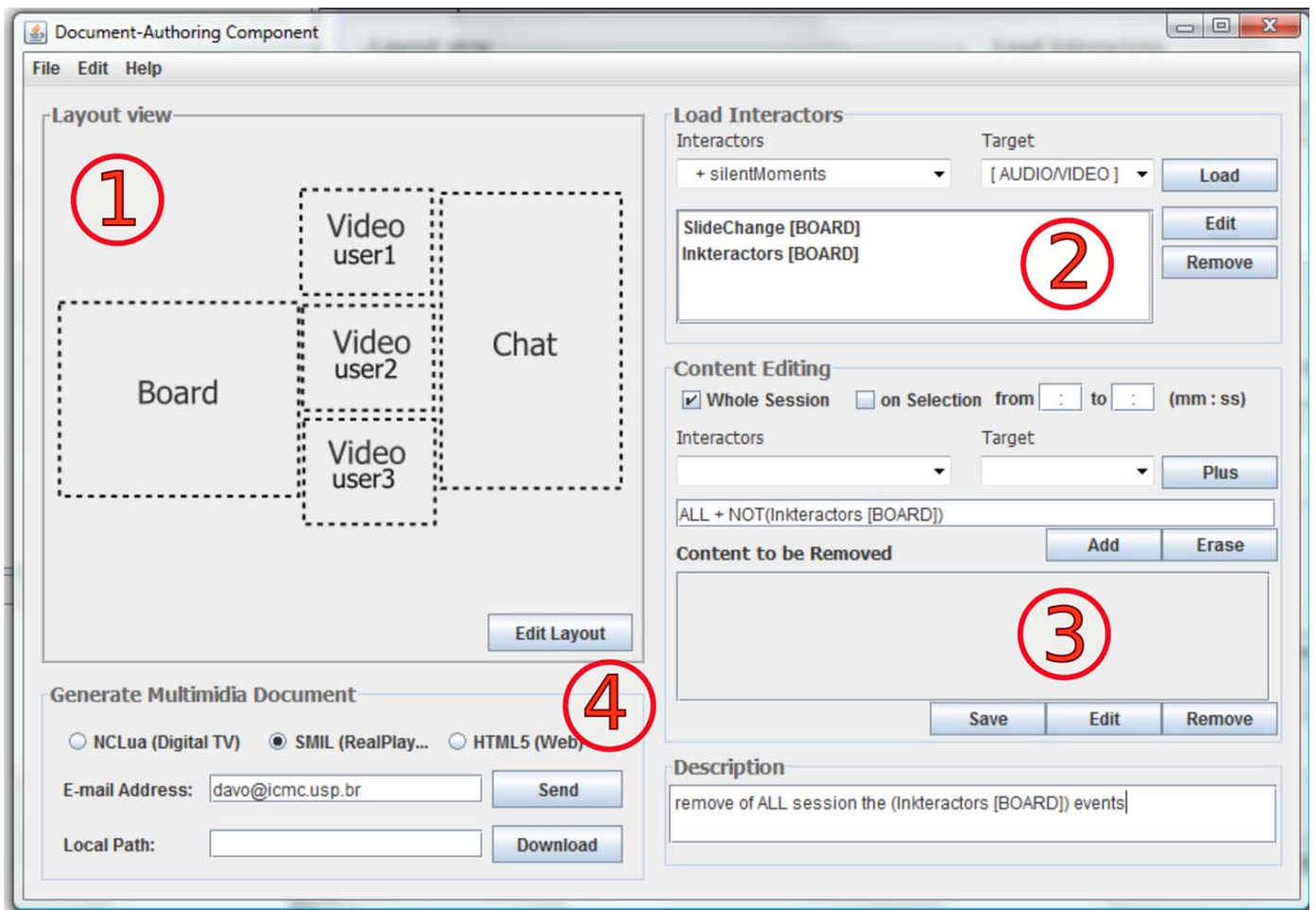

Figura 4.13: Exemplo de ferramenta de autoria com as possíveis opções para o usuário: (i) editar layout, (ii) enriquecer o documento, (iii) editar o documento e (iv) gerar o documento multimídia

nado momento, reduzir o tempo da apresentação tirando os momentos de silêncio, ou só apresentar as interações feitas por um usuário ou grupo de usuários, são edições simples de se fazer. A estratégia para fazer as edições no conteúdo da sessão é criar strings de edição via composições lógicas de operadores.

Para criar novas versões da sessão capturada, o produtor primeiro define se a string está relacionada com todo o tempo da sessão ou só com uma parte dela. Depois disso, o produtor vai escolhendo de uma lista de operadores carregados, os Interactors e as mídias que fazem parte da composição lógica. Para concatenar mais condições dentro da mesma string, usa o botão PLUS que simboliza o operador OR. Quando termina de formular a composição lógica, o produtor aperta o botão $A D D$ para adicionar a string na caixa de texto de baixo, que simboliza a entrada de uma nova regra de edição da sessão, que é concatenada por operadores AND. A vantagem que deste método é que a semântica da edição é dada diretamente pelo produtor.

Depois que o produtor termina de inserir as regras de edição que vão ser aplicadas, ele escolhe o formato do iMMD que será gerado e o modo que deseja recebê-lo (seja por email ou desscarregado-o), como mostra a Figura 4.13(4). Os eventos de interação armazenados, após a autoria sobre a sessão, são apresentados na Figura 4.14. 


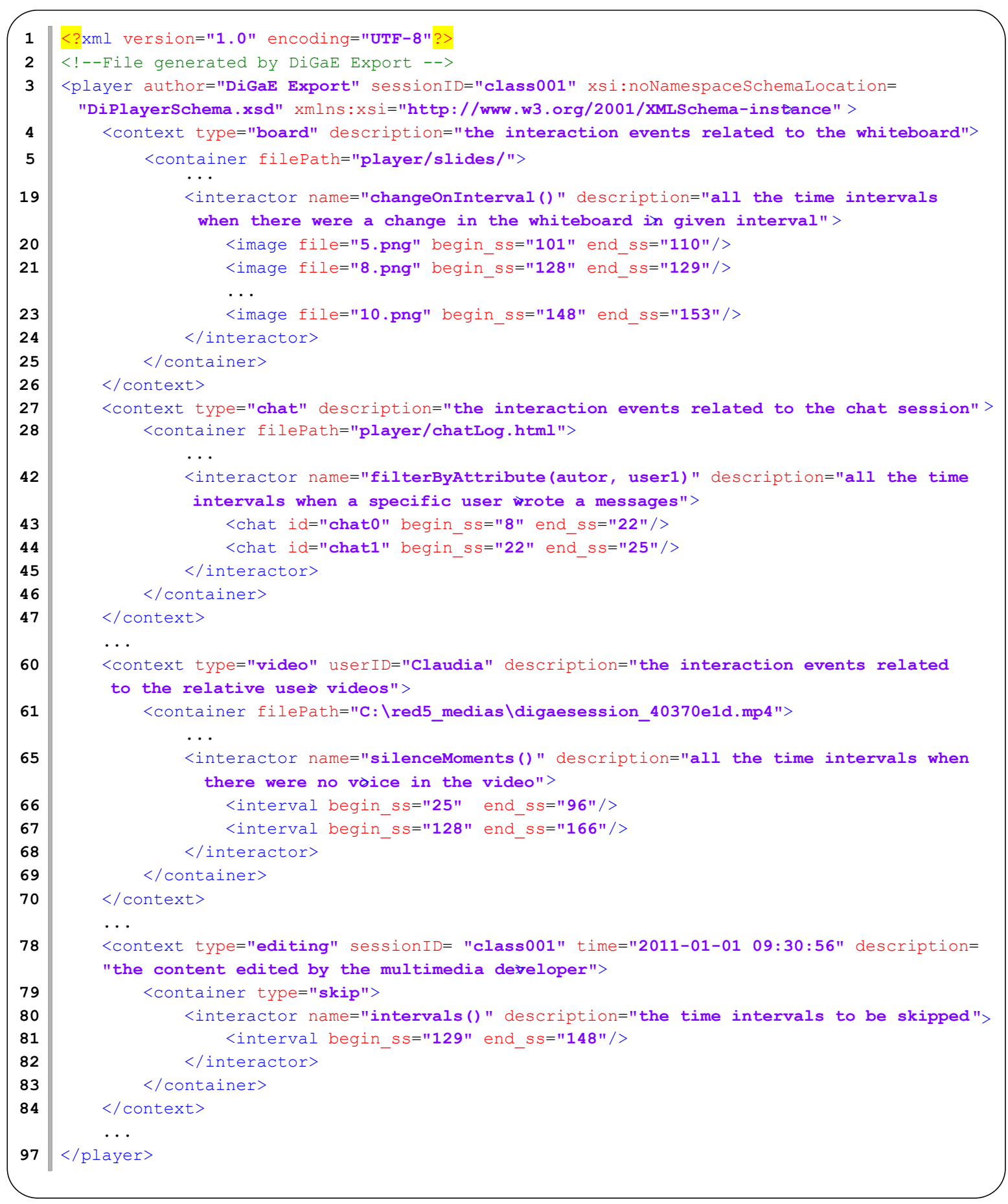

Figura 4.14: Exemplo de um documento de intercâmbio com os eventos de interação gerados após a fase de autoria.

No exemplo, o documento foi enriquecido agregando o BoardInteractor changeOnInterval() que por padrão toma o tempo todo da sessão e qualquer mudança que tenha ocurrido na lousa (linhas 19-24), o TexInteractor filterByAttribute(autor, user1), filtrando as mensagens escritas do primeiro usuário(linhas 42-45), e o AudioInteractor silenceMoments() para o caso do vídeo 2 (linhas 6568). Finalmente, também foi agregado um evento de autoria no documento, nas 
linhas 78-84. O elemento <container>, no caso de ser filho de um contexto editing, tem definido duas classes de atributos para o parâmetro type, que são skip/pular, e exclude/remover. O atributo skip faz com que sejam pulados os intervalos de tempo descritos dentro dele, ocasionando uma mudança no tempo total da aplicação. No caso do atributo exclude, o contexto da edição é tirar o conteúdo ou inabilitá-lo para que não seja apresentado na aplicação, sem mudar o tempo de execução da aplicação.

\subsubsection{Registro de Eventos da Fase de Extensão}

A fase de Extensão é compreendida como aquela em que o usuário interage com a aplicação gerando novos dados de entrada sobre a sessão. Interagir com a aplicação significa que ele navega e acessa pontos de interesse e que faz anotações do tipo áudio, tinta digital, texto, vídeo, entre outros, no documento. São vários os trabalhos que abordam mecanismos de entrada de dados para os usuários na TV digital, por exemplo, mediante o uso de interfaces multimodais usando teclados virtuais e comandos de voz (Vega-Oliveros et al., 2010c), ou aplicações whiteboard e gravação de arquivos de áudio (Cattelan et al., 2008a), ou entradas por multiples dispositivos como acelerômetros, microfones, câmeras, celulares entre outros (Pedrosa et al., 2010), ou simplesmente, capturando as ações do usuário com o controle remoto enquanto assiste a TV, como mudança de canal, de volumem, etc. (Vega-Oliveros et al., 2009; Teixeira et al., 2010a).

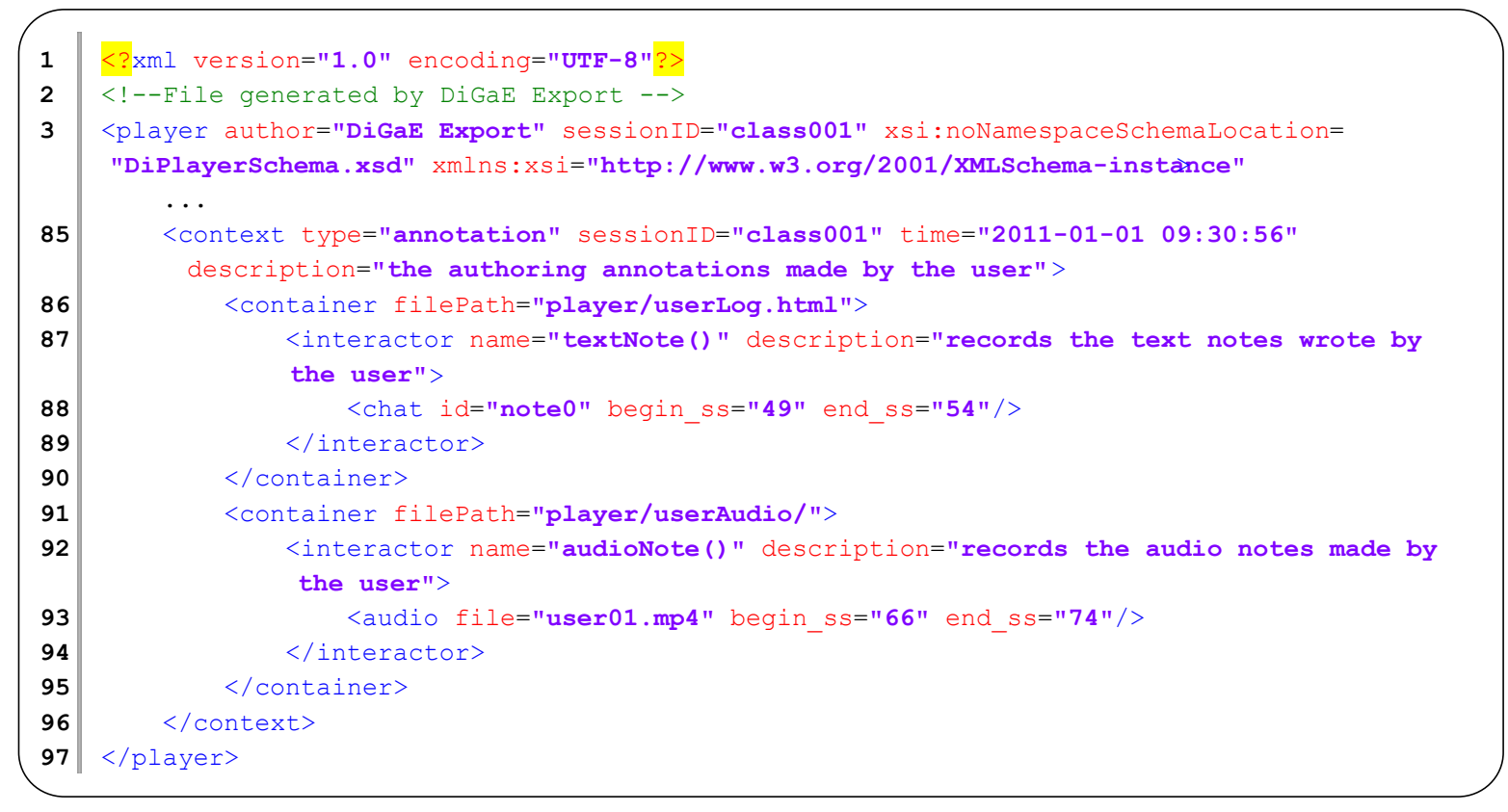

Figura 4.15: Exemplo de um documento de intercâmbio com os eventos de interação gerados após a fase de extensão. 
A Figura 4.15 ilustra os eventos registrados após a fase de extensão do documento tomado como exemplo. No documento estão registrados dois desses eventos, os quais estão dentro do contexto de anotação (annotation). Os tipos de contextos que foram definidos para a fase de extensão são o annotation, que reúne todas as anotações que possam ser realizadas baseadas no dado de entrada, (texto, sem importar o dispositivo nas linhas 87-89, o mesmo que áudio nas linhas 92-94, ou coordenadas para tinta digital, seja por caneta eletrônica, acelerômetros, etc.) e navegation, que documenta os eventos de navegação do usuário.

\subsection{Considerações Finais}

Neste capítulo foram descrito os resultados relacionados à geração automática de documentos com o uso de Interactors, à navegação e ao acesso, e à formalização do uso de um documento de intercâmbio de informação. A geração automática de documentos, mediante um protótipo como prova de conceito, mostrou a viabiliade do modelo de geração sincronizada de uma sessão capturada via eventos de interação.

Para fins de avaliação, fez-se experiências com um protótipo de prova de conceito multimídia usando informações capturadas de uma ferramenta de webconferência. Os resultados sugerem que os Interactors são meios eficazes para auxiliar a revisão de conteúdo capturado em sessões colaborativas, por permitir a navegação por pontos de interesse. Apesar de terem enfrentado alguns problemas relacionados a usabilidade, em geral os usuários reconheceram a vantagem de usar os operadores para revisar uma sessão. 


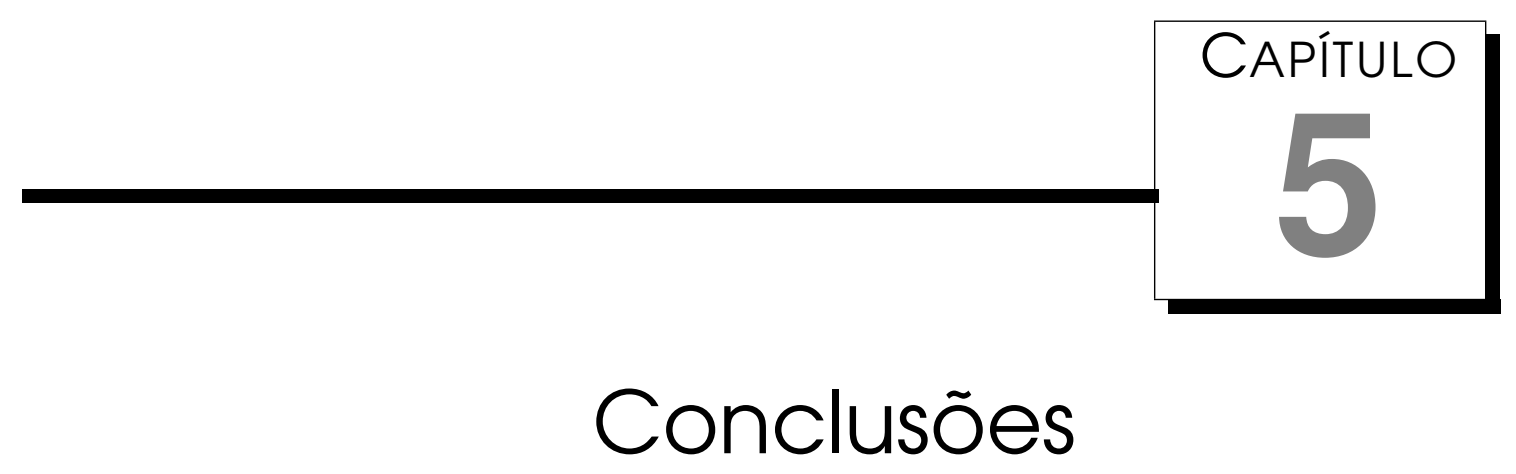

\subsection{Resultados e Contribuições}

Neste trabalho foi apresentada uma abordagem para gerar automaticamente documentos multimídia a partir da captura de eventos de interação de atividades colaborativas com significado semântico para usuário. A abordagem define vários operadores chamados Interactors que podem ser usados para indexar pontos de interesse em uma sessão síncrona capturada. Para isto, foi adotado um documento de intercâmbio estruturado para exportar os dados, o qual traz como vantagem o baixo acoplamento com sistema de captura e a capacidade de transfornar os dados para outras ferramentas e formatos.

Também foram formalizadas as operações booleanas de Interactors como uma composição lógica de operadores para fazer buscas que geram linhas de tempo dinâmicas, as quais servem para revisar sessões capturadas. Foram estendidos trabalhos anteriores redefinindo-se um novo modelo de visualização, seleção e navegação de pontos de interesse nos iMMD (documento multimídia interativo, do inglês Interactive Multimidia Document). Demonstrou-se que os Interactors provêem os meios para geração de mídias indexadas relacionadas à vários tipos de marcadores com significado para os usuários, visando enriquecer os iMMDs exportados.

Foi observado que os eventos de interação podem ser associados aos conceitos de teoria de conjuntos. A partir disto, mostraram-se as vantagens de criar cadeias lógicas de operadores como mecanismo de visualização de pontos de in- 
teresse para o usuário. Isto é devido ao fato que os usuários podem criar suas propias consultas lógicas a partir dos significados semânticos dos operadores e, desta forma, chegar a pontos específicos na sessão. Também foi observado que mediante a proposta de cadeias lógicas de operadores, é possivel fazer processos de autoria baseados no conteúdo das mídias.

Com o propósito de validação, foram realizados experimentos com um protótipo para prova de conceito, o qual foi desenvolvido em NCLua que faz uso de dados exportados a partir de um ambiente de captura. Foram analisados dois casos de uso, com informação multimídia capturada com uma ferramenta de webconferência, que foi utilizada na geração de documentos multimídia enriquecidos com Interactors. Os estudos com usuários sugerem que os Interactors têm um significado efetivo no auxílio da revisão da sessão capturada. Além disso, notaram-se alguns problemas com a composição da lógica de Interactors, especialmente no início do experimento, quando os usuários não estavam cientes de todas as possibilidades da ferramenta. Em geral, os usuários encontraram facilidade na revisão da sessão usando a abordagem proposta, posto que são eles que dão o significado semântico à consulta lógica. Inspeções de usabilidade por especialistas sugerem que a ferramenta fornece um nível satisfatório de usabilidade e observaram que "o sistema é simples, apresentando apenas as informações relevantes” sendo útil para acessar pontos específicos desejados.

\subsection{Limitações}

Uma limitação foi com a utilização da infraestrutura de um cenário real, pois os testes das avaliações sempre foram feitos simulando um set-top-box em um computador. Como resultado, a experiência do usuário não era suficientemente parecida com a de usar um controle remoto. Portanto, em alguns casos os usuários tendiam a ficar confusos ao não saber quais teclas pressionar no teclado. Outra limitação está relacionada com o player do Ginga, o qual está ainda em "versão beta"e não oferece as opções básicas de controle de vídeo (pausa, execusão, etc.), situação diferente ao que acontece com o RealPayer que roda a linguagem SMIL.

Uma limitação relacionada aos testes com usuários foi a indisponibilidade de pessoas para realizá-los, dado que não se contou com um grupo de usuários para as avaliações. Isto ocasionou que sempre fossem realizadas avaliações com poucas pessoas. 
O fato de que o player NCL de referência permita apenas que poucas mídias de vídeo possam ser suportadas em paralelo limitou os experimentos em relação ao tipo de sessões capturadas, dada a utilização do documento multimídia.

Segundo os resultados da avaliação heurística, o documento multimídia não apresenta muita familiaridade para os usuários, além do conceito de operadores booleanos ou lógicos poder ser muito técnico.

\subsection{Trabalhos Futuros}

Como trabalhos futuros podem ser formalizados novos operadores e desenvolvidos métodos para combiná-los eficazmente ao navegar no documento. Tal desenvolvimento pode permitir que os usuários gerem novas versões de documentos multimídia, combinando uma série de operadores que produzam uma versão mais resumida da mídia original.

Pode-se ainda realizar a combinação dos operadores de interação com outros paradigmas encontrados na literatura, por exemplo, o paradigma Watch-andComment $(\mathrm{WaC})$ pode ser enriquecido ao aplicar operadores de interação para poder rever as anotações feitas. Seguindo essa linha, o documento de intercâmbio de informação permite a entrada de dados de múltiplos dispositivos, o qual facilita o registro para o caso de trabalhos relacionados a aplicações multimodais.

Os eventos que são registrados durante a fase de extensão podem servir como dados a ser processados por um servidor para fazer descoberta de informação, ou mineração de dados. Por exemplo, os eventos de navegação dos usuários poderiam ser enviados as emissoras para assim saber o nivel de aceitação de um programa, um evento ou para aplicações do tipo governo eletrônico. Podem ainda ser exploradas as possibilidades de autoria para criação de versões personalizadas mediante o uso de consultas lógicas baseadas na composição de operadores.

Finalmente, pode-se também melhorar a interface do documento multimídia em termos dos mecanismos de navegação e do menu de operadores, realizando novos testes com usuários reais e novas avaliações de usabilidade com especialistas. 


\section{Referências Bibliográficas}

ABNT Abnt nbr 15606- 2 (2007) - Associação Brasileira de Normas Técnicas. Televisão Digital Terrestre - Codificação de dados e especificações de transmissão para radiodifusão digital - parte 2: Ginga-ncl para receptores fixos e móveis - linguagem de aplicação xml para codificação de aplicações. 2007.

Abowd, G. D.; Atkeson, C. G.; Brotherton, J.; Engvist, T.; Gulley, P.; LeMon, J. Investigating the capture, integration and access problem of ubiquitous computing in an educational setting. Em: CHI '98: Proceedings of the international conference on Human Factors in Computing Systems, New York, NY, USA: ACM Press/AddisonWesley Publishing Co., 1998, páginas 440-447.

Abowd, G. D.; Mynatt, E. D.; Rodden, T. The human experience [of ubiquitous computing]. IEEE Pervasive Computing, v. 4, n. 6, páginas 48-57, 2002.

Adcock, J.; Cooper, M.; Denoue, L.; Pirsiavash, H.; Rowe, L. A. TalkMiner: a lecture webcast search engine. Em: MM '10: Proceedings of the International Conference on Multimedia, New York, NY, USA: ACM, 2010, páginas 241-250.

Al-Imam, E.; LANK, E. PocketPad: Using Handhelds and Digital Pens to Manage Data in Mobile Contexts. Em: ICDS '07: First International Conference on the Digital Society., Los Alamitos, CA, USA: IEEE Computer Society, 2007, p. 13.

ARbaugh, J. B.; Benbunan-Fich, R. The importance of participant interaction in online environments. Decis. Support Syst., v. 43, n. 3, páginas 853-865, 2007.

Asteriadis, S.; Tzouveli, P.; Karpouzis, K.; Kollias, S. Estimation of behavioral user state based on eye gaze and head pose-application in an e-learning environment. Multimedia Tools and Applications, v. 41, n. 3, páginas 469-493, 2009.

Baptista, C.; Silveira, R.; Ruggiero, W. Msys: a monitoring system for e-learning feedback and content fitting. Em: Information Technology Based Higher Education and Training, 2006. ITHET '06. 7th International Conference on, 2006, páginas 639 $-646$. 
BARbosA, S.; SoARES, L. TV digital interativa no Brasil se faz com Ginga: Fundamentos, Padrões, Autoria Declarativa e Usabilidade. Em T. Kowaltowski \& K. Breitman (orgs.) Atualizações em Informática 2008. Rio de Janeiro. http://www.ncl.org. br/documentos/JAI2008.pdf, rJ: Editora PUC-Rio. 105-174. Último acesso Junho 5, $2011,2008$.

Behera, A.; Lalanne, D.; Ingold, R. DocMIR: An automatic document-based indexing system for meeting retrieval. Multimedia Tools and Applications, v. 37, n. 2, páginas 135-167, 2007.

Berglund, A. Augmenting the remote control: Studies in complex information navigation for digital t $v$. Tese de Doutoramento, Department of Computer and Information Science, Linköping University, Linköping, Sweden, 2004.

Biolchini, J. C.; Mian, P. G.; Natali, A. C. C.; Conte, T. U.; Travassos, G. H. Scientific research ontology to support systematic review in software engineering. Advanced Engineering Informatics, v. 21, n. 2, páginas 133-151, 2007.

Bouamrane, M.-M.; Luz, S. Meeting browsing. Multimedia Systems, v. 12, n. 4, páginas 439-457, 2007.

Brandão, D. M. R.; Souza Filho, G.; Batista, C.; Gomes Soares, L. Extended Features for the Ginga-NCL Environment: Introducing the LuaTV API. Em: ICCCN ' 10: Proceedings of 19th International Conference on Computer Communications and Networks, Zurich, Suiça, owner = Ginga, timestamp = 2010.11.02: IEEE Computer Society, 2010, páginas $1-6$.

Branham, S.; Golovchinsky, G.; Carter, S.; Biehl, J. T. Let's go from the whiteboard: supporting transitions in work through whiteboard capture and reuse. Em: CHI '10: Proceedings of the international conference on Human Factors in Computing Systems, New York, NY, USA: ACM, 2010, páginas 75-84.

Breuer, H.; Sousa, C.; Baloian, N.; Matsumoto, M. A lightweight open space for the classroom - collaborative learning with whiteboards and pen-tablets. Em: Advanced Learning Technologies, 2007. ICALT 2007. Seventh IEEE International Conference on, 2007, páginas $66-70$.

Brotherton, J. A.; Abowd, G. D. Lessons learned from eClass: Assessing automated capture and access in the classroom. Transaction on Computer-Human Interaction., v. 11, n. 2, páginas 121-155, 2004.

Brotherton, J. A.; Abowd, G. D.; Truong, K. N.; C\&A Supporting capture and access interfaces for informal and opportunistic meetings. Georgia Institute of Technology., v. Technical Report GITGVU 99-06, gVU Center,, 1999. 
Bulcão-Neto, R. F.; CAmacho-Guerrero, J.; Barreiro; Parapar, J.; Macedo, A. A. An automatic linking service of document images reducing the effects of OCR errors with latent semantics. Em: SAC '10: Proceedings of the Symposium on Applied Computing, Sierre, Switzerland: ACM, 2010, páginas 13-17.

Bulcão-Neto, R. F.; Camacho-Guerrero, J. A.; Macedo, A. A. Extension of Capture Information in Pervasive Healthcare Systems: A Case Study. Em: CSEWORKSHOPS '08: Workshops of the 11th IEEE International Conference on Computational Science and Engineering. , IEEE Computer Society, 2008a, páginas 19 -24.

Bulcão-Neto, R. F.; Camacho-Guerrero, J. A.; Macedo, A. A. A prototype documenter system for medical grand rounds. Em: DocEng '08: Proceeding of the Symposium on Document Engineering, Sao Paulo, Brazil: ACM, 2008b, páginas 104-105.

Bulterman, D. C. A. Using SMIL to encode interactive, peer-level multimedia annotations. Em: DocEng '03: Proceedings of the Symposium on Document engineering, New York, NY, USA: ACM, 2003, páginas 32-41.

Bulterman, D. C. A. User-centered control within multimedia presentations. Multimedia Systems, v. 12, páginas 423 - 438, 2007.

Bulterman, D. C. A.; Hardman, L. Structured multimedia authoring. TOMCCAP: Transactions on Multimedia Computing, Communications, and Applications , v. 1, n. 1, páginas 89-109, 2005.

Bulterman, D. C. A. ANd Rutledge, Lloyd SMIL 3.0 : Interactive Multimedia for the Web, Mobile Devices and Daisy Talking Books . X.media.publishing, Segunda Edição ed. Springer, 536 páginas, 2008.

Campbell, D.; Culley, S.; McMahon, C.; Sellini, F. An approach for the capture of context-dependent document relationships extracted from bayesian analysis of users' interactions with information. Information Retrieval, v. 10, n. 2, páginas 115-141, 2007.

Cattelan, R. G. Captura e acesso na produção, distribuição, apresentação e extensão de conteúdo multimídia. Tese de Doutoramento, Universidade de Sao Paulo - ICMC, orintadora Dra Maria da Graça Campos Pimentel, 2009.

Cattelan, R. G.; Teixeira, C.; Goularte, R.; Pimentel, M. G. C. Watch-andcomment as a paradigm toward ubiquitous interactive video editing. TOMCCAP: Transactions on Multimedia Computing, Communications, and Applications, v. 4, n. 4, páginas 1-24, 2008a.

Cattelan, R. G.; Teixeira, C.; Ribas, H.; Munson, E.; Pimentel, M. G. C. Inkteractors: interacting with digital ink. Em: SAC '08: Proceedings of the Symposium on Applied Computing, New York, NY, USA: ACM, 2008b, páginas 1246-1251. 
Cejudo, J.; Bermejo, D.; Guevara, J.; Alvarez, O. Televisión Digital Terrenal. Publicado em http: / / www . asenmac.com/tvdigital/marcos.htm, último acesso Junho 5, 2011, 2009.

Cesar, P.; Bulterman, D. C. A.; Jansen, A. J. The ambulant annotator: empowering viewer-side enrichment of multimedia content. Em: DocEng '06: Proceedings of the Symposium on Document Engineering, New York, NY, USA: ACM, 2006a, páginas 186187.

Cesar, P.; Bulterman, D. C. A.; Jansen, A. J. Benefits of structured multimedia documents in IDTV: the end-user enrichment system. Em: DocEng '06: Proceedings of the Symposium on Document Engineering, New York, NY, USA: ACM, 2006b, páginas 176-178.

Cesar, P.; Bulterman, D. C. A.; Jansen, A. J. Usages of the secondary screen in an interactive television environment: Control, enrich, share, and transfer television content. Em: EUROITV '08: Proceedings of the European conference on Changing Television Environments, Berlin, Heidelberg: Springer-Verlag, 2008, páginas 168-177.

Chen, H.; LI, S. Exploring many-to-one speech-to-text correlation for web-based language learning. Transactions on Multimedia Computing, Communications and Applications, v. 3, n. 3, 2007.

Chen, H.-Y.; LIU, K.-Y. Exploring Multimedia Correlation and Synchronization for Web-Based Language Learning. Multimedia, v. 13, n. 4, páginas 50-61, 2006.

Chen, H.-Y.; LIU, K.-Y. WMA: a marking-based synchronized multimedia tutoring system for english composition studies. Transactions on Multimedia, v. 11, páginas 324-332, 2009.

Chen, Y.; Jones, G. J. F. Augmenting human memory using personal lifelogs. Em: AH 10: Proceedings of the 1st Augmented Human International Conference, ACM, 2010, páginas 1-9.

CHeok, A. D.; LI, Y. Ubiquitous interaction with positioning and navigation using a novel light sensor-based information transmission system. Personal and Ubiquitous Computing, v. 12, n. 6, páginas 445-458, 2008.

Chiu, P.; Boreczky, J.; Girgensohn, A.; Kimber, D. LiteMinutes: an Internet-based system for multimedia meeting minutes. Em: WWW '01: Proceedings of the 10th international conference on World Wide Web, New York, NY, USA: ACM, 2001, páginas 140-149.

Costa, R. R. M.; Moreno, M. F.; Rodrigues, R. F.; Soares, L. F. G. Live editing of hypermedia documents. Em: DocEng '06: Proceedings of the Symposium on Document Engineering, New York, NY, USA: ACM, 2006, páginas 165-172. 
Costin, C.; Costin, M. New attempts in sound diarization. Em: Proceedings - 2009 3rd International Workshop on Soft Computing Applications, SOFA 2009, 2009, páginas 71-76.

Di, J.; Zhihan, L.; Ligang, Z.; Wei, Z. A SMIL-based multimedia system for mobile education. Em: IEEE IC-BNMT 2009: Proceedings of 2009 2nd IEEE International Conference on Broadband Network and Multimedia Technology, IEEE Computer Society, 2009, páginas 724-728.

DIRINGER, D. The encyclopedia americana, v. 29. Grolier inc. ed. 558-558 páginas, 1986.

EveritT, K.; Morris, M.; Brush, A.; Wilson, A. DocuDesk: An interactive surface for creating and rehydrating many-to-many linkages among paper and digital documents. Em: TABLETOP '08: Proceedings 3rd IEEE International Workshop on Horizontal Interactive Human Computer Systems., IEEE Computer Society, 2008, páginas 25 -28.

Ferati, M.; Bolchini, D.; MAnnheimer, S. Towards a modeling language for designing auditory interfaces, v. 5616 LNCS. 2009.

Friedland, G.; Yeo, C.; Hung, H. Dialocalization: Acoustic speaker diarization and visual localization as joint optimization problem. Transaction on Multimedia Computer and Communication Applications, v. 6, páginas 27:1-27:18, 2010.

Garzotto, F.; Forfori, M. Hyperstories and social interaction in 2D and 3D edutainment spaces for children. Em: Proceedings of the seventeenth conference on Hypertext and Hypermedia, Odense, Denmark: ACM, 2006, páginas 57-68.

Geyer, W.; Richter, H.; Abowd, G. D. Towards a Smarter Meeting Record-Capture and Access of Meetings Revisited. Multimedia Tools and Applications, v. 27, n. 3, páginas 393-410, 2005.

Glushko, R. J.; MCGrath, T. Document engineering for e-business. Em: DocEng '02: Proceedings of the Symposium on Document Engineering, New York, NY, USA: ACM, 2002, páginas 42-48.

Glushko, Robert J. And McGrath, T. Document Engineering: Analyzing And Designing Documents For Business Informatics And Web Services, v. 1. 2008 ed. MIT PRESS LTD, 728 páginas, 2008.

Goularte, R.; Cattelan, R. G.; Camacho-Guerrero, J. A.; InÁcio, Jr., V. R.; Pimentel, M. G. C. Interactive multimedia annotations: enriching and extending content. Em: DocEng '04: Proceedings of the Symposium on Document Engineering, New York, NY, USA: ACM, 2004, páginas 84-86. 
Guido, R. C.; Slaets, J. F. W.; Köberle, R.; Almeida, L. O. B.; Pereira, J. C. A new technique to construct a wavelet transform matching a specified signal with applications to digital, real time, spike, and overlap pattern recognition. Digital Signal Processing, v. 16, n. 1, páginas 24-44, 2006.

Guimarães, R. L.; Cesar, P.; Bulterman, D. C. Creating and sharing personalized time-based annotations of videos on the web. Em: DocEng '10: Proceedings of the Symposium on Document Engineering, New York, NY, USA: ACM, 2010, páginas 2736.

Guimarães, R. L.; Costa, R. R. M.; Soares, L. Composer: Authoring Tool for iTV Programs. Em: EUROITV '08: Proceedings of the European conference on Changing Television Environments, Berlin, Heidelberg: Springer-Verlag, 2008, páginas 61-71.

Hansen, T. R.; BARdram, J. E. ActiveTheatre - A Collaborative, Event-Based Capture and Access System for the Operating Theatre. Em: UbiComp 2005: Ubiquitous Computing, v. 3660 de Lecture Notes in Computer Science, Springer Berlin / Heidelberg, páginas 375-392, 2005.

Hardman, L. Canonical Processes of Media Production. Em: MHC '05: Workshop of the proceedings on Multimedia for Human Communication, New York, NY, USA: ACM, 2005, páginas 1-6.

Harvel, L.; Newstetter, W.; Truong, K.; Abowd, G. Work in progress-supporting automatic capture in problem based learning environments. Em: FIE '04: 34th Annual Frontiers in Education., 2004, páginas 17-21.

IBGE Características gerais da população: Resultado da amostra 2002. Instituto Brasileiro de Geografia e Estatística http://www.ibge.gov.br/home/, censo demográfico (2000), 2000.

Junuzovic, S.; Hegde, R.; Zhang, Z.; Chou, P. A.; Liu, Z.; Zhang, C. Requirements and recommendations for an enhanced meeting viewing experience. Em: Proceedings of International Conference on Multimedia, New York, NY, USA: ACM, 2008, páginas 539-548.

KAlnikait, V.; WhitTaker, S. Social summarization: does social feedback improve access to speech data? Em: Proceedings of the 2008 ACM conference on Computer supported cooperative work, San Diego, CA, USA: ACM, 2008, páginas 9-12.

Kawahara, T.; Hasegawa, M.; Shitaoka, K.; Kitade, T.; NanJo, H. Automatic indexing of lecture presentations using unsupervised learning of presumed discourse markers. IEEE Transactions on Speech and Audio Processing, v. 12, n. 4, páginas 409 $-419,2004$. 
Kientz, J. A.; Hayes, G. R.; Westeyn, T. L.; Starner, T.; Abowd, G. D. Pervasive Computing and Autism. Assisting Caregivers of Children with Special Needs. IEEE Pervasive Computing, v. 6, páginas 28-35, 2007.

Kirk, D.; Sellen, A.; Harper, R.; Wood, K. Understanding videowork. Em: CHI '07: Proceedings of the 28th international conference on Human factors in computing systems, New York, NY, USA: ACM, 2007, páginas 61-70.

Kitchenham, B. Procedures for performing systematic reviews. Relatório Técnico, Keele University and NICTA, 2004.

Kleek, M. V.; Bernstein, M.; Karger, D. R.; Schraefel Gui - phooey!: the case for text input. Em: UIST'O7: Proceedings of the 20th annual Symposium on User Interface Software and Technology, Newport, Rhode Island, USA: ACM, 2007, páginas 193-202.

Kong, C. K.; Muppala, J. K. ReCap: a tool for automated capture and generation of synchronized audio, PowerPoint and digital ink presentation. Em: IASTED: Proceedings of the 10th International Conference on Computers and Advanced Technology in Education, Beijing, China: ACTA Press, 2007, páginas 323-328.

KuiJk, F.; Guimarães, R.; Cesar, P.; Bulterman, D. Adding dynamic visual manipulations to declarative multimedia documents. Em: DocEng '09: Proceedings of the Symposium on Document Engineering, 2009, páginas 149-152.

Lee, D.-S.; Erol, B.; Graham, J.; Hull, J. J.; Murata, N. Portable meeting recorder. Em: MULTIMEDIA '02: Proceedings of the tenth International Conference on Multimedia, New York, NY, USA: ACM, 2002, páginas 493-502.

Li, Y.; CaO, X.; EveritT, K.; Dixon, M.; Landay, J. A. FrameWire: a tool for automatically extracting interaction logic from paper prototyping tests. Em: CHI '10: Proceedings of the 28th international conference on Human factors in computing systems, Atlanta, Georgia, USA: ACM, 2010, páginas 503-512.

LiNS, R. D. Special track on document engineering: editorial message. Em: SAC 'O8: Proceedings of the Symposium on Applied Computing, New York, NY, USA: ACM, 2008, páginas 395-396.

Macedo, A. A.; Baldochi, Jr., L.; Camacho-Guerrero, J. A.; Cattelan, R. G.; PiMENTEL, M. G. C. Automatically linking live experiences captured with a ubiquitous infrastructure. Multimedia Tools and Applications, v. 37, n. 2, páginas 93-115, 2008.

Macedo, A. A.; Camacho-Guerrero, J.; Cattelan, R.; Inácio-Jr, V.; Pimentel, M. G. C. Multimodal Interactions for Linking Everyday Presentations in a Ubiquitous Computing Infrastructure. Em: Webmedia '10: Proceedings of Brazilian Symposium on Multimedia and the Web, 2010, páginas 155-162. 
Macedo, A. A.; Camacho-Guerrero, J. A.; Cattelan, R. G.; Inácio-Jr., V. R.; Pimentel, M. G. C. Interaction alternatives for linking everyday presentations. Em: HYPERTEXT' O4: Proceedings of the fifteenth conference on Hypertext and Hypermedia, New York, NY, USA: ACM, 2004, páginas 112-113.

Manzato, M. G.; Coimbra, D. B.; Goularte, R. Multimedia content personalization based on peer-level annotation. Em: EuroITV '09: Proceedings of the European conference on Interactive Television, New York, NY, USA: ACM, 2009, páginas 57-66.

Mertens, R.; Ketterl, M.; Vornberger, O. Interactive content overviews for lecture recordings. Em: ISM 'O6: Eighth IEEE International Symposium on Multimedia, IEEE Computer Society, 2006, páginas 933 -937.

MikÁC, J.; RoIsin, C.; LE DUC, B. An export architecture for a multimedia authoring environment. Em: DocEng '08: Proceedings of the Symposium on Document Engineering, New York, NY, USA: ACM, 2008, páginas 28-31.

Minneman, S.; Harrison, S.; Janssen, B.; Kurtenbach, G.; Moran, T.; Smith, I.; MELLE, B. A confederation of tools for capturing and accessing collaborative activity. Em: ACM MULTIMEDIA’95, 1995, páginas 523-534.

Miranda, L. C.; Piccolo, L. S. G.; Baranauskas, M. C. C. Artefatos físicos de interação com a TVDI: desafios e diretrizes para o cenário brasileiro. Em: IHC '08: Proceedings of the VIII Brazilian Symposium on Human Factors in Computing Systems, Porto Alegre, RS, Brasil: Sociedade Brasileira de Computaç ao, 2008, páginas 60-69.

Montez, C.; Becker, V. TV Digital Interativa: Conceitos e Tecnologias. Porto Alegre, Brazil, Brazil, 2004, páginas 39 - 77.

Moreno, M. F.; Costa, R. M. R.; SoARes, L. F. G. Sincronismo entre fluxos de mídia contínua e aplicações multimídia em redes por difusão. WebMedia ACM, 2008.

Motti, V. G.; Fagá, JR., R.; Catellan, R. G.; Pimentel, M. G. C.; Teixeira, C. A. Collaborative synchronous video annotation via the watch-and-comment paradigm. Em: EUROITV '09: Proceedings of the European conference on Changing Television Environments, New York, NY, USA: ACM, 2009, páginas 67-76.

NiElsen, J. Multimedia and hypertext: the internet and beyond. San Diego, CA, USA: Academic Press Professional, Inc., 1995.

Nodenot, T.; Loustau, P.; Gaio, M.; Sallaberry, C.; Lopisteguy, P. From electronic documents to problem-based learning environments: an ongoing challenge for educational modeling languages. Em: ITHET '06: Proceedings of International Conference on Information Technology Based Higher Education and Training., IEEE Computer Society, 2006, páginas $280-291$. 
ONS Family spending: a report on the 2000-01 family expenditure survey. london: the stationery office, 2002.

Pedersen, E. R.; McCall, K.; Moran, T. P.; Halasz, F. G. Tivoli: an electronic whiteboard for informal workgroup meetings. Em: CHI'93: Proceedings of the INTERACT '93 and CHI '93 conference on Human factors in computing systems, New York, NY, USA: ACM, 1993, páginas 391-398.

Pedrosa, D. C.; Martins JR., J. A. C.; Melo, E. L.; Pimentel, M. G. C. Componente de interação multimodal no Ginga. Em: Webmedia '10: Adjunt proceedings of Brazilian Symposium on Multimedia and the Web, Belo Horizonte, 2010, páginas 197-202.

Piccolo, L. S. G.; Baranauskas, M. C. C. Desafios de design para a tv digital interativa. Em: IHC '06: Proceedings of VII Brazilian Symposium on Human factors in computing systems, New York, NY, USA: ACM, 2006, páginas 1-10.

Pimentel, M. G. C.; Abowd, G. D.; Ishiguro, Y. Linking by interacting: a paradigm for authoring hypertext. Em: HYPERTEXT 'OO: Proceedings of the eleventh ACM on Hypertext and hypermedia, New York, NY, USA: ACM, 2000, páginas 39-48.

Pimentel, M. G. C.; Baldochi-Jr, L. A.; Cattelan, R. G. Prototyping Applications to Document Human Experiences. IEEE Pervasive Computing, v. 6, n. 2, páginas 93100, 2007a.

Pimentel, M. G. C.; Goularte, R.; Cattelan, R. G.; Santos, F. S.; Teixeira, C. Enhancing multimodal annotations with pen-based information. Em: ISMW '07: Proceedings of the Ninth IEEE International Symposium on Multimedia Workshops, Washington, DC, USA: IEEE Computer Society, 2007b, páginas 207-213.

Pimentel, M. G. C.; Goularte, R.; Cattelan, R. G.; Santos, F. S.; Teixeira, C. Ubiquitous interactive video editing via multimodal annotations. Em: EUROITV '08: Proceedings of the European conference on Interactive Television., Berlin, Heidelberg: Springer-Verlag, 2008, páginas 72-81.

Pimentel, M. G. C.; Ishiguro, Y.; Kerimbaev, B.; Abowd, G.; Guzdial, M. Supporting educational activities through dynamic web interfaces. Interacting with Computers, páginas 353-374, 2001.

Pimentel, M. G. C.; Prazeres, C.; Ribas, H.; Lobato, D.; TeiXeira, C. Documenting the pen-based interaction. Em: WebMedia '05: Proceedings of the Brazilian Symposium on Multimedia and the web, New York, NY, USA: ACM, 2005, páginas 1-8.

Reynolds, D.; Torres-CARrasguillo, P. Approaches and applications of audio diarization. Em: Acoustics, Speech, and Signal Processing, 2005. Proceedings. (ICASSP 'O5). IEEE International Conference on, 2005, páginas v/953 - v/956 Vol. 5. 
Richter, H. A.; Abowd, G. D.; Geyer, W.; DaiJavad, S.; Fuchs, L.; Poltrock, S. Integrating meeting capture within a collaborative team environment. Georgia Institute of Technology, 2001.

Rigamonti, M.; LAiAnne, D.; Ingold, R. Faericworld: Browsing multimedia events through static documents and links, v. 4662 LNCS. Berlin, Heidelberg: SpringerVerlag, 102-115 páginas, 2007.

Rui, Y.; Rudolph, E.; He, L.; Malvar, R.; Cohen, M.; TAShev, I. PING: a group-toindividual distributed meeting system. Em: Multimedia and Expo, 2006 IEEE International Conference on, 2006, páginas 1141-1144.

SAntos, C. T. P.; SAntos, C. A. S. 5Cam: a multicamera system for panoramic capture of videos. Em: WebMedia '06: Proceedings of the Brazilian Symposium on Multimedia and the web, New York, NY, USA: ACM, 2006, páginas 99-107.

Schneiderman, H.; Kanade, T. A statistical method for 3d object detection applied to faces and cars. Computer Vision and Pattern Recognition, 2000. Proceedings. IEEE Conference on, páginas 746-751 vol.1, 2000.

Sgouros, N. M.; MARgaritis, A. Towards open source authoring and presentation of multimedia content. Em: HCM '07: Proceedings of the international workshop on Human-centered multimedia, New York, NY, USA: ACM, 2007, páginas 41-46.

SHAKSHUKI, E.; HALlidAY, R. An algorithm explanation agent for the SHALEX system. Em: Proceedings of the 10th International Conference on Information Integration and Web-based Applications and Services, iiWAS 2008, 2008, páginas 292-298.

Shamma, D. A.; Kennedy, L.; Churchill, E. F. Tweet the debates: understanding community annotation of uncollected sources. Em: WSM '09: Proceedings of the first SIGMM workshop on Social media, New York, NY, USA: ACM, 2009, páginas 3-10.

ShI, Y.; XIE, W.; Xu, G.; ShI, R.; Chen, E.; MAO, Y.; LIU, F. The smart classroom: Merging technologies for seamless tele-education. IEEE Pervasive Computing, v. 2, n. 2, páginas 47-55, 2003.

SoAres, Luiz, F. G.; Rodrigues; Rogério, F.; Moreno, M. F. Ginga - NCL: the Declarative Environment of the Brazilian Digital TV System. Biblioteca Digital Sociedad Brasilera de Computação http://bibliotecadigital.sbc.org.br/download. php?paper=624, departamento de Informática - PUC-Rio, 2007.

SoAres, L. F. G.; Rodrigues, R. F.; BARbosA, S. D. J. Manual de construção de programas audiovisuais interativos utilizando a NCL 2.3 Perfil Básico. 1a edição edPUC RIO, 2006. 
Soares, L. F. G.; Rodrigues, R. F.; Cergueira, R.; Barbosa, S. D. J. Variable handling in time-based XML declarative languages. Em: ACM SAC '09: Proceedings of the Symposium on Applied Computing, New York, NY, USA: ACM, 2009a, páginas $1821-1828$.

Soares, L. F. G.; Rodrigues, R. F.; Cergueira, R.; Barbosa, S. D. J. Variable handling in time-based XML declarative languages. Em: ACM SAC '09: Proceedings of the Symposium on Applied Computing, New York, NY, USA: ACM, 2009b, páginas 1821-1828.

SolAR, J. R.-D. Personal robots as ubiquitous-multimedial-mobile web interfaces. Em: Web Conference, 2007. LA-WEB 2007. Latin American, 2007, páginas 120 -127.

Steimle, J.; BrdiczKa, O.; Muhlhauser, M. Coscribe: Integrating paper and digital documents for collaborative knowledge work. Learning Technologies, IEEE Transactions on, v. 2, n. 3, páginas $174-188,2009$.

Streitz, N. A.; Geissler, J.; HaAke, J. M.; Hol, J. Dolphin: integrated meeting support across local and remote desktop environments and liveboards. Em: CSCW '94: Proceedings of the 1994 ACM conference on Computer supported cooperative work, New York, NY, USA: ACM, 1994, páginas 345-358.

Teixeira, C. A.; Melo, E. L.; Cattelan, R. G.; Pimentel, M. G. C. Taking advantage of contextualized interactions while users watch tv. Multimedia Tools and Applications, v. 50, páginas 587-607, 2010a.

Teixeira, C. A. C.; Freitas, G. B.; Pimentel, M. G. C. Distributed discrimination of media moments and media intervals: a watch-and-comment approach. Em: ACM SAC'10, 2010b, páginas 1929-1935.

Terken, J.; Sturm, J. Multimodal support for social dynamics in co-located meetings. Personal Ubiquitous Comput., v. 14, páginas 703-714, 2010.

TRUONG, K.; ABOwD, G. Inca a software infrastructure to facilitate the construction and evolution of ubiquitous capture access applications. In Proceedings of the 2004 International Conference on Pervasive Computing, páginas 140,157, 2004.

Truong, K. N.; Abowd, G. D.; Brotherton, J. A. Who, what, when, where, how: Design issues of capture \& access applications. Ubicomp 2001: Ubiquitous Computing, v. Volume 2201/2001, páginas 209-224, 2001.

Truong, K. N.; Hayes, G. R. Ubiquitous computing for capture and access. Found. Trends Hum.-Comput. Interact., v. 2, n. 2, páginas 95-171, 2009.

Tucker, S.; Whittaker, S. Accessing Multimodal Meeting Data: Systems, Problems and Possibilities. Em: Proc. Work. Machine Learning for Multimodal Interaction, 2004, páginas $1-11$. 
Vega-Oliveros, D. A.; Martins, D. S.; Pimentel, M. G. C. Interactors: operators to automatically generate interactive multimedia documents from captured media. Em: Webmedia '10: Proceedings of Brazilian Symposium on Multimedia and the Web, Belo Horizonte, MG, Brasil: ACM, 2010a, páginas 163-170.

Vega-Oliveros, D. A.; Martins, D. S.; Pimentel, M. G. C. "This conversation will be recorded": automatically generating interactive multimedia documents from captured media. Em: DocEng '10: Proceedings of the Symposium on Document Engineering, ACM, 2010b.

Vega-Oliveros, D. A.; Martins, D. S.; Pimentel, M. G. C. Media-oriented operators for authoring interactive multimedia documents generated from capture sessions. Em: SAC'11: Proceedings of the Symposium on Applied Computing, New York, NY, USA: ACM, 2011 a, páginas 1267-1272.

Vega-Oliveros, D. A.; Martins, D. S.; Pimentel, M. G. C. Viewing by interactions: Media-oriented operators for reviewing recorded sessions on tv. Em: EUROITV'11: Proceedings of the European Conference on Changing Television Environments, New York, NY, USA: ACM, 2011b.

Vega-Oliveros, D. A.; Pedrosa, D. D. C.; Pimentel, M. G. C.; Goularte, R. Video navigation based on recent frames. Em: Webmedia '09: Proceedings of Brazilian Symposium on Multimedia and the Web, Fortaleza, CE, Brasil: ACM, 2009, páginas 15-19.

Vega-Oliveros, D. A.; Pedrosa, D. D. C.; Pimentel, M. G. C.; Mattos Fortes, R. An approach based on multiple text input modes for interactive digital tv applications. Em: SIGDOC '10: Proceedings of the 28th ACM International Conference on Design of Communication, New York, NY, USA: ACM, 2010c, páginas 191-198.

WAng, F.; NGO, C.; POng, T. Structuring low-quality videotaped lectures for crossreference browsing by video text analysis. Pattern Recognition, v. 41, n. 10, páginas 3257-3269, 2008.

Westermann, U.; JAIN, R. rm E - a generic event model for event-centric multimedia data management in echronicle applications. Em: Data Engineering Workshops, 2006. Proceedings. 22nd International Conference on, 2006, páginas x106 -x106.

Whittaker, S.; Tucker, S.; Swampillai, K.; Laban, R. Design and evaluation of systems to support interaction capture and retrieval. Personal and Ubiquitous Computing, v. 12, n. 3, páginas 197-221, 2007.

Wright, P. C.; Monk, A. F. The use of Think-Aloud Evaluation Methods in Design. SIGCHI Bull., v. 23, n. 1, páginas 55-57, 1991. 
Wu, C.-I.; James Teng, C.-M.; Chen, Y.-C.; Lin, T.-Y.; Chu, H.-H.; Hsu, J. Y.-J. Point-of-capture archiving and editing of personal experiences from a mobile device. Personal Ubiquitous Comput., v. 11, n. 4, páginas 235-249, 2007.

YU, Z.; NAKAMURA, Y. Smart meeting systems: A survey of state-of-the-art and open issues. ACM Computing Surveys, v. 42, n. 2, páginas 1-20, 2010.

Yu, Z.; Yu, Z.; Zhou, X.; Becker, C.; Nakamura, Y. Tree-based mining for discovering patterns of human interaction in meetings. IEEE Transactions on Knowledge and Data Engineering, v. 99, n. PrePrints, 2010a.

YU, Z.; YU, Z.; ZHOU, X.; NAKAMURA, Y. Multimodal sensing, recognizing and browsing group social dynamics. Personal Ubiquitous Comput., v. 14, páginas 695-702, 2010b.

YuAN, S.; TABARD, A.; MACKAY, W. StreamLiner: A General-Purpose Interactive Course-Visualization Tool. Em: KAM '08: Workshop of IEEE International Symposium on Knowledge Acquisition and Modeling., IEEE Computer Society, 2008, páginas $915-919$.

Zucker, D. F.; Bulterman, D. C. A. Open standard and open sourced SMIL for interactivity. interactions, v. 14, n. 6, páginas 41-46, 2007. 



\section{Operadores de Interação nas Aplicações de Captura e Acesso}

Neste apêndice são apresentadas a elaboração e a condução de uma revisão sistemática (Kitchenham, 2004) da literatura realizada em 2010, com o objetivo de identificar estudos primários relacionados ao tema de captura, geração e extração de eventos de interação para facilitar o acesso de mídias capturadas das aplicações de C\& A. Dentre as metodologias existentes para a condução do estudo, foi utilizada a sugerida por Biolchini et al. (2007). A revisão se insere na proposta geral do trabalho de mestrado como uma forma de identificar e classificar os diferentes operadores-eventos de interação e os mecanismos de geração e visualização usados na área para a definição do modelo proposto.

O planejamento, a condução e o análises dos estudos encontrados na revisão sistemática são apresentados no apêndice A.1; e o apêndice 2.4 mostra a classificação dos estudos primários.

\section{A.1 Eventos de Interação: Uma Revisão Sistemática}

Uma revisão sistemática da literatura é uma maneira de identificar, avaliar e interpretar todas as informações relevantes de pesquisa disponíveis para uma questão específica, ou área-tópico, ou fenômeno de interesse. Os estudos individuais que contribuem para uma revisão sistemática são chamados de estudos primários e a revisão sistemática vem a ser um estudo secundário (Kitchenham, 
2004). Dada a diferença entre uma revisão da literatura e o desenvolvimento de uma revisão sistemática é requerido ao pesquisador estabelecer um protocolo mais formal e controlado para condução da investigação (Biolchini et al., 2007), com o objetivo de assegurar rigor científico às análises que forem efetuadas.

O principal objetivo da revisão sistemática foi a identificação de trabalhos que usam mecanismos de reconhecimento, captura ou geração de informações relevantes a eventos de interação sobre as mídias capturadas de sistemas de C\&A. Esses índices podem ser úteis como modo de visualização e acesso sobre essas mídias. A revisão também visou à identificação de trabalhos que utilizam alguma forma de visualização, especificamente, na geração (automática ou não) de documentos multimídia interativos. Além dos resultados obtidos ao final da revisão, esta seção também inclui o detalhamento das atividades intermediárias realizadas, sendo elas: o planejamento da revisão (Seção A.1.1), a estratégia adotada para utilizar as máquinas de busca junto com a seleção de trabalhos (Seção A.1.2) e umas primeiras análises dos estudos primários (Seção A.1.3).

\section{A.1.1 Planejamento}

Na etapa de planejamento são definidos os aspectos motivacionais e operacionais necessários para a condução da revisão. O planejamento foi realizado de acordo com o modelo de protocolo apresentado por Biolchini et al. (2007). A seguir são apresentados os principais pontos contidos no documento de protocolo da revisão gerado no planejamento:

Objetivo: O objetivo deste estudo foi obter uma lista classificando os tipos de processamento ou técnicas de extração de índices derivados das mídias, os mecanismos de visualização e acesso frequentemente usados e o domínio de atuação dessas aplicações de C\&A.

Questão: Quais são os métodos, técnicas, e abordagens existentes atualmente na literatura que possam gerar índices para facilitar o acesso às informações contidas nas mídias capturadas de uma sessão, e como é abordado o problema de visualização dos dados capturados?

Palavras-chave e Sinônimos: capture and access applications, C\&A, interactive multimedia documents, automatic authoring, interactive video, Nontextual retrieval methods, Image and multimedia search, content-based search e content-based retrieval.

Efeito: Listar técnicas, métodos e abordagens usadas para gerar índices que sirvam na visualização e no acesso no contexto das aplicações de C\&A, e 
classificar os estudos de acordo com o domínio de aplicação, operadores para a geração de índices e ferramentas de visualização.

Língua de Estudo: Inicialmente foram escolhidas o inglês, o português e o espanhol. Depois de fazer algumas buscas nas fontes, não foram encontrados resultados satisfatórios nas línguas espanhola e portuguesa. Portanto, foram descartadas como língua de estudo. É importante destacar que isto não significa que não existam trabalhos relacionados ao tema nos países falantes destas línguas. A razão pode dever-se ao predomínio do inglês como idioma padrão no mundo acadêmico, fazendo com que a maioria das publicações indexadas esteja nessa língua.

String de Busca: Para a correta definição da string de busca, foram realizados vários testes sobre as bases de dados avaliando a qualidade dos estudos retornados. Foi definida uma string composta por quatro blocos descritos a seguir:

- O primeiro bloco faz referência aos sinônimos para aplicações de C\&A, sessões remotas e web-conferência.

- O segundo bloco foi definido como os sinônimos relacionados ao conceito de documentos multimídia, hipermídia e multimídia interativos.

- Em um terceiro bloco se definiram os sinônimos para a capacidade de navegação, acesso, revisualização e indexação das sessões capturadas.

- Por último, o bloco que estabelece as palavras relacionadas com eventos de interação, operadores de interação e em geral a interação do usuário.

Os quatro blocos foram conectados por operadores lógicos AND, destacando o interesse de encontrar trabalhos que tivessem esses quatro elementos.

Lista de fontes: Artigos disponíveis em bibliotecas digitais. Foram utilizadas as fontes ACM Portal ${ }^{1}$, IEEE Xplore ${ }^{2}$, Springer ${ }^{3}$ e Scopus ${ }^{4}$.

Especificação das Consultas: Foi considerado para todas as consultas que as buscas fossem restritas ao período compreendido entre os anos 2006-2010

Processo de seleção de estudos primários: A seleção dos estudos primários observou as seguintes fases: a) seleção preliminar, na qual os estudos obtidos a partir das fontes de busca especificadas foram inspecionados pelos

\footnotetext{
1 http://portal.acm.org

2http://ieeexplore.ieee.org/Xplore/dynhome.jsp

3http://www.springerlink.com/

4http://www.scopus.com/home.url
} 
abstracts e analisados segundo a conformidade com os critérios de inclusão e exclusão; b) seleção final, na qual os estudos pré-selecionados foram analisados em relação à introdução, resultados e conclusão para avaliar a pertinência dos estudos com os critérios de inclusão e exclusão.

Critérios e Procedimento para a Seleção dos Estudos: Os seguintes critérios de inclusão foram considerados:

I1. métodos e técnicas de acesso usados nos documentos multimídia interativos;

12. métodos e técnicas de geração de marcadores durante a fase de pósprocessamento dos dados;

13. métodos e técnicas de indexação de eventos de interação do usuário;

I4. métodos e técnicas de geração de marcadores durante a fase de captura dos dados;

15. métodos e técnicas de operadores de interação que gerem índices de acesso sobre os dados capturados;

16. métodos e técnicas de operadores de interação que expandam o conteúdo capturado;

I7. métodos e técnicas de autoria/geração automática de documentos multimídia interativos;

18. métodos e técnicas de geração de eventos relacionados com os temas de "Non-textual retrieval methods", "Image and multimedia search", "content-based search", "content-based retrieval";

Os seguintes critérios de exclusão foram considerados:

E1. referenciais teóricos sobre autoria e/ou documentos multimídia;

E2. trabalhos que não ofereçam mecanismos de indexação de eventos;

E3. trabalhos que estejam focados com os outros temas de Engenharia de documentos;

E4. trabalhos que não permitam o acesso/navegação sobre os dados capturados;

E5. trabalhos cujo foco central esteja na captura dos dados;

E6. trabalhos que não ofereçam mecanismos de visualização dos dados;

E7. trabalhos sem resultados ou que não apresentem a informação completa do estudo primário;

Os seguintes critérios de qualidade foram considerados:

Q1. artigos de workshops de teses e dissertações; 
Q2. resumos de palestras e minicursos ministrados em conferências;

Q3. resumos de demos, pôsteres, artigos curtos e sessões de ferramentas;

Q4. introdução a special issues de periódicos;

Q5. cartas de abertura de conferências e periódicos;

Q6. estudos duplicados em relação às diferentes fontes de estudo;

Q7. artigos que não puderam ser acessados;

\section{A.1.2 Condução}

A condução da revisão sistemática foi conduzida no período de março/2010 a Junho/2010, de acordo com o planejamento apresentado nas seções anteriores. A coleta de resultados de todas as fontes ocorreu no dia 15/05/2010. Ao todo, foram recuperados 227 estudos primários, os quais passaram pelas fases de seleção preliminar, seleção final e extração de resultados. Nessa etapa foram realizadas as buscas na literatura por trabalhos relacionados ao tema definido e a leitura dos mesmos. A etapa de condução consistiu das seguintes atividades: execução da busca, seleção dos artigos considerando os critérios de inclusão e exclusão, avaliação da qualidade dos estudos e execução da extração. A seguir são apresentadas as principais atividades realizadas.

Tabela A.1: Seleção preliminar dos trabalhos

\begin{tabular}{|l|r|r|r|r|}
\hline & Aceitos & Rejeitados & Qualidade & Total \\
\hline ACMPortal & 28 & 80 & 11 & 119 \\
\hline IEEExplorer & 15 & 43 & 4 & 62 \\
\hline Springer(SpringerLink) & 3 & 8 & 1 & 12 \\
\hline Scopus & 13 & 12 & 10 & 35 \\
\hline TOTAL & 59 & 143 & 26 & 228 \\
\hline & $\mathbf{2 5 . 8 7 \%}$ & $\mathbf{6 2 . 7 1 \%}$ & $\mathbf{1 1 . 4 0 \%}$ & $\mathbf{1 0 0 \%}$ \\
\hline
\end{tabular}

Inicialmente, foram realizadas as strings de busca, encontrando 227 artigos relacionados, com uma distribuição de artigos por motor de busca de 119 estudos na ACM Portal, 62 estudos na IEEExplorer, 12 estudos na Springer (SpringerLink) e 35 estudos na Scopus, como mostra a coluna Total da Tabela A.1.

Em um primeiro ciclo de filtragem, considerando os critérios de seleção dos estudos mediante análises dos abstracts, foram aprovados na fase preliminar 59 artigos para compor os resultados desta pesquisa. A Tabela A.1, reporta à classificação dos artigos encontrados segundo os motores de busca utilizados. Foi observada uma maior proporção de estudos aceitos para o caso de Scopus, com 13 dos 35 estudos encontrados, representando 37\% de aprovação, diferente dos outros sistemas de busca, os quais não superaram os $25 \%$ de aprovação. 
A Tabela (A.1) também descreve os valores de inclusão, rejeição por critério de exclusão e por critério de qualidade, dos resultados obtidos para cada motor de busca.

Tabela A.2: Seleção final dos trabalhos

\begin{tabular}{|l|r|r|r|r|}
\hline & Seleção Final & Rejeitados & Qualidade & pré-Selecionados \\
\hline \hline ACMPortal & 21 & 4 & 3 & 28 \\
\hline IEEEXplorer & 12 & 3 & 0 & 15 \\
\hline Springer(SpringerLink) & 3 & 0 & 0 & 3 \\
\hline Scopus & 12 & 0 & 1 & 13 \\
\hline TOTAL & $\mathbf{4 8}$ & $\mathbf{7}$ & $\mathbf{4}$ & $\mathbf{5 9}$ \\
\hline \hline
\end{tabular}

Em uma segunda fase, foram analisados os estudos da etapa de pré-seleção analisando as partes de introdução, resultados e conclusões, avaliando a pertinência aos critérios de inclusão e exclusão. Também foi considerado o critério de qualidade 37 , o qual faz referência aos artigos que não puderam ser acessados por causa de limitação de permissões. No total foram rejeitados 11 dos 59 artigos pré-selecionados (Tabela A.2), que representam 21\% dos estudos primários encontrados.

\section{A.1.3 Resultados}

Os artigos selecionados foram classificados de acordo com seus anos de publicação e os motores de busca em que foram disponibilizados para download. Contudo, é preciso filtrar esses estudos segundo as fontes em que foram publicados e não nos sistemas de busca em que foram encontrados. A nova distribuição dos estudos segundo as fontes de publicação é mostrada na Figura A.1.

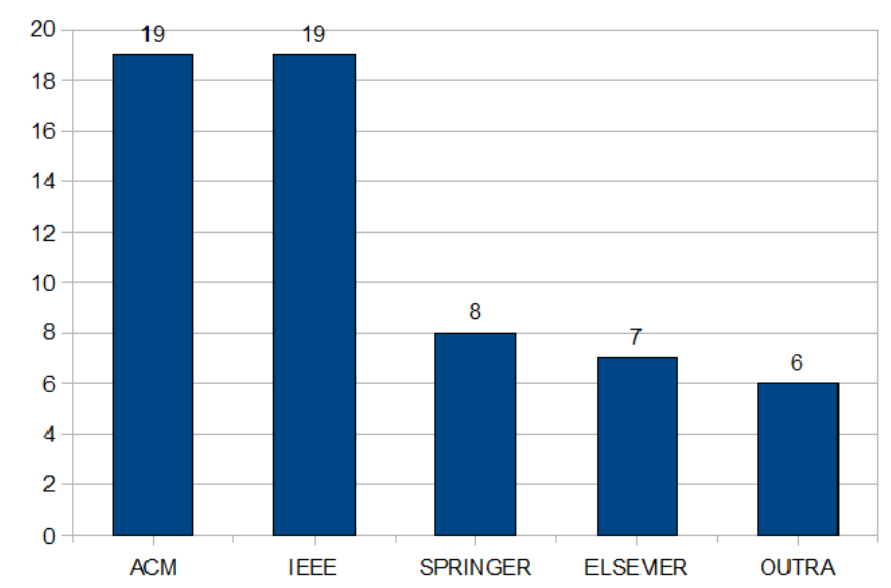

Figura A.1: Distribuição de estudos primários em relação ao tipo de fonte

Alguns artigos selecionados pertencem a outras bibliotecas indexadas que não foram originalmente selecionadas, como MIT Press ou ELSEVIER. Esses estu- 
dos foram encontrados pelos motores de busca selecionados, os quais mapeiam os artigos presentes em suas bibliotecas e nas bibliotecas de outros agentes publicadores. As Fontes ACM e IEEE contam com a mesma quantidade de trabalhos, representando juntas o $64 \%$ dos estudos encontrados. A fonte denominada OUTRA significa todos aqueles estudos cujas fontes de publicação tiveram pouca participação nos trabalhos selecionados. Diferente foi o caso da ELSEVIER, a qual teve uma participação do $12 \%$ do total de estudos selecionados.

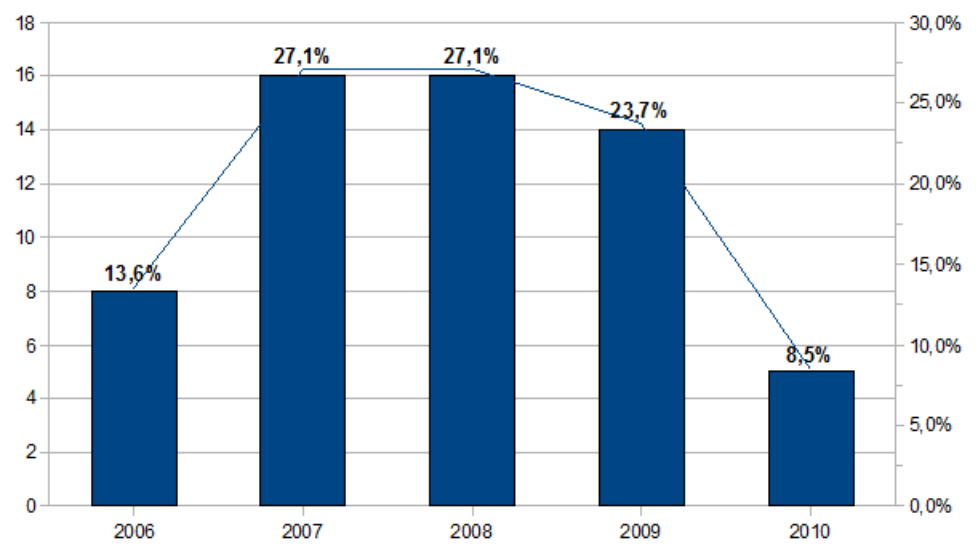

Figura A.2: Distribuição dos estudos primários por ano

Na Figura A.2 é ilustrada a participação de cada fonte no período de 2006 2010. Nesta figura vemos que o maior nível de publicação dos estudos foi realizado entre os anos 2007 e 2008, ambos com uma representação de $27,1 \%$ sobre o total selecionado. No caso do ano 2009, o número de publicações diminuiu com relação aos dois anos anteriores, com uma participação dos estudos primários de 23,7\%. O ano de 2010, embora o levantamento de estudos tenha sido realizado no segundo trimestre do ano, já conta com uma participação do 8,5\%, o que poderia indicar um bom começo para o ano em questão.

Quanto à quantidade de publicação de trabalhos por ano para cada uma das fontes, a Figura A.3 ilustra a distribuição dos estudos primários. Para o caso da $A C M$, vemos que há participações significativas nos anos de 2008 e 2010 . Em 2006 houve a menor participação dentre os estudos selecionados, e em 2007 e 2009 tiveram valores estáveis. Esse comportamento poderia representar um aumento de interesse na publicação de trabalhos deste tipo. Diferente do caso da fonte IEEE, que no ano de 2006 tinha uma participação destacada e foi caindo a quantidade de trabalhos por ano, tanto assim que para o segundo trimestre do 2010, nos estudos primários selecionados, não havia nenhuma participação.

No caso da Springer, foi observada uma participação média nos trabalhos selecionados por ano, tendo como melhor ano de 2009, com uma distribuição 


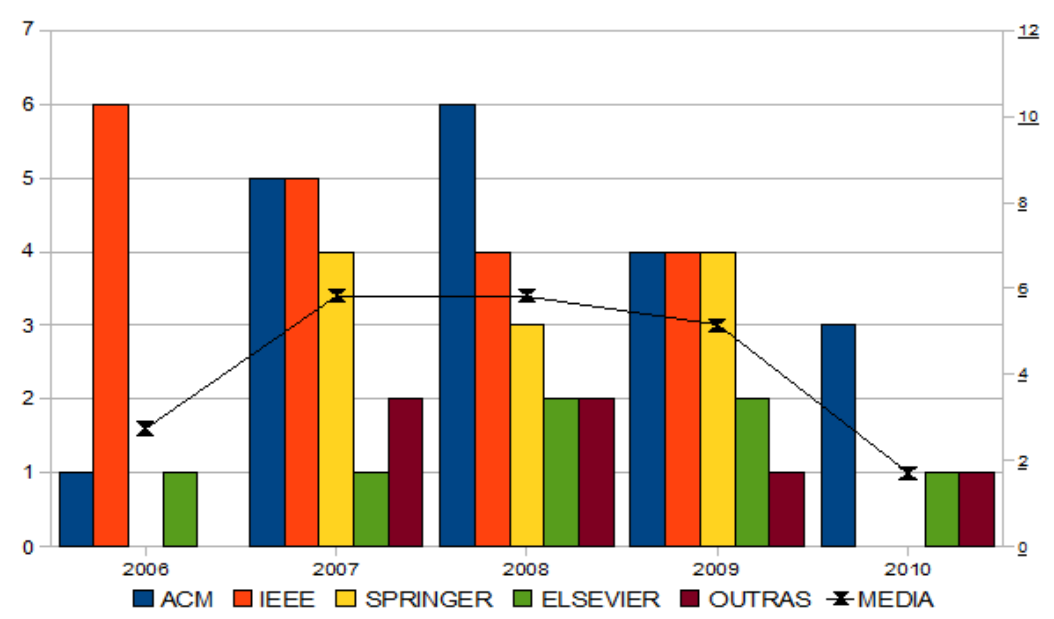

Figura A.3: Distribuição dos estudos primários em relação às fontes por ano. Em sua ordem ACM, IEEE, Springer, Elsevier, Outros e a curva das médias por ano

igual à da ACM e IEEE. Finalmente, a Elsevier apresenta a menor quantidade de trabalhos publicados dentro dos estudos primários selecionados.

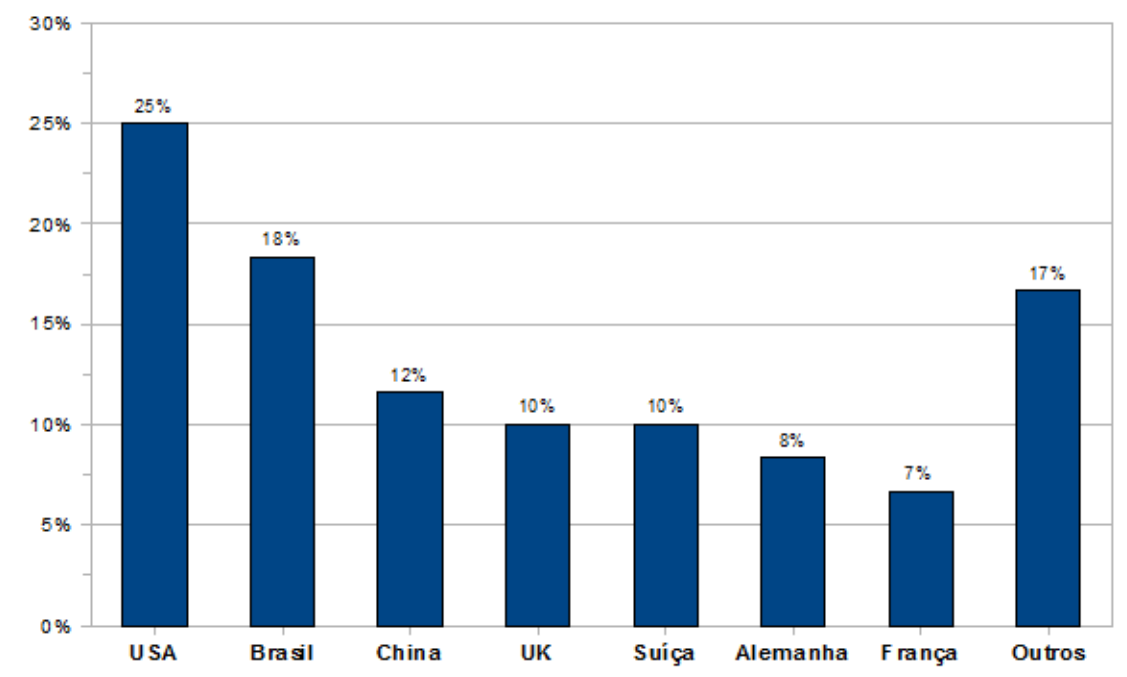

Figura A.4: Distribuição dos estudos primários por países

Também foram analisados os países de residência dos autores dos estudos primários selecionados. Para tal fim, foram extraídos os países das universidades de onde eram os autores de cada um dos estudos. Foi quantificado o número de estudos primários, da seleção final, em que tinha participado algum pesquisador de um dado país.

Na Figura A.4 podemos apreciar que o país com a maior número de estudos foi os Estados Unidos da América (USA), com uma participação de pesquisadores de universidades americanas de $25 \%$ nos trabalhos selecionados, seguido de Brasil, com uma participação de 18\%. A categoria denominada Outros, compreende 
todos os países cuja participação numérica não foi muito representativa nos estudos primários. Entre estes países (em ordem) temos: Espanha, Romênia, Grécia, Índia, Holanda, Chile e Itália.

Finalmente, foi analisada a proporção dos estudos primários selecionados na fase final, relacionados aos critérios de inclusão, definidos na Seção A.1.1. Na Figura A.5 podemos ver que os critérios I2, I6, I7 e I8 foram menos representativos nos estudos selecionados. No caso do critério I2, falamos sobre estudos primários que abordem os métodos e técnicas para geração de marcadores de indexação durante a fase de pós-processamento dos dados. Este critério, com apenas 4\% de participação, indica os poucos trabalhos relacionados ao pósprocessamento das mídias para as aplicações de C\&A. O mesmo aconteceu com o critério I8, que está co-relacionado com o critério I2 ao se tratar das técnicas e métodos de geração de eventos relacionados com os temas de recuperação de informação e buscas no conteúdo nas mídias. Em contra partida, o critério I5 trata das técnicas que geram índices de acesso sobre os dados no momento da captura, situação muito mais comum e simples de resolver ao contar com uma entrada de ação direta dos dados.

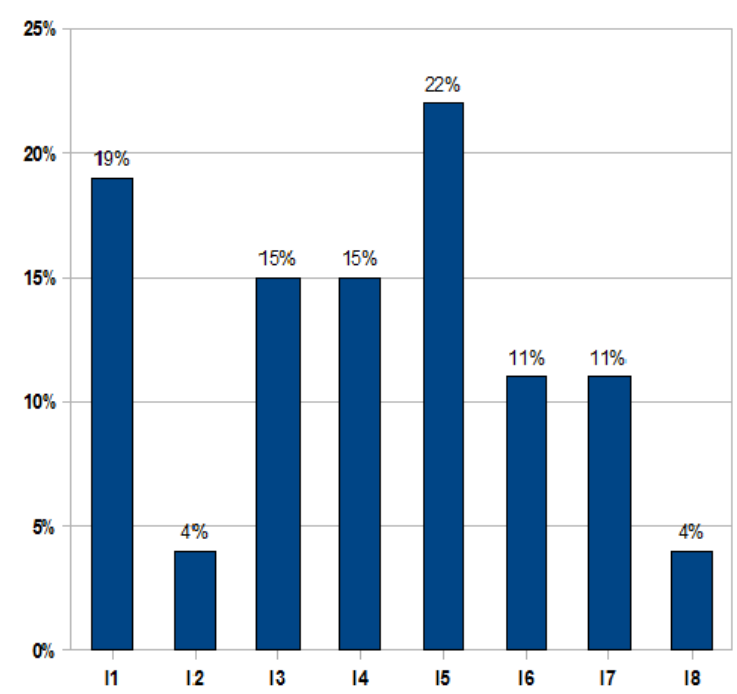

Figura A.5: Distribuição dos critérios de inclusão sobre os estudos primários

No caso dos critérios I6 e I7 se observou que existem poucos estudos que oferecem a possibilidade de criar novos conteúdos (expandir) a partir do conteúdo previamente capturado, e que podem gerar de forma automática documentos multimídia interativos como mecanismo de visualização dos dados. 



$\overline{8}$

\section{Classificação dos Estudos Primarios}

Este apêndice reporta os resultados da fase de seleção final dos artigos encotrados no processo da revisão sistemática. Para cada estudo primário é reportada sua citação, fonte da biblioteca de indexação ao qual pertence, critério de seleção aplicado e observações.

\section{B. 1 Classificação dos estudos por Domínio de Aplicação}

\section{B.1.1 Domínio Educacional}

Foi evidenciado que uma boa parte dos estudos selecionados estão relacionados ao domínio educacional. Os estudos com a correspondente descrição são reportados a seguir:

1. Structuring low-quality videotaped lectures for cross-reference browsing by video text analysis. F. Wang; C.-W. Ngo \& T.-C. Pong. Pattern Recognition. (Wang et al. (2008))

- Conceito de Aceitação: I5

- Fonte: Outra Ano: 2008

- Domínio: Educação a distancia 
- Descrição: Uma câmera captura o vídeo da palestra de um professor junto com os slides projetados em uma tela. Isto é chamado de vídeo leituras. Eles propõem identificar automaticamente as mudanças de slides, o fundo dos slides e o texto contido neles. Também propõem fazer uso da voz do professor para adicionar/encontrar informação semântica que possa ser útil na indexação da do vídeo. Finalmente fazem experimentos e avaliações de 5 vídeo leituras e mostram a acurácia do método proposto.

2. PocketPad: Using Handhelds and Digital Pens to Manage Data in Mobile Contexts. E. Al-Imam \& E. Lank. First International Conference on the Digital Society (ICDS’07). (Al-Imam e Lank (2007))

- Conceito de Aceitação: I5

- Fonte: IEEE Ano: 2007

- Domínio: Educação a distancia usando pocket pc, e pcs

- Descrição: Propõem um software para PDAs que se interconecta com um pc para auxiliar as aulas remotas. O software permite fazer anotações de tinta digital, descarregar os conteúdos da aula e compartilhar informações.

3. A SMIL-based multimedia system for mobile education. J. Di; L. Zhihan; Z. Ligang \& Z. Wei. Broadband Network \& Multimedia Technology, 2009. IC-BNMT '09.. (Di et al. (2009))

- Conceito de Aceitação: I4

- Fonte: IEEE Ano: 2009

- Dominio: Educação móvel

- Descrição: A idéia do artigo é gerar de forma automática um documento multimídia da captura de apresentação que está na tela do PC, para logo ser tocada em um dispositivo móvel, o qual permite aos usuários fazer anotações sobre a sessão capturada.

4. Gui - phooey!: the case for text input. Max Van Kleek \& Michael Bernstein \& David R. Karger \& mc schraefel. Proceedings of the 20th annual ACM symposium on User interface software and technology. (Kleek et al. (2007))

- Conceito de Aceitação: I4

- Fonte: ACM Ano: 2007

- Dominio: Educacional

- Descrição: Eles propõem um sistema cujo objetivo seja abordar da melhor forma a relação entre rápido, baixo custo, captura simples de dados baseada em texto junto com um pouco de captura automática do contexto, e recuperação eficaz de dados baseado no modelo estruturado e interfaces enriquecidas. 
O protótipo desenvolvido, chamado de Jourknow, faz reconhecimento de estruturas e regras no texto, usando técnicas de processamento de linguagem natural e funciona como se fosse uma interface gráfica de uma wiki dinâmica enriquecida. Fazendo uso de algumas heurísticas, divide a sessão por episódios, os quais agrupam informações capturadas que tem alguma relação em um intervalo de tempo específico.

5. ReCap: a tool for automated capture and generation of synchronized audio, PowerPoint and digital ink presentation. Chan Kin Kong \& Jogesh K. Muppala. Proceedings of the 10th IASTED International Conference on Computers and Advanced Technology in Education. (Kong e Muppala (2007))

- Conceito de Aceitação: I7

- Fonte: ACM Ano: 2007

- Dominio: Educacional

- Descrição: Os autores propõem uma ferramenta de captura, de sincronização de áudio, slides de power point e tinta digital, de modo que seja gerada automaticamente um documento multimídia interativo como forma de apresentação. A ferramenta captura o áudio codificando-lo em formato MP3 e identifica os traços de tinta digital e os eventos de interação de tinta do usuário, gerando imagens que são armazenadas como slides e logo sincronizadas usando um documento SMIL para ser apresentado.

6. StreamLiner: A General-Purpose Interactive Course-Visualization Tool. S. Yuan; A. Tabard \& W. Mackay. Knowledge Acquisition and Modeling Workshop, 2008. KAM Workshop 2008. IEEE International Symposium on. (Yuan et al. (2008))

- Conceito de Aceitação: I5

- Fonte: IEEE Ano: 2008

- Dominio: Educacional

- Descrição: Um modelo de indexação de documentos com varias formas de visualização dependendo do rol ( professor, aluno, tutor). O documento é estático e o protótipo adiciona uma linha de tempo para poder acessar a informação de acordo à data e hora que foi criada. Também permite que o professor receba por RSS informação sobre as últimas atualizações realizadas.

7. An Algorithm Explanation agent for the SHALEX system. E.M. Shakshuki \& R. Halliday. Proceedings of the 10th International Conference on Information Integration and Web-based Applications \& Services. (Shakshuki e Halliday (2008))

- Conceito de Aceitação: I5 
- Fonte: ACM Ano: 2008

- Dominio: Educacional

- Descrição: Propõe um ambiente chamado SHALEX. Este ambiente monitora as interações dos usuários baseada na navegação e os eventos de click sobre os links da ferramenta. O ambiente tem um agente que recebe estas informações e determina o estagio e os avances acadêmicos dos estudantes.

8. An automatic linking service of document images reducing the effects of OCR errors with latent semantics. Renato F. Bulcão-Neto; José Camacho-Guerrero; Álvaro Barreiro; Javier Parapar \& Alessandra A. Macedo. Proceedings of the 2010 ACM Symposium on Applied Computing. (Bulcão-Neto et al. (2010))

- Conceito de Aceitação: I3

- Fonte: ACM Ano: 2010

- Dominio: Educacional

- Descrição: O paper apresenta o LinkDI (Linking of Document Images Service), um protótipo que permite fazer reconhecimento de imagens via algoritmos OCR apoiado na técnica LSI (Latent Semantic Indexing). Desta forma, consegue indexar de forma precisa vários tipos de imagens, fornecendo informações adicionais as aplicações de captura e acesso, como no caso do iClass.

9. Exploring many-to-one speech-to-text correlation for web-based language learning. H.-Y. Chen \& S.-W. Li. ACM Transactions on Multimedia Computing, Communications and Applications. (Chen e Li (2007))

- Conceito de Aceitação: I1

- Fonte: ACM Ano: 2007

- Dominio: Educacional

- Descrição: Partindo da captura previa de vídeos de pessoas falando, sincroniza o áudio com o movimento dos lábios, além de recuperar a voz para texto. Depois passa a sincronizar estes elementos fazendo uso de um documento multimídia interativo. Foi criado um player para este documento multimídia, o qual permite varias formas de navegação pelo conteúdo, acesso aleatório aos dados, fácil visualização das mídias, entre outras.

10. Hyperstories and social interaction in 2D and 3D edutainment spaces for children. Franca Garzotto \& Matteo Forfori. Proceedings of the seventeenth conference on Hypertext and hypermedia. (Garzotto e Forfori (2006))

- Conceito de Aceitação: I1

- Fonte: ACM Ano: 2006

- Dominio: Educacional 
- Descrição: Fazem uso de um software especializado chamado FaTe2, abordam o ensino para crianças usando interfaces 2D e 3D. Eles explicam que uma hipernavegação e um hiperdocumento como é entendido por um adulto, tem limitações que podem dificultar o uso e entendimento para uma criança. Também abordam os conceitos de espaços de interação com as crianças, junto com o hypertexto multimídia interativo.

11. Inkteractors: interacting with digital ink. Renan G. Cattelan; Cesar Teixeira; Heider Ribas; Ethan Munson \& Maria Pimentel. Proceedings of the 2008 ACM symposium on Applied computing. (Cattelan et al. (2008b))

- Conceito de Aceitação: I6

- Fonte: ACM Ano: 2008

- Domínio: Educacional

- Descrição: Os Inkteractors são definidos como os operadores de interação de tinta digital. Podem ser divididos em filtros e expansores, alem de classificarse baseados no tempo, na posição, nos atributos, e em ação. Propõem quatorze inkteractors para apoio das interações via caneta eletrônica, para assim conseguir gerar e acessar de forma simples os dados.

12. Prototyping Applications to Document Human Experiences. M. G.C Pimentel; R. G Cattelan \& L. S Baldochi. Pervasive Computing, IEEE. (Pimentel et al. (2007a))

- Conceito de Aceitação: I1

- Fonte: IEEE Ano: 2007

- Dominio: Educacional

- Descrição: Apresentam dois protótipos: M4Note, uma ferramenta de captura de dados multimodais (tinta, texto, áudio e vídeo). Permite eventos de interação de entrada e fazer anotações de áudio e de tinta digital. Reconhece alguns comandos de fala e também reconhece o texto contido nos traços de tinta digital. O segundo protótipo é o eClass, uma ferramenta síncrona presencial de sala de aula instrumentada que permite a interação dos alunos com a smartboard do professor, por meio de tablets-PC.

13. Social summarization: does social feedback improve access to speech data?. Vaiva Kalnikaité \& Steve Whittaker. Proceedings of the 2008 ACM conference on Computer supported cooperative work. (Kalnikait e Whittaker (2008))

- Conceito de Aceitação: I4

- Fonte: ACM Ano: 2008

- Domínio: Educacional 
- Descrição: Eles estendem a noção de tagging social para a construção de sumários sociais de materiais multimédia complexos. Nosso sistema permite que os alunos indexem em relação do tempo multimédia, tais como anotações de tinta ou fotografias de diferentes partes de gravações de aula. Estas marcações podem ser usadas para o fácil acesso de diferentes partes da sessão gravada. O componente social da interface apresenta informações sobre quais as marcações que são mais freqüentemente acessados por outros: permitir que os alunos conheçam as partes da palestra de maior interesse para os outros. Eles demonstram a utilidade da abordagem em 6 estudo de campo a semana. resumos Social são usados muito mais do que os sistemas correspondentes que não fornecem informações sociais. Além disso, use a ferramenta social foi correlacionado com marcas de alto curso.

14. The importance of participant interaction in online environments. J. B. Arbaugh \& Raquel Benbunan-Fich. Decision Support Systems. (Arbaugh e BenbunanFich (2007))

- Conceito de Aceitação: I5

- Fonte: Outra Ano: 2007

- Domínio: Educacional

- Descrição: Eles propõem um estudo sobre a importância da interação entre o aprendiz - professor, aprendiz - aprendiz e aprendiz - sistema, para assim descobrir quais estão diretamente relacionadas com a evolução do estudante. O estudo conclui que os estudantes mais comprometidos como sistemas remotos de aprendizagem tendem a estar mais satisfeitos e reportam melhor percepção do aprendizagem. Também concluem que enquanto os ambientes colaborativos foram associados com maiores níveis de interação aprendiz-sistema e aprendiz-aprendiz, somente as interações aprendiz-professor e aprendizsistema foram significativamente associadas com o aumento da percepção do aprendizagem.

15. rm E - A Generic Event Model for Event-Centric Multimedia Data Management in eChronicle Applications. U. Westermann \& R. Jain. Learning Technologies, IEEE Transactions on. (Westermann e Jain (2006))

- Conceito de Aceitação: I3

- Fonte: IEEE Ano: 2009

- Domínio: Educacional Conexão remota e colaborativa de tabletpc

- Descrição: Apresentam um protótipo robusto que permite a interação direta de caneta eletrônica com papel, capturando as interações, identificando o texto (reconhecimento de símbolos) criando os links em documentos estáticos. 
16. A Lightweight Open Space for the Classroom - Collaborative Learning with Whiteboards and Pen-Tablets. H. Breuer; C. Sousa; N. Baloian \& M. Matsumoto. Advanced Learning Technologies, 2007. ICALT 2007. . (Breuer et al. (2007))

- Conceito de Aceitação: I1

- Fonte: IEEE Ano: 2007

- Dominio: Educacional Conexão remota e colaborativa de tablets-pc

- Descrição: Propõem uma arquitetura/modelo, que foi testada por meio de um protótipo o qual permite que os estudantes de uma sala de aula, fazendo uso de tablets pc, possam interatuar com o que o professor tem na lousa eletrônica de forma colaborativa.

17. Interactive Content Overviews for Lecture Recordings. Robert Mertens; Markus Ketterl \& Oliver Vornberger. Proceedings of the Eighth IEEE International Symposium on Multimedia (ISM'06). (Mertens et al. (2006))

- Conceito de Aceitação: I3

- Fonte: IEEE Ano: 2006

- Domínio: Educacional, apresentações e vídeo-leituras

- Descrição: Foi proposto um modelo para converter uma sessão de leitura gravada em um documento multimídia FLASH ou usando animações SVG. Está baseado na paradigma "linking by interacting"usando documentos multimídia. No caso dos slides, podem ser convertidos a SVG para logo ser passados a Power-Point

18. DocMIR: An automatic document-based indexing system for meeting retrieval. A. Behera; D. Lalanne \& R. Ingold. Multimedia Tools and Applications. (Behera et al. (2007))

- Conceito de Aceitação: I5

- Fonte: Springer Ano: 2008

- Domínio: Educacional, comercial e organizacional

- Descrição: O projeto apresenta um sistema totalmente automatizado chamado (DocMIR) que suporta captura de videoconferências baseada indexação e recuperação de documentos. Consiste em 3 grandes ferramentas: A ferramenta de captura, a de análises e indexação e a de recuperação. Estas ferramentas podem ser usadas em vários tipos de cenários como reuniões, leituras, seminários, etc. A ferramenta de recuperação permite aos usuários a navegação (acesso) linear ou não linear no conteúdo capturado, e arquiva os documentos de áudio e vídeo baseado em um documento de dados extraídos durante a fase de pós-processamento, permitindo buscas no conteúdo. 
Tudo isto, considerando a baixa resolução dos dados, já que são capturados fazendo uso de câmeras web.

19. Watch-and-comment as a paradigm toward ubiquitous interactive video editing. Renan G. Cattelan; Cesar Teixeira; Rudinei Goularte \& Maria Da Graça C. Pimentel. ACM Transactions on Multimedia Computing, Communications, and Applications (TOMCCAP). (Cattelan et al. (2008a))

- Conceito de Aceitação: I6

- Fonte: ACM Ano: 2008

- Domínio: Educacional, entretenimento

- Descrição: O paradigma WAC consiste em poder fazer anotações em um video em quanto se está assistindo. Propõem que sejam realizadas as anotações de forma ubíqua usando tinta digital e áudio para não atrapalhar o vídeo. Estas anotações podem ser colaborativas, o que faz mais interessante anotar e compartilhar a informação. Finalmente, geram documentos multimídia interativos em SMIL e NCL, mas o vídeo interativo não mostra alternativas de acesso ao conteúdo.

20. WMA: A Marking-Based Synchronized Multimedia Tutoring System for English Composition Studies. Herng-Yow Chen \& Kuo-Yu Liu. Multimedia IEEE Transactions. (Chen e Liu (2009))

- Conceito de Aceitação: I5

- Fonte: IEEE Ano: 2009

- Dominio: Educacional. Ensino de inglês

- Descrição: O sistema Web-based Multimedia Annotation (WMA), tem como objetivo o melhoramento das habilidades de escrita do inglês como segunda língua.

21. From electronic documents to problem-based learning environments: An ongoing challenge for educational modeling languages. T. Nodenot; P. Loustau; M. Gaio; C. Sallaberry \& P. Lopistéguy. Information Technology Based Higher Education and Training, 2006. ITHET '06. 7th International Conference on . (Nodenot et al. (2006))

- Conceito de Aceitação: I7

- Fonte: IEEE Ano: 2006

- Domínio: Educacional. Linguagem de modelamento no domínio de LMS

- Descrição: Os autores propõem um modelos de linguagem chamado CPM que ajuda a resolver os problemas dos alunos baseados em baixa taxa de aprendizagem. Eles fazem extração a posteriori de informação semântica dos 
documentos eletrônicos, a qual está relacionada com a localização espaçotemporal do usuário,

22. Exploring Multimedia Correlation and Synchronization for Web-Based Language Learning. Herng-Yow Chen \& Kuo-Yu Liu. Multimedia, IEEE . (Chen e Liu (2006))

- Conceito de Aceitação: I7

- Fonte: IEEE Ano: 2006

- Dominio: Educacional. Ensino de inglês

- Descrição: O projeto Web-based Synchronized Multimedia Lecture (WSML) foi desenvolvido para o aprendizagem de inglês de alunos chineses Tem como objetivo oferecer conteúdos multimídia interativos e propõem uma nova linguagem chamada WSML. No projeto sincronizam (palavra por palavra) o texto guia da lição junto com o correspondente áudio. Também sincronizam as anotações/correções do professor sobre os trabalhos entregues pelos alunos, destacando os erros cometidos.

\section{B.1.2 Domínios de Reuniões e Trabalho de Escritório}

Este conjunto representa os estudos que visam auxiliar a captura e o acesso das informações geradas nos ambientes de reuniões e/ou trabalho de escritório ou de mesa. Os estudos com a correspondente descrição e sub-classificação, são reportados a seguir:

1. DocuDesk: An interactive surface for creating and rehydrating many-to-many linkages among paper and digital documents. K. M Everitt; M. R Morris; A. J.B Brush \& A. D Wilson. Horizontal Interactive Human Computer Systems, 2008. TABLETOP 2008. (Everitt et al. (2008))

- Conceito de Aceitação: I5

- Fonte: IEEE Ano: 2008

- Domínio: trabalho de mesa, escritório

- Descrição: DocuDesk é um protótipo que permite aos usuários trabalhar com documentos físicos e eletrônicos ao mesmo tempo. Ele tem uma especie de escaner que captura a imagem do documento físico e permite que possam ser adicionados (conetados) outros documentos eletrônicos a este conteúdo Pode ser enviado por email, pode ser selecionados trechos,fazer comentários.. e o programa guarda o estado do trabalho. Quando se quer voltar a trabalhar sobre o documento é simplesmente colocá-lo novamente no DocuDesk e ele automaticamente identifica o trabalho anterior e carrega todo o q tinha sido realizado, na última versão. 
2. FaericWorld: Browsing multimedia events through static documents and links. M. Rigamonti; D. Laianne \& R. Ingold. Human-Computer Interaction - INTERACT 2007. (Rigamonti et al. (2007))

- Conceito de Aceitação: I6

- Fonte: Springer Ano: 2007

- Domínio: trabalho de mesa, escritório

- Descrição: O trabalho analisa os links e relações entre documentos, como se fosse uma rede social, e permite a correta navegação (browsing) e acesso dos documentos relacionados mediante o uso de "query"de busca. Eles fortalecem o processo de descoberta de informação por médio das relações dos links e os meta dados contidos nas mídias Propõe uma nova forma de busca e visualização de links e conteúdos

3. FrameWire: a tool for automatically extracting interaction logic from paper prototyping tests. Yang Li \& Xiang Cao \& Katherine Everitt \& Morgan Dixon \& James A. Landay. Proceedings of the 28th international conference on Human factors in computing systems. (Li et al. (2010))

- Conceito de Aceitação: I3

- Fonte: ACM Ano: 2010

- Domínio: trabalho de mesa, escritório

- Descrição: Os autores propõem um modelo em que o usuário interage diretamente com com o papel e usando tinta eletrônica. O sistema permite que sejam escaneados documentos e criadas conexões e links de forma fácil, usando uma interface dispositivos de reconhecimento de tacto. Podem ser realizadas anotações sobre os documentos e recuperadas de forma aleatória.

4. An approach for the capture of context-dependent document relationships extracted from Bayesian analysis of users' interactions with information. D.R. Campbell; S.J. Culley; C.A. McMahon \& F. Sellini. Information Retrieval. (Campbell et al. (2007))

- Conceito de Aceitação: I2

- Fonte: Springer Ano: 2007

- Domínio: trabalho de mesa, escritório

- Descrição: A ideai é usar a técnica de classificação naíve bayes para identificar as conexões e os clusters entre os documentos que o usuário esta acessando. Ele propõe que documentos de internet, janelas dos sistema operacional e documentos (files) possam ser monitorados pelo sistema para logo encontrar os pontos de interesse do usuário e a relação entre os documentos. 
Para isto, usa os eventos de navegação que gera o sistema operacional (S.O) fazendo uma captura automatizada dos dados.

5. Estimation of behavioral user state based on eye gaze and head pose-application in an e-learning environment. S. Asteriadis; P. Tzouveli; K. Karpouzis \& S. Kollias. Multimedia Tools and Applications. (Asteriadis et al. (2009))

- Conceito de Aceitação: I3

- Fonte: Springer Ano: 2009

- Dominio: Trabalho de mesa, Reuniões

- Descrição: Eles propõem um modelo de representação de emoções que identificam o engajamento do usuário associado com o "prazer"e "emoção", o que pode ser interessante em vários domínios. Também apresentam um sistema usado no contexto de HCI para extrair o grau de interesse e envolvimento dos alunos na leitura de documentos via tela de computador. Usa uma câmera web para capturar o estado de ânimo dos usuários, fazendo que o sistema seja não-invasivo e em tempo real, sendo útil em aplicações onde a espontaneidade e o comportamento natural primam sobre as condições do ambiente. A partir deste modelo implementaram um sistema que é utilizado para correlacionar o desempenho e os hábitos de leitura de crianças que apresentam indícios de dislexia, para assim fornecer um feedback mensurável sobre o seu progresso.

\section{B.1.3 Outros Domínios}

Este conjunto agrupa os estudos cujos domínios foram pouco representativos no estudos selecionados nesse relatório. Dentre os trabalhos encontrados temos como subconjuntos estudos relacionados com o domínio dos diários pessoais, da robótica, da saúde, da web e com os estudos que podem ser úteis para vários domínios. A descrição e sub-classificação dos trabalhos são reportados a seguir:

1. Augmenting human memory using personal lifelogs. Yi Chen \& Gareth J. F. Jones. Proceedings of the 1st Augmented Human International Conference. (Chen e Jones (2010))

- Conceito de Aceitação: I3

- Fonte: ACM Ano: 2010

- Dominio: Outros, Diários pessoais

- Descrição: O protótipo iClips melhora a forma de apresentação dos logs diários pessoais. Argumentam que a melhor forma de apresentação da informação é por imagens em vez de usar vídeos. Também propõem uma forma de 
busca simples e fácil sobre os dados capturados para o usuário, equivalente ao modo de Google.

2. Personal Robots as Ubiquitous-Multimedial-Mobile Web Interfaces. J. Ruizdel-Solar. Web Conference, 2007. LA-WEB 2007. Latin American. (Solar (2007))

- Conceito de Aceitação: I4

- Fonte: IEEE Ano: 2007

- Domínio: Outros, Robótica. Robots pessoais

- Descrição: Um robot pessoal que está conectado na rede sem fio e que oferece algumas tarefas para seu dono. Entre elas, fazer buscas em sites como Google, Wikipédia, jornais, clima, etc. Tem como saída de dados uma tela de de 12 polegadas e 7 estados de emocinais que podem ser transmitidos por expressões faciais.

3. A prototype documenter system for medical grand rounds. Renato de Freitas Bulcão-Neto; José Antonio Camacho-Guerrero \& Alessandra Alaniz Macedo. Proceeding of the eighth ACM symposium on Document engineering. (Bulcão-Neto et al. (2008b))

- Conceito de Aceitação: I4

- Fonte: ACM Ano: 2008

- Domínio: Outros, Saúde

- Descrição: Propõem um modelo sustentado com um protótipo que documenta reuniões médicas de psiquiatras. Abradam as quatro etapas de criação de conteúdo hipermídia e permitem que os psiquiatras possam capturar informação de tinta digital durante a reunião, além de poder visualizar esta informação depois.

4. Extension of Capture Information in Pervasive Healthcare Systems: A Case Study. R. B.-N de Freitas; J. A Camacho-Guerrero \& A. A Macedo. The 11th IEEE International Conference on Computational Science and Engineering - Workshops. (Bulcão-Neto et al. (2008a))

- Conceito de Aceitação: I1

- Fonte: IEEE Ano: 2008

- Dominio: Outros, Saúde

- Descrição: Propõem um modelo de aplicação de captura e acesso para reuniões medicas, onde abordam as 4 fases de produção de conteúdo hypermidia (pre-processamento, captura, pós-processamento, acesso). Os dados podem ser acessados pela web e por documentos pdf em um PDA. 
5. Adding dynamic visual manipulations to declarative multimedia documents. F. Kuijk; R.L. Guimarães; P. Cesar \& D.C.A. Bulterman. Proceedings of the 9th ACM symposium on Document engineering. (Kuijk et al. (2009))

- Conceito de Aceitação: I1

- Fonte: ACM Ano: 2009

- Domínio: Outros, Web

- Descrição: Fazem uma breve discussão sobre as ferramentas e tecnologia e ambientes com mídias enriquecidas na internet, fazendo uso ou não de documentos multimídias interativos. Fala sobre algumas aplicações que usam as vantagens de zoom e panorâmica que oferece a linguagem SMIL.

6. Towards a modeling language for designing auditory interfaces. M. Ferati; D. Bolchini \& S. Mannheimer. Universal Access in Human-Computer Interaction. Applications and Services. (Ferati et al. (2009))

- Conceito de Aceitação: I7

- Fonte: Springer Ano: 2009

- Domínio: Outros, Web

- Descrição: No artigo propõem uma nova linguagem de modelamento de interação multimodal chamada AIDM. Durante o recorrer da leitura mostra diferentes aplicações realizadas com esta linguagem ilustrando as possíveis vantagens, como captura da informação multimodal de um usuário emquanto navega na internet, por exemplo.

7. Enhancing Multimodal Annotations with Pen-Based Information. Maria G Pimentel; Rudinei Goularte; Renan G Cattelan; Felipe S Santos \& Cesar Teixeira. Multimedia Workshops, 2007. ISMW '07. Ninth IEEE International Symposium on. (Pimentel et al. (2007b))

- Conceito de Aceitação: I6

- Fonte: IEEE Ano: 2007

- Dominio: Outros, Vários

- Descrição: Propõem o paradigma "watching and commentig", o qual visa que uma pessoa em quanto asiste algum conteúdo de vídeo possa fazer comentários relacionados com o que está assistindo no momento, fazendo autoria sobre os vídeos e possibilitando a recuperação desta informação.

8. New attempts in sound diarization. C. Costin \& M. Costin. Soft Computing Applications, 2009. SOFA '09. (Costin e Costin (2009))

- Conceito de Aceitação: I8 
- Fonte: IEEE Ano: 2009

- Domínio: Outros, Vários

- Descrição: O trabalho faz uma introdução sobre os conceitos de diarização, o estado da arte e as técnicas recentemente reportadas em um workshop importante da área. Explica a abordagem hibrida que adotaram para melhor as características de identificação de falantes como também o reconhecimento de quem fala. Está totalmente focado na técnica e enfatiza em que pode ser muito útil em vários domínios.

\section{B.2 Classificação dos estudos baseados em operadores de interação}

Nesta seção são reportados os estudos primários que usam ou propóem operadores de interação como mecanismos de geração e acesso as novas informações, classificando-os segundo as mídias que aplicam. Na Tabela B.1, está sumarizada a informação correspondete dos estudos.

Tabela B.1: Classificação dos estudos primários baseados nos operadores de interação

\begin{tabular}{|c|c|c|c|}
\hline TITULO & MIDIA & $\begin{array}{l}\text { OPERADORES DE IN- } \\
\text { TERAÇÃO }\end{array}$ & OBSERVAÇÃO \\
\hline $\begin{array}{l}\text { A SMIL-based mul- } \\
\text { timedia system for } \\
\text { mobile education. } \\
\text { J. Di; L. Zhihan; } Z \text {. } \\
\text { Ligang \& } Z \text {. Wei. }\end{array}$ & Vídeo & $\begin{array}{l}\text { Usa um operador de } \\
\text { interação que identifica } \\
\text { dentro dos quadros de } \\
\text { um vídeo (com caracte- } \\
\text { rísticas especias) da tela } \\
\text { do PC os slides de uma } \\
\text { apresentação e a mú- } \\
\text { sica que esta sendo to- } \\
\text { cada. }\end{array}$ & $\begin{array}{l}\text { É útil como sistemas } \\
\text { multimídia para educa- } \\
\text { ção móvel. }\end{array}$ \\
\hline
\end{tabular}




\begin{tabular}{|c|c|c|c|}
\hline $\begin{array}{l}\text { A Lightweight } \\
\text { Open Space for the } \\
\text { Classroom - Colla- } \\
\text { borative Learning } \\
\text { with Whiteboards } \\
\text { and Pen-Tablets. H. } \\
\text { Breuer; C. Sousa; } \\
\text { N. Baloian \& M. } \\
\text { Matsumoto. }\end{array}$ & $\begin{array}{l}\text { Tinta ele- } \\
\text { trônica }\end{array}$ & $\begin{array}{l}\text { Interações de tinta ele- } \\
\text { trônica, além da sincro- } \\
\text { nização colaborativa na } \\
\text { sala de aula. }\end{array}$ & $\begin{array}{l}\text { Na sala de aula, apren- } \\
\text { dizado colaborativo }\end{array}$ \\
\hline $\begin{array}{l}\text { A prototype do- } \\
\text { cumenter system } \\
\text { for medical grand } \\
\text { rounds. } \\
\text { de Freitas Bulcão- } \\
\text { Neto; José Antonio } \\
\text { Camacho-Guerrero } \\
\text { \& Alessandra Alaniz } \\
\text { Macedo. }\end{array}$ & $\begin{array}{l}\text { Tinta digi- } \\
\text { tal }\end{array}$ & $\begin{array}{l}\text { Atributos de tinta digi- } \\
\text { tal }\end{array}$ & Muitas áreas \\
\hline $\begin{array}{l}\text { An Algorithm Expla- } \\
\text { nation agent for the } \\
\text { SHALEX system. } \\
\text { E.M. Shakshuki \& R. } \\
\text { Halliday. }\end{array}$ & $\begin{array}{l}\text { Navegação. } \\
\text { Eventos } \\
\text { de click do } \\
\text { mouse }\end{array}$ & $\begin{array}{l}\text { Propõe novas formas } \\
\text { para medir o desempe- } \\
\text { nho do estudante em } \\
\text { quanto toma uma aula } \\
\text { de programação. Va- } \\
\text { ria o tempo das pro- } \\
\text { vas e muda o enfo- } \\
\text { que de aprendizagem de } \\
\text { acordo com um agente } \\
\text { que monitora as ações } \\
\text { do aluno. }\end{array}$ & Educação \\
\hline
\end{tabular}




\begin{tabular}{|c|c|c|c|}
\hline $\begin{array}{l}\text { An approach for } \\
\text { the capture of } \\
\text { context-dependent } \\
\text { document relati- } \\
\text { onships extracted } \\
\text { from } \\
\text { analysis of users' } \\
\text { interactions with } \\
\text { information. D.R. } \\
\text { Campbell; S.J. Cul- } \\
\text { ley; C.A. McMahon \& } \\
\text { F. Sellini. }\end{array}$ & Navegação & $\begin{array}{l}\text { Operadores de intera- } \\
\text { ção de navegação. Ex- } \\
\text { plicitamente navegação } \\
\text { sobre os documentos } \\
\text { em que o usuário teve } \\
\text { maior interesse }\end{array}$ & $\begin{array}{l}\text { Utilidade para um } \\
\text { usuário que manípula } \\
\text { grandes quantidades } \\
\text { de informação. Tem } \\
\text { como desvantagem que } \\
\text { não pode ser remoto, } \\
\text { situação que não per- } \\
\text { mite a interação entre } \\
\text { documentos com outros } \\
\text { usuários. }\end{array}$ \\
\hline $\begin{array}{l}\text { An automatic lin- } \\
\text { king service of } \\
\text { document images } \\
\text { reducing the effects } \\
\text { of OCR errors with } \\
\text { latent semantics. } \\
\text { Renato F. Bulcão- } \\
\text { Neto; José Camacho- } \\
\text { Guerrero; Álvaro } \\
\text { Barreiro; Javier Pa- } \\
\text { rapar \& Alessandra } \\
\text { A. Macedo. }\end{array}$ & Imagem & $\begin{array}{l}\text { Reconhecimento de } \\
\text { texto em imagens, } \\
\text { pesquisa e educação. } \\
\text { Poderia beneficiar os } \\
\text { cenários onde o ob- } \\
\text { jetivo é recuperar e } \\
\text { recomendar a infor- } \\
\text { mação disponível não } \\
\text { apenas no texto, mas } \\
\text { também como imagens } \\
\text { de documentos. }\end{array}$ & $\begin{array}{l}\text { Pode ser útil para o aná- } \\
\text { lise de patente, desco- } \\
\text { berta de relações entre } \\
\text { referências de patentes } \\
\text { e suas imagens. }\end{array}$ \\
\hline $\begin{array}{l}\text { rm E - A Gene- } \\
\text { ric Event Model for } \\
\text { Event-Centric Mul- } \\
\text { timedia Data Mana- } \\
\text { gement in eChro- } \\
\text { nicle Applications. } \\
\text { U. Westermann \& R. } \\
\text { Jain. }\end{array}$ & $\begin{array}{l}\text { Tinta digi- } \\
\text { tal }\end{array}$ & $\begin{array}{l}\text { Pen and paper interac- } \\
\text { tion (inkteractors) }\end{array}$ & Muitas áreas \\
\hline
\end{tabular}




\begin{tabular}{|c|c|c|c|}
\hline $\begin{array}{l}\text { DocMIR: An auto- } \\
\text { matic document- } \\
\text { based indexing } \\
\text { system for meeting } \\
\text { retrieval. A. Behera; } \\
\text { D. Lalanne \& R. } \\
\text { Ingold. }\end{array}$ & $\begin{array}{l}\text { Quadros } \\
\text { de vídeos } \\
\text { (imagens), } \\
\text { áudio, }\end{array}$ & $\begin{array}{l}\text { 1) speech to text para } \\
\text { identificar palavras } \\
\text { chaves - 2) OCR ima- } \\
\text { gem em texto image to } \\
\text { text - 3) identifica as } \\
\text { mudanças de slides de } \\
\text { um vídeo slideChange } \\
\text { Detection - 4) opera- } \\
\text { dores de interação de } \\
\text { vídeo relacionados a: } \\
\text { melhora das cores do } \\
\text { slide capturado pela } \\
\text { câmera, re-orientação } \\
\text { da imagem colocando- } \\
\text { la no ângulo certo, } \\
\text { identificação de formas } \\
\text { e contornos da imagem. }\end{array}$ & $\begin{array}{l}\text { Problemas com as ani- } \\
\text { mações no vídeos de } \\
\text { apresentação. Propõem } \\
\text { criar um novo opera- } \\
\text { dor de interação, ani- } \\
\text { mationDetection. Útil } \\
\text { para sistemas de reali- } \\
\text { dade aumentada e vide- } \\
\text { oconferências 3D. }\end{array}$ \\
\hline $\begin{array}{l}\text { DocuDesk: An in- } \\
\text { teractive surface } \\
\text { for creating and } \\
\text { rehydrating many- } \\
\text { to-many linkages } \\
\text { among paper and } \\
\text { digital documents. } \\
\text { K. M Everitt; M. R } \\
\text { Morris; A. J.B Brush } \\
\text { \& A. D Wilson. }\end{array}$ & $\begin{array}{l}\text { Tinta digi- } \\
\text { tal, even- } \\
\text { tos de na- } \\
\text { vegação }\end{array}$ & $\begin{array}{l}\text { Eventos de interação de } \\
\text { tinta eletrônica }\end{array}$ & Trabalho de escritório \\
\hline $\begin{array}{l}\text { Enhancing } r \text { Multi- } \\
\text { modal Annotations } \\
\text { with Pen-Based } \\
\text { Information. Maria } \\
\text { G Pimentel; Rudinei } \\
\text { Goularte; renan } \\
\text { G Cattelan; Felipe } \\
\text { S Santos \& Cesar } \\
\text { Teixeira. }\end{array}$ & $\begin{array}{l}\text { Tinta digi- } \\
\text { tal }\end{array}$ & $\begin{array}{l}\text { Inkteractors, operado- } \\
\text { res de interação de tinta } \\
\text { eletônica }\end{array}$ & $\begin{array}{l}\text { Varias, sempre que se } \\
\text { queira fazer autoria so- } \\
\text { bre documento multi- } \\
\text { mídia pre-existente. }\end{array}$ \\
\hline
\end{tabular}




\begin{tabular}{|c|c|c|c|}
\hline $\begin{array}{l}\text { Estimation of beha- } \\
\text { vioral user state } \\
\text { based on eye gaze } \\
\text { and head pose- } \\
\text { application in an } \\
\text { e-learning environ- } \\
\text { ment. S. Asteriadis; } \\
\text { P. Tzouveli; K. Kar- } \\
\text { pouzis \& S. Kollias. }\end{array}$ & Vídeos & $\begin{array}{l}\text { Reconhecimento do ní- } \\
\text { vel de atenção e estado } \\
\text { de animo da pessoa. }\end{array}$ & $\begin{array}{l}\text { Como forma de ajuda } \\
\text { para melhorar proble- } \\
\text { mas de dislexia em cri- } \\
\text { anças, para descobrir } \\
\text { se uma pessoa tem inte- } \\
\text { resse ou está aborrecida } \\
\text { (não gosta) do que está } \\
\text { olhando, no caso de vi- } \\
\text { trines de lojas, a tela } \\
\text { do pc, ou ambientes de } \\
\text { teste. }\end{array}$ \\
\hline $\begin{array}{l}\text { Exploring many-to- } \\
\text { one speech-to-text } \\
\text { correlation for web- } \\
\text { based language lear- } \\
\text { ning. H.-Y. Chen \& } \\
\text { S.-W. Li. }\end{array}$ & Áudio & $\begin{array}{l}\text { Analisa a informa- } \\
\text { ção contida na mídia } \\
\text { de vídeo, sincroni- } \\
\text { zando o áudio com os } \\
\text { lábios. Depois per- } \\
\text { mite varias formas de } \\
\text { acesso a partir da in- } \\
\text { formação capturada e } \\
\text { pós-processada }\end{array}$ & $\begin{array}{l}\text { O paper fala que o } \\
\text { resultado pode ser } \\
\text { muito útil para es- } \\
\text { tudantes que estão } \\
\text { aprendendo uma nova } \\
\text { linguá, melhorando o } \\
\text { nível de escuta e en- } \\
\text { tendimento. Os alunos } \\
\text { podem detalhar um } \\
\text { trecho específico do } \\
\text { áudio, fazer buscas } \\
\text { pelas palavras contidas } \\
\text { no áudio, ver textos que } \\
\text { estão relacionados com } \\
\text { o que está sendo falado, } \\
\text { etc }\end{array}$ \\
\hline $\begin{array}{l}\text { Exploring Multi- } \\
\text { media Correlation } \\
\text { and Synchroniza- } \\
\text { tion for Web-Based } \\
\text { Language Learning. } \\
\text { Herng-Yow Chen \& } \\
\text { Kuo-Yu Liu. }\end{array}$ & $\begin{array}{l}\text { Documento } \\
\text { eletrôni- } \\
\text { cos, áudio } \\
\text { clips, e } \\
\text { navegação }\end{array}$ & $\begin{array}{l}\text { Operadores de navega- } \\
\text { ção dos alunos na ferra- } \\
\text { menta, e das anotações } \\
\text { sobre o conteúdo. }\end{array}$ & $\begin{array}{l}\text { Útil para ensino de se- } \\
\text { gunda língua. Os es- } \\
\text { tudantes podem ver em } \\
\text { granularidade os dife- } \\
\text { rentes sons relaciona- } \\
\text { dos com as palavras, } \\
\text { podem receber as cor- } \\
\text { reções do professor e } \\
\text { ver exatamente as ano- } \\
\text { tações sobre os pontos } \\
\text { de erro. }\end{array}$ \\
\hline
\end{tabular}




\begin{tabular}{|c|c|c|c|}
\hline $\begin{array}{l}\text { Extension of Cap- } \\
\text { ture Information } \\
\text { in Pervasive He- } \\
\text { althcare Systems: } \\
\text { A Case Study. R. } \\
\text { B.-N de Freitas; J. A } \\
\text { Camacho-Guerrero } \\
\text { \& A. A Macedo. }\end{array}$ & $\begin{array}{l}\text { Tinta digi- } \\
\text { tal }\end{array}$ & $\begin{array}{l}\text { Inkteractors, operado- } \\
\text { res de interação de tinta } \\
\text { eletônica }\end{array}$ & $\begin{array}{l}\text { Útil nas reuniões dos } \\
\text { médicos para discutir } \\
\text { sobre a situação especí- } \\
\text { fica de um paciente }\end{array}$ \\
\hline $\begin{array}{l}\text { FrameWire: a tool } \\
\text { for automatically } \\
\text { extracting inte- } \\
\text { raction logic from } \\
\text { paper prototyping } \\
\text { tests. Yang Li \& Xi- } \\
\text { ang Cao \& Katherine } \\
\text { Everitt \& Morgan } \\
\text { Dixon \& James A. } \\
\text { Landay. }\end{array}$ & $\begin{array}{l}\text { Tinta digi- } \\
\text { tal }\end{array}$ & $\begin{array}{l}\text { Operadores de intera- } \\
\text { ção de tinta digital }\end{array}$ & $\begin{array}{l}\text { Útil em situações em } \\
\text { que se tenha que ar- } \\
\text { mazenar documentos, } \\
\text { criar conexões entre } \\
\text { eles, fazer anotações e } \\
\text { poder recuperar toda a } \\
\text { informação. }\end{array}$ \\
\hline $\begin{array}{l}\text { From electronic } \\
\text { documents to } \\
\text { problem-based } \\
\text { learning environ- } \\
\text { ments: An ongoing } \\
\text { challenge for edu- } \\
\text { cational modeling } \\
\text { languages. T. Node- } \\
\text { not; P. Loustau; M. } \\
\text { Gaio; C. Sallaberry \& } \\
\text { P. Lopistéguy. }\end{array}$ & $\begin{array}{l}\text { Documento } \\
\text { eletrôni- } \\
\text { cos }\end{array}$ & $\begin{array}{l}\text { São propostas fer- } \\
\text { ramentas de proces- } \\
\text { samento semântico } \\
\text { para o análises da } \\
\text { informação espacial e } \\
\text { temporal embarcada } \\
\text { nos documentos ele- } \\
\text { trônicos. Podem ser } \\
\text { propostos operado- } \\
\text { res de informação de } \\
\text { eventos de interação } \\
\text { semânticos, para re- } \\
\text { cuperar informações } \\
\text { espaço-temporais. }\end{array}$ & $\begin{array}{l}\text { Utilidade nas situações } \\
\text { de problema de apren- } \\
\text { dizado }\end{array}$ \\
\hline $\begin{array}{l}\text { Gui - phooey!: the } \\
\text { case for text in- } \\
\text { put. Max Van Kleek } \\
\text { and Michael Berns- } \\
\text { tein and David R. } \\
\text { Karger and me sch- } \\
\text { raefEL. }\end{array}$ & Texto & $\begin{array}{l}\text { Operadores de reconhe- } \\
\text { cimento de padrões e } \\
\text { regras no texto. Par- } \\
\text { ser específicos de arma- } \\
\text { zenamento e recupera- } \\
\text { ção. }\end{array}$ & $\begin{array}{l}\text { Útil em varias áreas } \mathrm{q} \\
\text { tenham a ver com com- } \\
\text { partilhamento de infor- } \\
\text { mação remota, como no } \\
\text { contexto das wikis, ou } \\
\text { agendas pessoais, sala } \\
\text { de aula, reuniões etc. }\end{array}$ \\
\hline
\end{tabular}




\begin{tabular}{|c|c|c|c|}
\hline $\begin{array}{l}\text { Hyperstories and } \\
\text { social interaction } \\
\text { in } 2 D \text { and } 3 D \text { edu- } \\
\text { tainment spaces for } \\
\text { children. Franca } \\
\text { Garzotto \& Matteo } \\
\text { Forfori. }\end{array}$ & Navegação & $\begin{array}{l}\text { Navegação interativa } \\
\text { para crianças, cons- } \\
\text { truindo interfaces } 2 \mathrm{D} \\
\text { ou 3D }\end{array}$ & Educação infantil \\
\hline $\begin{array}{l}\text { Inkteractors: inte- } \\
\text { racting with digital } \\
\text { ink. Renan G. Cat- } \\
\text { telan; Cesar Teixeira; } \\
\text { Heider Ribas; Ethan } \\
\text { Munson \& Maria Pi- } \\
\text { mentel. }\end{array}$ & $\begin{array}{l}\text { Tinta digi- } \\
\text { tal }\end{array}$ & $\begin{array}{l}\text { Intkteractors, operado- } \\
\text { res de interação de tinta } \\
\text { digital }\end{array}$ & $\begin{array}{l}\text { Fazer anotações, gerar } \\
\text { e fitar traços específicos } \\
\text { da tinta digital }\end{array}$ \\
\hline $\begin{array}{l}\text { New attempts in } \\
\text { sound diarization. } \\
\text { C. Costin \& M. } \\
\text { Costin. }\end{array}$ & Áudio & $\begin{array}{l}\text { Operadores de intera- } \\
\text { ção de áudio, centrados } \\
\text { na "diarização"da voz } \\
\text { digital. Isto significa } \\
\text { a plena identificação } \\
\text { e reconhecimento das } \\
\text { vozes de varias pes- } \\
\text { soas em um mesmo } \\
\text { arquivo de áudio. In- } \\
\text { ter speaker determina } \\
\text { variáveis relacionadas } \\
\text { com a nacionalidade, } \\
\text { sexo, idade, etc. Intra- } \\
\text { speaker determina } \\
\text { estados emocionais ou } \\
\text { físicos, como o estado } \\
\text { emocional, quando } \\
\text { se está enfatizando } \\
\text { alguma sentença ou } \\
\text { idéia, etc. }\end{array}$ & $\begin{array}{l}\text { Pode ser útil em siste- } \\
\text { mas de seguridade, em } \\
\text { reuniões, salas de au- } \\
\text { las.. como mecanismo } \\
\text { de acesso a dados con- } \\
\text { tidos nas mídias }\end{array}$ \\
\hline
\end{tabular}




\begin{tabular}{|c|c|c|c|}
\hline $\begin{array}{l}\text { Personal Robots } \\
\text { as Ubiquitous- } \\
\text { Multimedial-Mobile } \\
\text { Web Interfaces. J. } \\
\text { Ruiz-del-Solar. }\end{array}$ & Vídeo & $\begin{array}{l}\text { Tem algumas funções } \\
\text { que podem ser boas } \\
\text { para entrada de da- } \\
\text { dos e poderiam servir } \\
\text { como operadores de ví- } \\
\text { deo. Tem detecção e } \\
\text { reconhecimento de ros- } \\
\text { tros, determinar gênero } \\
\text { e idade de uma pessoa, } \\
\text { detecção de objetos, de- } \\
\text { tecção de mãos, detec- } \\
\text { ção de expressões faci- } \\
\text { ais, detecção de gestos } \\
\text { das mãos e finalmente } \\
\text { detecção de fala. }\end{array}$ & $\begin{array}{l}\text { Robótica, robots pesso- } \\
\text { ais }\end{array}$ \\
\hline $\begin{array}{l}\text { PocketPad: Using } \\
\text { Handhelds and Digi- } \\
\text { tal Pens to Manage } \\
\text { Data in Mobile Con- } \\
\text { texts. E. Al-Imam \& } \\
\text { E. Lank. }\end{array}$ & $\begin{array}{l}\text { Tinta ele- } \\
\text { trônica }\end{array}$ & $\begin{array}{l}\text { Usam tinta eletrônica } \\
\text { que pode ser conver- } \\
\text { tida a texto. Além é } \\
\text { usada para gerar ano- } \\
\text { tações sobre os conteú- } \\
\text { dos. }\end{array}$ & $\begin{array}{l}\text { Para fazer anotações em } \\
\text { aulas universitárias e } \\
\text { poder re-editar as ano- } \\
\text { tações. }\end{array}$ \\
\hline $\begin{array}{l}\text { Prototyping } \\
\text { plications to Do- } \\
\text { cument Human } \\
\text { Experiences. } \\
\begin{array}{ll}\text { G.C Pimentel; } \\
\text { G Cattelan \& }\end{array} \\
\text { Baldochi. }\end{array}$ & $\begin{array}{l}\text { Tinta digi- } \\
\text { tal }\end{array}$ & $\begin{array}{l}\text { Interactors de tinta, } \\
\text { proposta ink-teractors }\end{array}$ & $\begin{array}{l}\text { Varias que tenham a ver } \\
\text { com educação }\end{array}$ \\
\hline $\begin{array}{l}\text { ReCap: a tool for } \\
\text { automated capture } \\
\text { and generation of } \\
\text { synchronized au- } \\
\text { dio, PowerPoint and } \\
\text { digital ink presen- } \\
\text { tation. Chan Kin } \\
\text { Kong \& Jogesh K. } \\
\text { Muppala. }\end{array}$ & $\begin{array}{l}\text { Tinta digi- } \\
\text { tal }\end{array}$ & $\begin{array}{l}\text { Operadores de intera- } \\
\text { ção de tinta digital }\end{array}$ & $\begin{array}{l}\text { Útil para armazenar e } \\
\text { depois poder ver au- } \\
\text { las cátedras. Contudo, } \\
\text { só têm em consideração } \\
\text { os arquivos de áudio } \\
\text { do professor e as ima- } \\
\text { gens (slides) apresenta- } \\
\text { das durante a aula. }\end{array}$ \\
\hline
\end{tabular}




\begin{tabular}{|c|c|c|c|}
\hline $\begin{array}{l}\text { Structuring low- } \\
\text { quality videotaped } \\
\text { lectures for cross- } \\
\text { reference browsing } \\
\text { by video text analy- } \\
\text { sis. F. Wang; C.-W. } \\
\text { Ngo \& T.-C. Pong. }\end{array}$ & Vídeos & $\begin{array}{l}\text { Operadores de intera- } \\
\text { ção de vídeos que iden- } \\
\text { tificam as mudanças } \\
\text { de slides rastreando as } \\
\text { imagens de um vídeo; } \\
\text { identificam as imagens } \\
\text { dos textos dos slides e } \\
\text { os converte em textos } \\
\text { real. }\end{array}$ & $\begin{array}{l}\text { Faz o que eles chamam } \\
\text { uma super reconstru- } \\
\text { ção da resolução do ví- } \\
\text { deo. Muito útil para } \\
\text { adicionar índices e in- } \\
\text { formação as vídeo leitu- } \\
\text { ras já gravadas. }\end{array}$ \\
\hline $\begin{array}{l}\text { Watch-and- } \\
\text { comment as a } \\
\text { paradigm toward } \\
\text { ubiquitous interac- } \\
\text { tive video editing. } \\
\text { Renan G. Cattelan; } \\
\text { Cesar Teixeira; Ru- } \\
\text { dinei Goularte \& } \\
\text { Maria Da Graça C. } \\
\text { Pimentel. }\end{array}$ & $\begin{array}{l}\text { Tinta digi- } \\
\text { tal, }\end{array}$ & $\begin{array}{l}\text { Inkteractos, e eventos } \\
\text { de anotações de áudio }\end{array}$ & $\begin{array}{l}\text { Para fazer anotações so- } \\
\text { bre vídeos }\end{array}$ \\
\hline $\begin{array}{l}\text { WMA: A } \\
\text { Based } \\
\text { Synchro- } \\
\text { nized Multimedia } \\
\text { Tutoring } \\
\text { for English Com- } \\
\text { position Studies. } \\
\text { Herng-Yow Chen \& } \\
\text { Kuo-Yu Liu. }\end{array}$ & $\begin{array}{l}\text { Tinta digi- } \\
\text { tal, even- } \\
\text { tos de na- } \\
\text { vegação }\end{array}$ & $\begin{array}{l}\text { Operadores de eventos } \\
\text { de interação de tinta } \\
\text { eletrônica e de navega- } \\
\text { ção, indexados em uma } \\
\text { linha de tempo }\end{array}$ & $\begin{array}{l}\text { Aprendizagem de uma } \\
\text { segunda língua }\end{array}$ \\
\hline
\end{tabular}

\section{B.3 Classificação dos estudos segundo a forma de visualização}

A extração e classificação dos estudos primários que apresentam mecanismos de visualização, são sumarizados na tabela a seguir:

Tabela B.2: Classificação dos estudos primários baseados nos mecanismo de visualização 


\begin{tabular}{|c|c|c|}
\hline $\begin{array}{l}\text { DocMIR: An } \begin{array}{r}\text { automatic } \\
\text { document-based }\end{array} \text { indexing } \\
\text { system for meeting retrieval. } \\
\text { Behera et al. (2007) }\end{array}$ & $\begin{array}{l}\text { Geração e uso de documentos mul- } \\
\text { timídia interativos SMIL e propõem } \\
\text { uma linguagem de marcação de in- } \\
\text { formações multimodais IM2 (Interac- } \\
\text { tive Multimodal Information Manage- } \\
\text { ment). Seguem uma abordagem cen- } \\
\text { trada em documentos. }\end{array}$ & SMIL \\
\hline 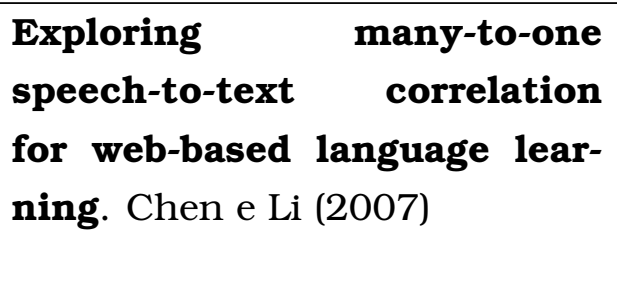 & $\begin{array}{l}\text { Documento multimídia interativo } \\
\text { para web. Não foi claramente dita } \\
\text { a linguagem que foi utilizada. O } \\
\text { trabalho está mais focado nas cara- } \\
\text { terísticas do player. }\end{array}$ & $\begin{array}{l}\text { Player do } \\
\text { DMI }\end{array}$ \\
\hline $\begin{array}{l}\text { A SMIL-based multimedia sys- } \\
\text { tem for mobile education. Di } \\
\text { et al. (2009) }\end{array}$ & $\begin{array}{l}\text { Gera um documento multimídia inte- } \\
\text { rativo SMIL para ser tocado em dis- } \\
\text { positivos móveis }\end{array}$ & SMIL \\
\hline $\begin{array}{l}\text { Towards a modeling language } \\
\text { for designing auditory interfa- } \\
\text { ces. Ferati et al. (2009) }\end{array}$ & $\begin{array}{l}\text { Documento multimídia interativo e } \\
\text { multimodal chamado AIDM }\end{array}$ & AIDM \\
\hline $\begin{array}{l}\text { Adding dynamic visual mani- } \\
\text { pulations to declarative mul- } \\
\text { timedia documents. Kuijk et } \\
\text { al. (2009) }\end{array}$ & $\begin{array}{l}\text { Ilustra uma vantagem de imagem pa- } \\
\text { norâmica e zoom que pode ser reali- } \\
\text { zado com SMIL. }\end{array}$ & SMIL \\
\hline $\begin{array}{l}\text { From electronic documents to } \\
\text { problem-based learning envi- } \\
\text { ronments: An ongoing chal- } \\
\text { lenge for educational mode- } \\
\text { ling languages. Nodenot et al. } \\
(2006)\end{array}$ & $\begin{array}{l}\text { Propõem um modelo chamado CP, o } \\
\text { qual é gerado com diagramas UML e } \\
\text { tem um parser para ser convertido a } \\
\text { XML. Como desvantagem, falam que } \\
\text { ainda não existe um um player para } \\
\text { esta linguagem, já que seria muito di- } \\
\text { fícil desenvolve-lo. É por isto que eles } \\
\text { fazem a conversão do modelo a XML }\end{array}$ & $\begin{array}{l}\text { Visualiza } \\
\text { usando } \\
\text { UML }\end{array}$ \\
\hline $\begin{array}{l}\text { FaericWorld: Browsing multi- } \\
\text { media events through static } \\
\text { documents and links. Riga- } \\
\text { monti et al. (2007) }\end{array}$ & $\begin{array}{l}\text { Apresenta um visualizador para o } \\
\text { modelo proposto. A interface é com- } \\
\text { plexa e tem que fazer um parser para } \\
\text { XML para poder ser tocado. }\end{array}$ & $\begin{array}{l}\text { Usa Rad- } \\
\text { Viz para } \\
\text { visualizar } \\
\text { os links } \\
\text { encontra- } \\
\text { dos }\end{array}$ \\
\hline
\end{tabular}




\begin{tabular}{|l|l|l|}
\hline $\begin{array}{l}\text { An Algorithm Explanation } \\
\text { agent for the SHALEX sys- } \\
\text { tem. Shakshuki e Halliday } \\
\text { (2008) }\end{array}$ & $\begin{array}{l}\text { Gera um documento XML que sincro- } \\
\text { niza e mantem a informação da inte- } \\
\text { ração do usuário, junto com seu es- } \\
\text { tatus, nevel de aprendizagem e nivel } \\
\text { em q está no curso }\end{array}$ & $\begin{array}{l}\text { Som dados } \\
\text { armazen- } \\
\text { dados em } \\
\text { XML }\end{array}$ \\
\hline $\begin{array}{l}\text { Structuring low-quality vide- } \\
\text { otaped lectures for cross- } \\
\text { reference browsing by video } \\
\text { text analysis. Wang et al. } \\
\text { (2008) }\end{array}$ & $\begin{array}{l}\text { Capacidade de processamento em } \\
\text { tempo real. Problemas para identifi- } \\
\text { cares. Não gera um documento multi- }\end{array}$ & $\begin{array}{l}\text { Pagina } \\
\text { web html }\end{array}$ \\
\hline $\begin{array}{l}\text { PocketPad: Using Handhelds } \\
\text { and Digital Pens to Manage } \\
\text { Data in Mobile Contexts. Al- } \\
\text { Imam e Lank (2007) }\end{array}$ & $\begin{array}{l}\text { Usam um software que sincroniza as } \\
\text { mídias na PDA. Falam que usam do- } \\
\text { cumentos hypermidia para realizar } \\
\text { as conexões e sincronização. }\end{array}$ & Software \\
\hline $\begin{array}{l}\text { Msys: a Monitoring System } \\
\text { for E-learning Feedback and } \\
\text { Content Fitting. Baptista et al. } \\
\text { (2006) }\end{array}$ & $\begin{array}{l}\text { Gera documentos de dados e/ou con- } \\
\text { trole, que são usados para fazer o o } \\
\text { monitoramento das atividades dos } \\
\text { estudantes. Não visualiza com docu- } \\
\text { mento multimídia interativos e nem } \\
\text { oferece pontos de acesso. }\end{array}$ & \\
\hline $\begin{array}{l}\text { A Lightweight Open Space for } \\
\text { the Classroom ae Collabora- } \\
\text { tive Learning with Whitebo- } \\
\text { ards and Pen-Tablets. Breuer } \\
\text { et al. (2007) }\end{array}$ & $\begin{array}{l}\text { Gera um documento XML que é a } \\
\text { fonte de dados do software da smart- } \\
\text { board }\end{array}$ & Software \\
\hline $\begin{array}{l}\text { WMA A Marking-Based Synch- } \\
\text { ronized Multimedia Tutoring } \\
\text { tion Studies. Chen e Liu (2009) }\end{array}$ & Gera um documento multimídia & \\
\hline
\end{tabular}




\begin{tabular}{|c|c|c|}
\hline $\begin{array}{l}\text { Exploring Multimedia Corre- } \\
\text { lation and Synchronization } \\
\text { for Web-Based Language Lear- } \\
\text { ning. Chen e Liu (2006) }\end{array}$ & $\begin{array}{l}\text { Classificam a correlação multimídia } \\
\text { em dois tipos: as relações explíci- } \\
\text { tas e implícitas. Relações explícitas } \\
\text { referem-se as correlações de mídia } \\
\text { que são pré-orquestrada, ou seja, as } \\
\text { relações entre mídia (como os docu- } \\
\text { mentos Synchronized Multimedia In- } \\
\text { tegrated Language (SMIL)) captura- } \\
\text { dos durante a fase de criação ou a } \\
\text { gravação de uma apresentação mul- } \\
\text { timédia. Em contrapartida, resulta } \\
\text { difícil determinar as correlações im- } \\
\text { plícitas (como o índice de tempo entre } \\
\text { a transcrição da notícia e se apresen- } \\
\text { tador está falando no correspondente } \\
\text { momento) por um processo de detec- } \\
\text { ção simples, por isso é preciso fazer } \\
\text { novas análises computacionais para } \\
\text { descobri-los. }\end{array}$ & $\begin{array}{l}\text { WSML fra- } \\
\text { mework }\end{array}$ \\
\hline $\begin{array}{l}\text { Extension of Capture Infor- } \\
\text { mation in Pervasive Health- } \\
\text { care Systems: A Case Study. } \\
\text { Bulcão-Neto et al. (2008a) }\end{array}$ & $\begin{array}{l}\text { Geram documentos (html e pdf) e } \\
\text { usam um documento XML como su- } \\
\text { porte de armazenamento de links }\end{array}$ & $\begin{array}{l}\text { Pela web } \\
\text { ou pdf } \\
\text { com PDA }\end{array}$ \\
\hline $\begin{array}{l}\text { Interactive Content Overvi- } \\
\text { ews for Lecture Recordings. } \\
\text { Mertens et al. (2006) }\end{array}$ & $\begin{array}{l}\text { Geram automaticamente documen- } \\
\text { tos FLASH e animações de imagens } \\
\text { SVG. }\end{array}$ & $\begin{array}{l}\text { FLASH e } \\
\text { SVG }\end{array}$ \\
\hline $\begin{array}{l}\text { Prototyping Applications to } \\
\text { Document Human Experien- } \\
\text { ces. Pimentel et al. (2007a) }\end{array}$ & $\begin{array}{l}\text { Gera automaticamente documentos } \\
\text { XML que funcionam como suporte da } \\
\text { informação de interação do usuário. }\end{array}$ & Software \\
\hline $\begin{array}{l}\text { Enhancing Multimodal Anno- } \\
\text { tations with Pen-Based Infor- } \\
\text { mation. Pimentel et al. (2007b) }\end{array}$ & $\begin{array}{l}\text { Gera um documento multimídia in- } \\
\text { terativo SMIL para o caso do eClass. } \\
\text { Porem não contém pontos de acesso, } \\
\text { simplesmente é uma apresentação li- } \\
\text { near. No caso do M4note, é gerado } \\
\text { um XmL que contém as informações } \\
\text { de captura para ser visualizados por } \\
\text { um software. }\end{array}$ & SMIL \\
\hline
\end{tabular}




\begin{tabular}{|c|c|c|}
\hline $\begin{array}{l}\text { rm E - A Generic Event Model } \\
\text { for Event-Centric Multimedia } \\
\text { Data Management in eChroni- } \\
\text { cle Applications. Westermann } \\
\text { e Jain (2006) }\end{array}$ & $\begin{array}{l}\text { Gera documentos multimídias, mas } \\
\text { está focado só na teoria da estrutura- } \\
\text { ção dos documentos multimídia, que } \\
\text { está centrada em Eventos. Estão mu- } \\
\text { dando o conceito de agrupamento da } \\
\text { informação e propondo novos mode- } \\
\text { los para capturar as informações dos } \\
\text { eventos. Porem, não fica claro como } \\
\text { são as formas de acesso de informa- } \\
\text { ção dentro das mídias, ou de infor- } \\
\text { mação implícita }\end{array}$ & Variado \\
\hline $\begin{array}{l}\text { CoScribe: Integrating Pa- } \\
\text { per and Digital Documents } \\
\text { for Collaborative Knowledge } \\
\text { Work. Steimle et al. (2009) }\end{array}$ & Gera documentos estáticos & $\begin{array}{l}\text { Documentos } \\
\text { estáticos }\end{array}$ \\
\hline $\begin{array}{l}\text { StreamLiner: A General- } \\
\text { Purpose Interactive Course- } \\
\text { Visualization Tool. Yuan et al. } \\
(2008)\end{array}$ & Gera documentos estáticos & Software \\
\hline $\begin{array}{l}\text { An automatic linking service } \\
\text { of document images reducing } \\
\text { the effects of OCR errors with } \\
\text { latent semantics. Bulcão-Neto } \\
\text { et al. (2010) }\end{array}$ & Documento multimídia estático & Html \\
\hline $\begin{array}{l}\text { Watch-and-comment as a pa- } \\
\text { radigm toward ubiquitous in- } \\
\text { teractive video editing. Catte- } \\
\text { lan et al. (2008a) }\end{array}$ & $\begin{array}{l}\text { Geração de dois tipos de documentos } \\
\text { multimídias interativos. }\end{array}$ & NCL, SMIL \\
\hline $\begin{array}{l}\text { Inkteractors: interacting with } \\
\text { digital ink. Cattelan et al. } \\
(2008 \mathrm{~b})\end{array}$ & Geração de documentos estáticos & html \\
\hline $\begin{array}{l}\text { A prototype documenter sys- } \\
\text { tem for medical grand rounds. } \\
\text { Bulcão-Neto et al. (2008b) }\end{array}$ & $\begin{array}{l}\text { Geram documentos XML de dados e } \\
\text { podem ser visualizados os dados por } \\
\text { XHTML ou pdf }\end{array}$ & Xhtml \\
\hline $\begin{array}{l}\text { Hyperstories and social inte- } \\
\text { raction in } 2 D \text { and } 3 D \text { edu- } \\
\text { tainment spaces for children. } \\
\text { Garzotto e Forfori (2006) }\end{array}$ & $\begin{array}{l}\text { Geram hipermídia interativa e } \\
\text { apóiam-se em documentos de dados } \\
\text { XML }\end{array}$ & $\begin{array}{l}\text { Software } \\
\text { usando } \\
\text { FLASH }\end{array}$ \\
\hline
\end{tabular}




\begin{tabular}{|l|l|l|}
\hline $\begin{array}{l}\text { Social summarization: does } \\
\text { social feedback improve ac- } \\
\text { cess to speech data?. Kalni- } \\
\text { kait e Whittaker (2008) }\end{array}$ & $\begin{array}{l}\text { Geração de documentos estáticos in- } \\
\text { dexados na linha do tempo }\end{array}$ & HTML \\
\hline $\begin{array}{l}\text { Gui phooey!: the case for text } \\
\text { input. Kleek et al. (2007) }\end{array}$ & $\begin{array}{l}\text { Fazem a geração automática de um } \\
\text { documento multimídia que mistura a } \\
\text { abordagem dos documentos estáticos } \\
\text { e das aplicações dinâmicas. O resul- }\end{array}$ & Software \\
& $\begin{array}{l}\text { tado é um documento multimídia pa- } \\
\text { recido a uma wiki que reúne elemen- } \\
\text { tos multimídia, links a sites da Inter- }\end{array}$ & \\
net, e texto. A apresentação e recu- & \\
peração não é linear e pode ser reali- \\
zada a uma navegação por atividades \\
e ou episódios.
\end{tabular}

